\title{
Improving the reproductive health of adolescents in Senegal
}

\author{
Nafissatou J. Diop \\ Population Council \\ Heli Bathidja \\ Isseu Diop Toure \\ Thierno Dieng \\ Babacar Mane \\ Population Council
}

See next page for additional authors

Follow this and additional works at: https://knowledgecommons.popcouncil.org/departments_sbsr-rh

Part of the Demography, Population, and Ecology Commons, International Public Health Commons, and the Public Health Education and Promotion Commons How does access to this work benefit you? Let us know!

\section{Recommended Citation}

Diop, Nafissatou J., Heli Bathidja, Isseu Diop Toure, Thierno Dieng, Babacar Mane, Saumya RamaRao, Susan E. Adamchak, Emelita Wong, Adama Ndoye, Aboubacry Sy, and Babacar Fall. 2004. "Improving the reproductive health of adolescents in Senegal," FRONTIERS Final Report. Washington, DC: Population Council. 


\section{Authors}

Nafissatou J. Diop, Heli Bathidja, Isseu Diop Toure, Thierno Dieng, Babacar Mane, Saumya RamaRao,

Susan E. Adamchak, Emelita Wong, Adama Ndoye, Aboubacry Sy, and Babacar Fall 


\title{
Improving the Reproductive Health of Adolescents in Senegal
}

\author{
Nafissatou J. Diop ${ }^{1}$ \\ Heli Bathidja $^{2}$ \\ Isseu Diop Touré ${ }^{2}$ \\ Thierno Dieng ${ }^{3}$ \\ Babacar Mané ${ }^{3}$ \\ Saumya RamaRao ${ }^{4}$ \\ Susan Adamchak ${ }^{5}$ \\ Emelita Wong ${ }^{5}$ \\ Colonel Adama Ndoye ${ }^{6}$ \\ Aboubacry $\mathrm{Sy}^{6}$ \\ Babacar Fall ${ }^{7}$ \\ ${ }^{1}$ Frontiers in Reproduction Health Program \\ ${ }^{2}$ World Health Organization \\ ${ }^{3}$ Centre de Formation et de Recherche en Santé de la Reproduction \\ ${ }^{4}$ Frontiers in Reproduction Health Program \\ ${ }^{5}$ Frontiers in Reproduction Health Program, Family Health International \\ ${ }^{6}$ Ministry of Health, Division of Reproductive Health \\ ${ }^{7}$ Groupe d'Etude et d'Enseignement de la Population
}

\section{December 2004}

This study was funded by the U.S. AGENCY FOR INTERNATIONAL DEVELOPMENT (USAID) under the terms of Cooperative Agreement Number HRN-A-00-98-00012-00 and Subproject number A199.92A. The opinions expressed herein are those of the authors and do not necessarily reflect the view of USAID. 


\section{EXECUTIVE SUMMARY}

In October 1999, the Frontiers in Reproductive Health Program (FRONTIERS) began a threeyear collaboration with the World Health Organization (WHO), the Ministries of Health, Education, and Youth, the Center for Research and Training in Health and Population (CEFOREP), and the Population Training Group (GEEP) to test interventions to improve the reproductive health of youth aged 10-19. The community-based intervention included sensitization on adolescent reproductive health for community and religious leaders, reaching parents through women's groups, and education sessions led by peer educators using a life skills curriculum. As part of the clinic-based intervention, providers and peer educators were trained to offer youth-friendly services. The school-based intervention trained teachers and peer educators to provide reproductive health information through a reproductive health curriculum tailored to in-school youth.

The study took place in three urban communities in northern Senegal. The communities of Louga and Saint-Louis served as intervention sites, while Diourbel served as a control site. Both intervention sites offered the community- and clinic-based interventions; and Saint-Louis also introduced the school-based intervention. A quasi-experimental design was used to determine the feasibility, effectiveness, and cost of a systematic intervention to foster a supportive environment for dealing with reproductive health problems of youth, to make existing services more accessible to youth, and to provide reproductive health information and skills in schools.

\section{Findings}

The evaluation showed that interventions exposed one-third of adolescents to information on reproductive health in Saint-Louis and Louga. While both sexes were reached at school, boys' knowledge improved more than girls'. Outside school, the 15-19 year age group was more widely reached than the younger adolescents. In Diourbel, the control site, the large proportion of adolescents who received reproductive health information implies that intensive activities were also carried out in this area.

- Parents knew the reproductive health programs for adolescents well after the intervention, and their approval of such programs increased in most cases. Women's approval of program efforts was higher than men's.

- Community members strongly endorsed improving youth reproductive health but expressed mixed beliefs about adolescent sexuality. Religious leaders believed that parents should discuss reproductive health issues openly with their children. However, parents lack the knowledge to do so with confidence.

- Communication, both on the part of the parents and adolescents, has greatly improved. Adolescents sought more information from adults and qualified sources than from their friends. Nevertheless, there is still the lack of a family atmosphere conducive to communication, and at the same time, adolescents' expectations of receiving reproductive health information from their parents have risen greatly. 
- Young people's knowledge of reproductive health increased. Knowledge of puberty and risks associated with early sexuality was generally low, but significantly greater among adolescents who were exposed to the interventions, especially those aged 15-19 years.

- The proportion of adolescents knowing one or more contraceptive methods rose significantly at intervention sites, Saint-Louis and Louga, but not in the control site of Diourbel. Considering the distribution according to age and sex, better knowledge of the ways of using contraceptives, especially condoms, was noted in Saint-Louis. Attitudes towards the use of these methods developed in the sense of greater tolerance vis-à-vis unmarried adolescents.

- Knowledge of HIV/AIDS was quite widespread before the implementation of the interventions; however, the interventions reinforced this knowledge. Other STIs were much less known. Before the intervention one in 10 adolescents knew about the existence of other STIs in the three areas of study. After the intervention, knowledge increased significantly to nearly 18 percent among the adolescents in Saint-Louis and Louga. The situation remained virtually unchanged in Diourbel.

- Adolescent sexual activity is more common among males (one-third) than females (10\%), and the average age of first sexual experience is about 14. Adolescents in school and exposed to the intervention were less likely to report sex in the prior six months than those not exposed. Students exposed to intervention were less likely to have recent sexual activity than non-students. Religious beliefs and practices and living with biological parents were also protective factors against sex in the past six months. When compared with adolescents in Diourbel, the control site, adolescents in Louga were more likely to adopt secondary abstinence (limiting sexual activity following sexual initiation) and had fewer sexual partners.

- Sexually active adolescents reported using contraceptive methods significantly less at the time of the endline survey than they did at the baseline. This decrease in protection can be explained in part by the fact that the adolescents' sexual partners had become regular, with lower perceived risk of STIs including HIV/AIDS while in the baseline partners were reported as casual, with a greater risk of exposure to STIs. This new trend should lead to efforts to better inform sexually active adolescents of the need to protect themselves against unwanted pregnancies, in addition to STIs. Having one sexual partner cannot protect them against unwanted pregnancy, even if fidelity is a protective strategy against STIs.

- Knowledge of health facilities increased in Saint-Louis and in the control site of Diourbel, but not in Louga where the levels were already relatively high. Visits to health facilities were rare before the intervention, with low utilization in all three sites. Following the intervention, there was a significant rise in these visits, particularly in Saint-Louis and Diourbel.

For all indicators, adolescents directly exposed to the interventions had better knowledge, attitudes, and behaviors than adolescents living in the intervention sites but who had not been exposed to the intervention during the 12 months prior to the endline survey. 
In conclusion, reaching adolescents with reproductive health information is feasible despite the sensitive nature of this issue in Senegal's socio-cultural context. A multi-agency partnership between the health department, the communities, the schools, and the media proved that the multi-sectorial approach is feasible when organized through an operational technical committee.

Young people's involvement in making youth associations responsible and in clarifying the collaboration terms, often by a contract, created a huge mobilization and very little dropout of peer educators. This study showed that values such as abstinence are the main reference and source of protection among young people. Thus, secondary abstinence and being faithful to one partner were more used than condoms or other contraceptive methods among the sexually active adolescents. The interventions seem to have had an effect on limiting sexual activity but not on protection through the use of contraceptive methods including condoms. Adolescents directly exposed to the interventions had improved knowledge, attitudes, and behavior in general compared to those who were not exposed. This is promising as more systematic interventions and exposure to reproductive health programs will be developed. 


\section{TABLE OF CONTENTS}

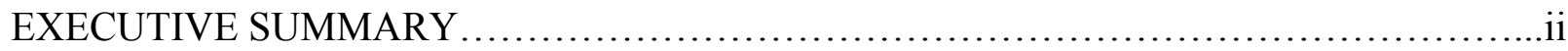

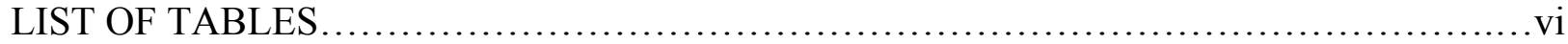

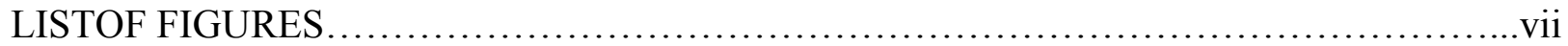

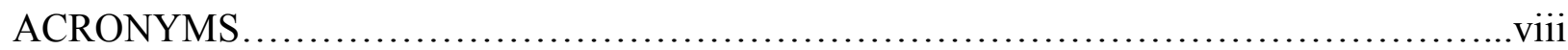

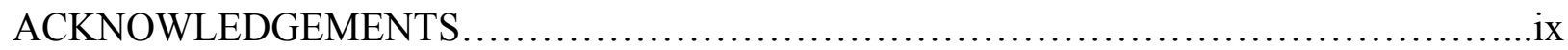

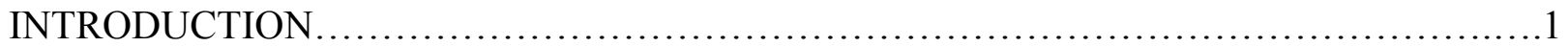

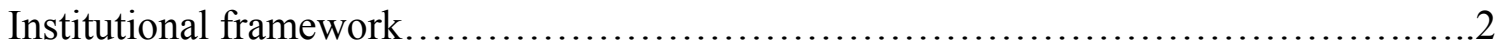

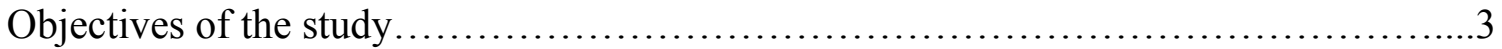

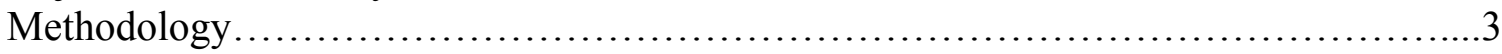

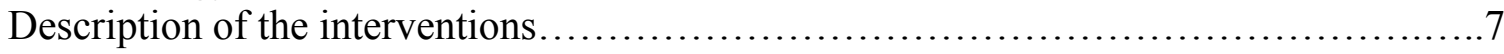

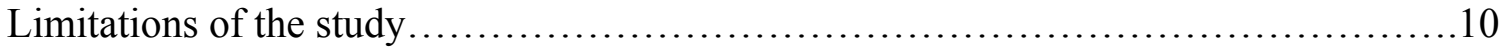

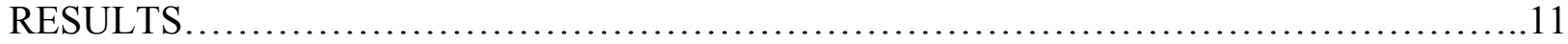

Socio-demographic characteristics.............................................11

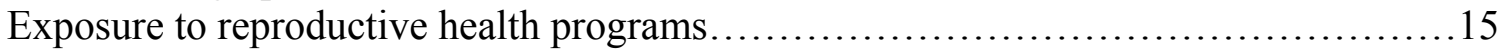

Parents' attitudes toward reproductive health programs............................. 19

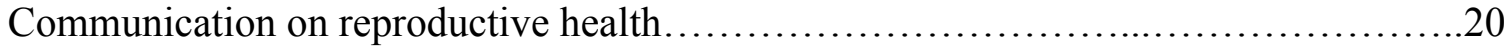

Knowledge and attitudes towards reproductive health.............................24

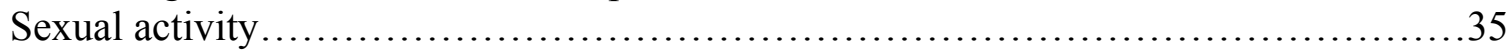

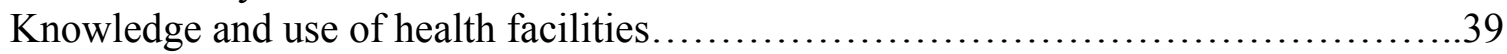

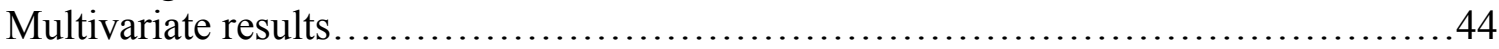

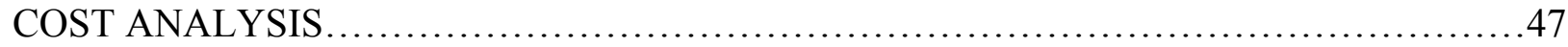

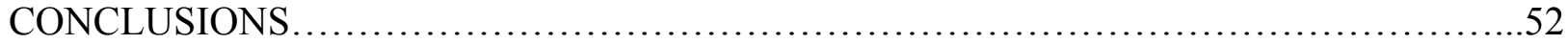

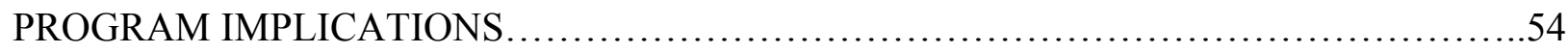

ANNEX A Sample size and explanatory variables......................................56

ANNEX B Construction of sampling and analysis weights.................................63

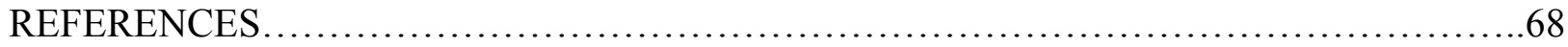




\section{LIST OF TABLES}

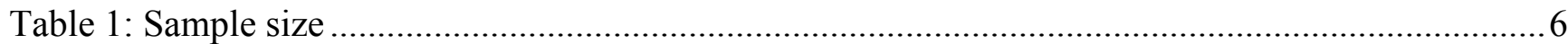

Table 2: Socio-demographic characteristics of adolescents (percent) ........................................... 12

Table 3: Socio-demographic characteristics of parents .............................................................. 14

Table 4: Distribution of adolescents who received information on reproductive health at school......... 15

Table 5. Distribution of adolescents who received information on reproductive health outside

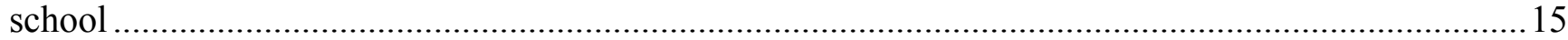

Table 6: Percent distribution of reproductive health topics that adolescents want to learn more

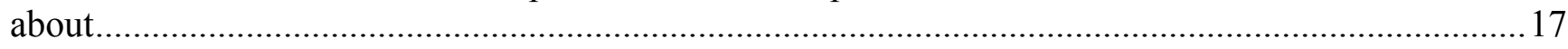

Table 7: Percent distribution of adolescents by preferred sources of information on reproductive

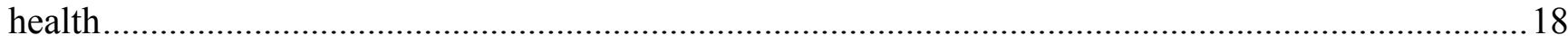

Table 8: Parents' knowledge of reproductive health programs at school and support for the

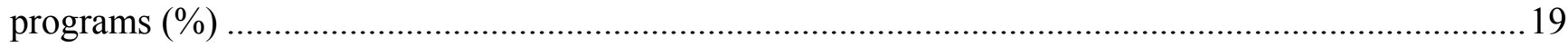

Table 9: Parents' attitudes towards reproductive health programs according to topic (\%) ...................20

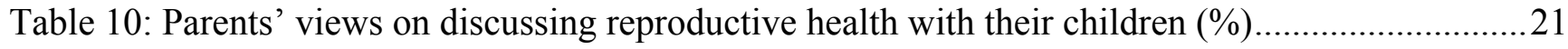

Table 11: Adolescents reporting no communication on reproductive health $(\%)$..............................22

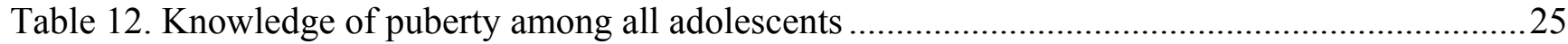

Table 13: Knowledge of risks by adolescents according to the area of study and time of interview .....27

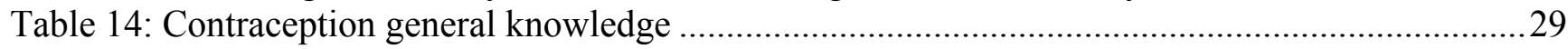

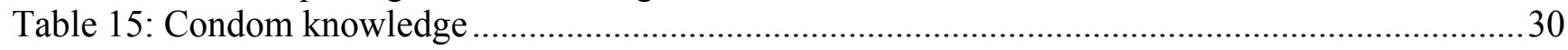

Table 16: Knowledge of correct condom use (boys aged 13 to 19 years) .......................................30

Table 17: Percent approving use of contraception by adolescents ................................................3

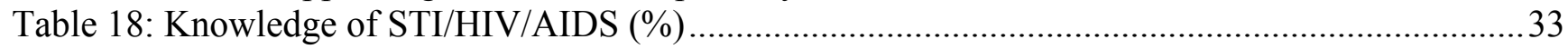

Table 19: Sexual experience (\%) and mean age of first sexual experience.......................................36

Table 20: Percent distribution of adolescents having desired first intercourse, reasons for first

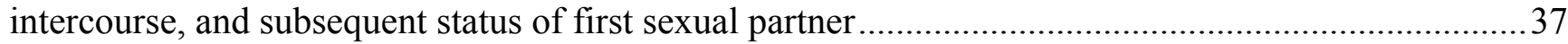

Table 21: Distribution of adolescents (both boys and girls) according to their sexual activities

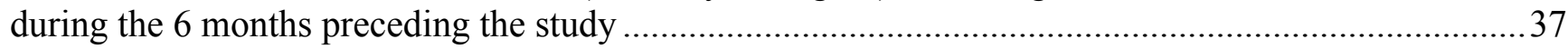

Table 22: Protective behavior and sexual experience of adolescents ..............................................39

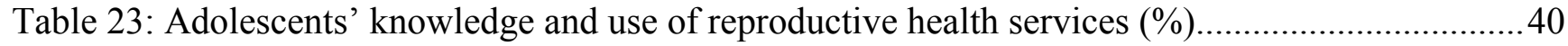

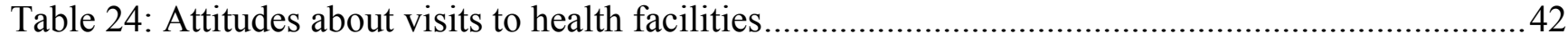

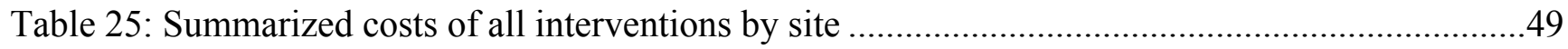

Table A-1: Sample and response rates................................................56

Table A-2: Perception of adolescents on the discussion with their parents $(\%) \ldots \ldots \ldots \ldots \ldots \ldots \ldots . . \ldots 57$

Table A-3: Communication of adolescents on reproductive health according to their main

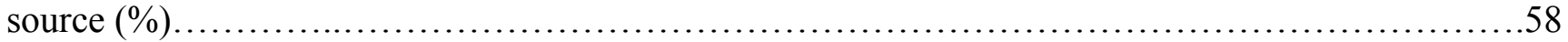

Table A-4: Odds Ratios and confidence intervals of key explanatory variables...................60 


\section{LIST OF FIGURES}

Figure 1: Data collection and intervention sites............................................

Figure 2: Sources of reproductive health information ......................................................... 16

Figure 3: Communication on reproductive health according to exposure to interventions ...................23

Figure 4: Knowledge of puberty according to exposure to interventions........................................26

Figure 5: Analysis of risks of sexual relations by exposure to interventions: all youth ......................28

Figure 6: Theoretical and practical knowledge of the pill and condoms according to exposure to

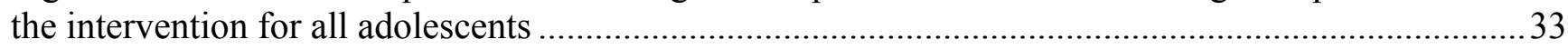

Figure 7: Knowledge of means of protection against STI/HIV/AIDS .......................................... 34

Figure 8: Knowledge of STI/HIV/AIDS according to exposure to the intervention....................35

Figure 9: Percent distribution of adolescents according to the reasons for the latest visit to a

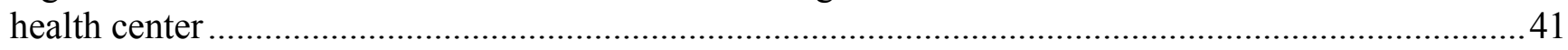

Figure 10: Proportion of adolescents who think that they would be well received at a health

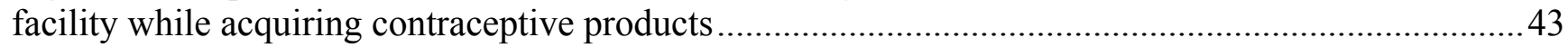

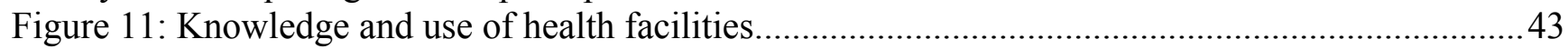

Figure B-1: An illustration of measuring intervention effect................................65 


\section{ACRONYMS}

ASBEF .............Association Sénégalaise pour le Bien-Etre Familial

ASPF ................Association Sénégalaise pour la Planification Familiale

CAs ..................Collaborating Agencies

CBO .................Community-Based Organization

CDEPS ..............Centre Départemental d'Education Physique et Sportive

CEFOREP ..........Centre de Formation et de Recherche en Santé de la Reproduction

COPE ................Client Oriented, Provider Efficient Services

DR ...................District de Recensement

FHI.............Family Health International

FLE ..................Family Life Education

FP ....................Family Planning

GEEP................Groupe pour l'Etude et l'Enseignement de la Population

HIV/AIDS........Human Immunodeficiency Virus/Acquired Immunodeficiency Syndrome

IEC ...................Information, Education, and Communication

LEA..................Leader Elèves Animateurs

MIS ..................Management Information System

$\mathrm{MOH}$..................Ministry of Health

MSH............Management Sciences for Health

NGO ...................Non-Governmental Organization

PPJ...................Projet de Promotion des Jeunes

RH..............Reproductive Health

SNSR .................Service National de la Santé de la Reproduction

STI.....................Sexually Transmitted Infection

UNFPA .............United Nations Population Fund

UNICEF ............United Nations Children's Fund

USAID ..............United States Agency for International Development

WHO...........World Health Organization 


\section{ACKNOWLEDGEMENTS}

We would like to thank our many partners who contributed to this project. In particular, we would like to acknowledge the Ministry of Health's Direction of Research and Training (DERF), Division of Reproductive Health (DSR), and the Regional and District staff of Saint-Louis, Louga, and Diourbel. We would also like to acknowledge the regional staff of the Ministry of Youth, the Ministry of Social Affairs, and the Ministry of Education.

Partners constituted the technical committees operating in the district of Saint-Louis and Louga. The study also benefited from the technical expertise provided by WHO and FHI. We want to thank particularly Hally Malher and Dr Isseu Diop Toure. Others to whom we express our gratitude include the National Scientific Committee for its guidance and support, the Maternal Health and Family Planning Project for its contribution to the funding of IEC materials, and the USAID mission in Senegal for their support and encouragement.

\section{Contributors to this study:}

Alimata Deme, Centre de Formation et de Recherche en Santé de la Reproduction Marieme Ba Gueye, Centre de Formation et de Recherche en Santé de la Reproduction Nancy Williamson, Family Health International Hally Malher, Family Health International Khady Sy, Ministry of Health, Division of Reproductive Health (DSR) Nogaye Ndoye, Ministry of Health, Division of Reproductive Health (DSR) Colonel Babacar Dramé, Ministry of Health, Direction of Research and Training (DERF) Mamadou Diagne, Ministry of Health, Direction of Research and Training (DERF) Nafissatou Diop, Ministry of Health, Direction of Research and Training (DERF) Adjaratou Ndiaye, Ministry of Health, Division of Primary Health Care Ibrahima Diallo, Consultant, Afrique Ado SR Project, World Health Organization Virgile Capo Chichi, Consultant, Afrique Ado SR Project, World Health Organization Famara Mané, Scouts Eclaireuses et Eclaireurs du Sénégal Dr Ousmane Faye, Maternal Health and Family Planning Project, MSH

\section{Local Technical Committees in Saint-Louis and Louga:}

\begin{tabular}{ll}
\hline \hline Saint-Louis & Louga \\
\hline Dr Selly Kane, Ministère de la Santé & Dr Malick Ndiaye, Ministère de la Santé \\
Mme Oumou Khairy Niang, Ministère de la Santé & Mme Binta Bocoum, Ministère de la Santé \\
Mme Até Fall, Ministère de la Santé & Mr Sidi Wade, Ministère de la Santé \\
Mr Amar Diagne, Ministère de la Santé & Mme Nafissatou Aidara, Ministère de la Santé \\
Mme Awa Thioune, Ministère de la Jeunesse & Mr Badji, Ministère de la Justice et ASPF \\
Mme Awa Mbow, Ministère du Développement & Mme Arame Coumba Fall, Ministère du \\
Social & Développement Social \\
Mr Fara Tall, Conseil Communal de la Jeunesse & Mr Diack Fall, représentant des jeunes \\
Mr Mamadou Diallo, GEEP & \\
\hline \hline
\end{tabular}




\section{Steering Committee}

World Health Organization, U.S. Agency for International Development, United Nations Fund for Population, United Nations Children's Fund, Service National de 1'Education pour la Santé, Projet Promotion des Jeunes, Groupe d'Etude et d'Enseignement de la Population, Centre de Formation et de Recherche en Santé de la Reproduction, Association pour le Bien être Familial, Ministère de l'Education, Division de la Santé de la Reproduction, Division des Etudes et de la Recherche, and the Population Council. 


\section{INTRODUCTION}

Navigating the transition to adulthood can be hazardous for youth in Senegal. In the traditional culture, this transition consisted of a process of socialization with rites of passage; nowadays this transition is more difficult without this initial guidance. Indeed the process of modernization has changed the norms of the society, particularly regarding the relationship between youth and their family. Youth are trying to get an education, find a job, find a partner, and establish their identities and place in society. Throughout this transition, the lives and situations of girls and boys differ greatly. As part of this transition period, youth typically have unmet needs for reproductive health information and services. This is a result of a rise in early sexual activity among young adults and increased exposure to unwanted pregnancy or sexually transmitted infections. In Senegal, where 28 percent of the population is between 10-19 years of age, a renewed focus on adolescent reproductive health services appears timely.

There are many barriers to youths' reproductive health knowledge and use of services in Senegal. Youth have difficulty in recognizing their own sexuality and preventing unwanted and unsafe encounters by using protection, but there are also other exogenous factors.

Family structure is still very strong in Senegal and plays a major role in the lives of youth. The family often provides support, love, and a caring environment but fails to respond to the need for reproductive health information for youth. In the family there is also gender discrimination against girls. Many cultural values and communication patterns differ according to gender. It is expected that a girl will stay at home, work in the household setting, and remain a virgin until marriage, while a boy spends most of his time outside the household, completing his education with peers.

Lack of communication between parents and their adolescent children is an important problem. Parents think that they should serve as role models for their adolescents, but that role does not include providing sexual information. There remains a strong undercurrent of skepticism or opposition to strategies that address the reproductive health needs of youth. Health facilities generally offer mediocre quality of care, and reproductive health services tend to be underutilized. There are practically no public health services geared to adolescents and to which they can have access without psychological, material, financial, or socio-cultural barriers.

For adolescents, the obstacles include the disapproving and even accusatory reception they receive from some health providers. Thus, many adolescents do not go to public clinics to present their problems regarding sexuality, sexually transmitted infections (STIs), and pregnancy to people older than they are. The charges for conventional services are generally beyond the financial means of adolescents. In addition, the fact that the services operate during school hours does not facilitate their use by adolescents. Furthermore, boys are embarrassed to use services that are generally designed for women.

There are no formal, mandated family life education (FLE) courses in Senegalese schools. However, a number of FLE programs currently exist and are administered through various nongovernmental organizations (NGOs) or the Ministry of Youth. Most of these programs have been implemented since 1990. There is no standardized program, and each operates independently. 
This operations research (OR) project addresses several facets of youths' situation. The study has its origins in the WHO Project, "Operations research on improving reproductive health services for adolescents in French-speaking countries of Africa (Afrique Ado SR)". The theme had been selected as one of the research priorities for francophone countries at a consultation in Yaoundé, Cameroon, December 1994. Given that WHO and FRONTIERS have common objectives, collaboration is a way of maximizing the effect of a systematic intervention. The OR study was timely in that it coincided with the creation of the Ministry of Health's Office of Adolescent Health, and the results have helped the new agency to develop its strategy.

\section{Institutional framework}

This OR study was multi-sectorial and involved several partners in its implementation at different levels of administrative organization. A series of meetings was needed before implementation began to ensure that there was common understanding of the project between the different stakeholders. This process of discussion and negotiation highlighted the critical areas of the project and increased the ownership of stakeholders over the project and its outcome. It provided a common forum for various constituencies to participate - different ministries of the government, NGOs, development activists and researchers. Three committees were constituted to oversee the project and their roles.

\section{National Steering Committee}

A national steering committee was set up before the official start of the project in May 1999. The overall purpose of this committee was to define the intervention and provide direction to the research questions posed. Specifically, the committee participated in the development of the proposal, the selection of intervention sites, and the development of a common understanding of what the project would address in its modules of adolescent reproductive health. Committee members included the following: staff from the research unit of the Ministry of Health $(\mathrm{MOH})$ and its Division of Reproductive Health (DSR), the Ministry of Education, the Ministry of Youth, and representatives from NGOs, multilateral partners, and donors including UNICEF, UNFPA, WHO and USAID.

It was decided to give the responsibility for the health service and the community interventions to DSR, the school intervention to GEEP, and the evaluation to CEFOREP. These institutions received technical assistance from FRONTIERS, FHI and WHO at the central level and coordinated the details of the strategy of intervention.

\section{Regional Steering Committee}

The governor of each region formed a consultative group at the regional level. This group was to follow the project and provide the requisite governmental support. Members of this group included representatives from a variety of constituencies: the government perspective was presented by the governor of the region, the medical chief of the region, representatives from the Ministries of Education, Social Affairs, and Community Development; the youth perspective by youth councils at the regional level; and community perspectives by religious leaders and members of women's groups. 


\section{Local Technical Committee}

This committee implemented, coordinated, and supervised the activities in the two study sites. Members of this group included the MOH district staff, and partners from GEEP, representatives from the Ministry of Education, the Ministry of Social Affairs, the Ministry of Youth, and representatives from youth associations. The meetings of this committee facilitated the sharing of information between different members of the group, the planning of future activities, identification of problems and potential solutions, issues of supervision, and encouraged greater communication and transparency of project activities.

\section{Objectives of the study}

1. To establish an empirical basis for the intervention and its evaluation through a diagnostic process to understand the reproductive health issues of youth in each local setting.

2. To determine the feasibility, cost, and impact of an environmental intervention addressing opinion leaders, existing adult networks, and existing youth networks to provide information about youth reproductive health.

3. To determine the feasibility, cost, and effect of improving the youth-friendliness of existing reproductive health services on the willingness and ability of service providers to offer quality counseling and services to youth, and on the number of youth using these services when they are needed.

4. To determine whether there is an additional contribution from a school-based intervention on the reproductive health knowledge of youth, their attitudes, sexual behavior, and use of reproductive health services.

\section{Methodology}

The study used a pre- and post-test control group design. Three study sites were employed to investigate the relative effectiveness of two sets of interventions, comparing one to the other and to a comparison group. Group A received two components of the interventions: the communitybased intervention and the health services-based intervention. Group B received the three components of the interventions: the community-based intervention, the health services-based intervention, and the school-based intervention. Group $\mathrm{C}$ was used as a control group and did not receive any of the intervention components.

\begin{tabular}{lccc}
\hline \hline \multicolumn{1}{c}{ Types of intervention } & Site A & Site B & Site C \\
\hline Community Intervention & Yes & Yes & - \\
Health Services Intervention & Yes & Yes & - \\
School Intervention & - & Yes & - \\
\hline \hline
\end{tabular}




\section{Hypotheses}

1. Study sites A and B will show greater improvement in the environment for youth reproductive health programs than site $\mathrm{C}$.

2. Study sites A and B will show greater improvement in youth-friendly services than site $\mathrm{C}$ and greater utilization of services by youth. The percentage of adolescents who use the health facilities will increase after the interventions.

3. Study site B will show greater improvement in school-based reproductive health education than sites $\mathrm{A}$ and $\mathrm{C}$ and greater improvement in reproductive health knowledge, attitudes, and behaviors by youth.

4. Overall, site B will show the most improvement in reproductive health knowledge, attitudes, and behaviors of youth according to a set of key indicators, with site A next, and site $\mathrm{C}$ last.

\section{Study sites}

The regions of Saint-Louis and Louga in Northern Senegal were chosen because of similar socioeconomic status and ethnic group composition. The distance between them is great enough to avoid contamination. Louga was site A, Saint-Louis was site B, and the town of Diourbel, also distant from Saint-Lois and Louga, was the control site C. Diourbel was chosen because of its urban status, many socio-cultural similarities with the previous cities, and a population over 30,000 inhabitants. Also, there were no important reproductive health programs active when the study started.

\section{Research design}

This operations research (OR) study had four phases, as shown in Figure 1:

1. A diagnostic phase was conducted in January 2000 to determine what youth want and what services/programs youth might use. It used mainly qualitative techniques with key informants, focus groups and in-depth interviews with youth, service providers, religious leaders, and teachers, and site visits. This information was used to guide the design of the interventions.

2. A population-based survey was conducted in April 2000 to measure baseline indicators in the three sites.

3. An intervention phase in which the community, health services, and school interventions were implemented in Louga and in Saint-Louis over approximately 15 months.

4. An endline survey was conducted in the three sites in July 2002.

\section{Sample size}

At each interview period 500 households with family members aged 10-19 were sampled in each of the experimental and control groups. With an average of two adolescents per household, young adults were selected for interviews, with expected response rates of $80 \%$ and design effects of 1.5. Both parents of the adolescent selected for interview were eligible for the survey. 


\section{Selection procedures for the baseline and endline samples of young adults}

At baseline the eligible study participants were selected using a two-stage cluster design where:

1) Twenty enumeration districts (DR) were selected proportionate to the total number of households in each, for a total of 60 sample DRs.

2) From a listing of all households in each of the $60 \mathrm{DRs}, 25$ households were randomly selected.

3) From the household roster of each sample household, all age-eligible study participants were selected for interviews.

Figure 1 Data Collection and Intervention Sites

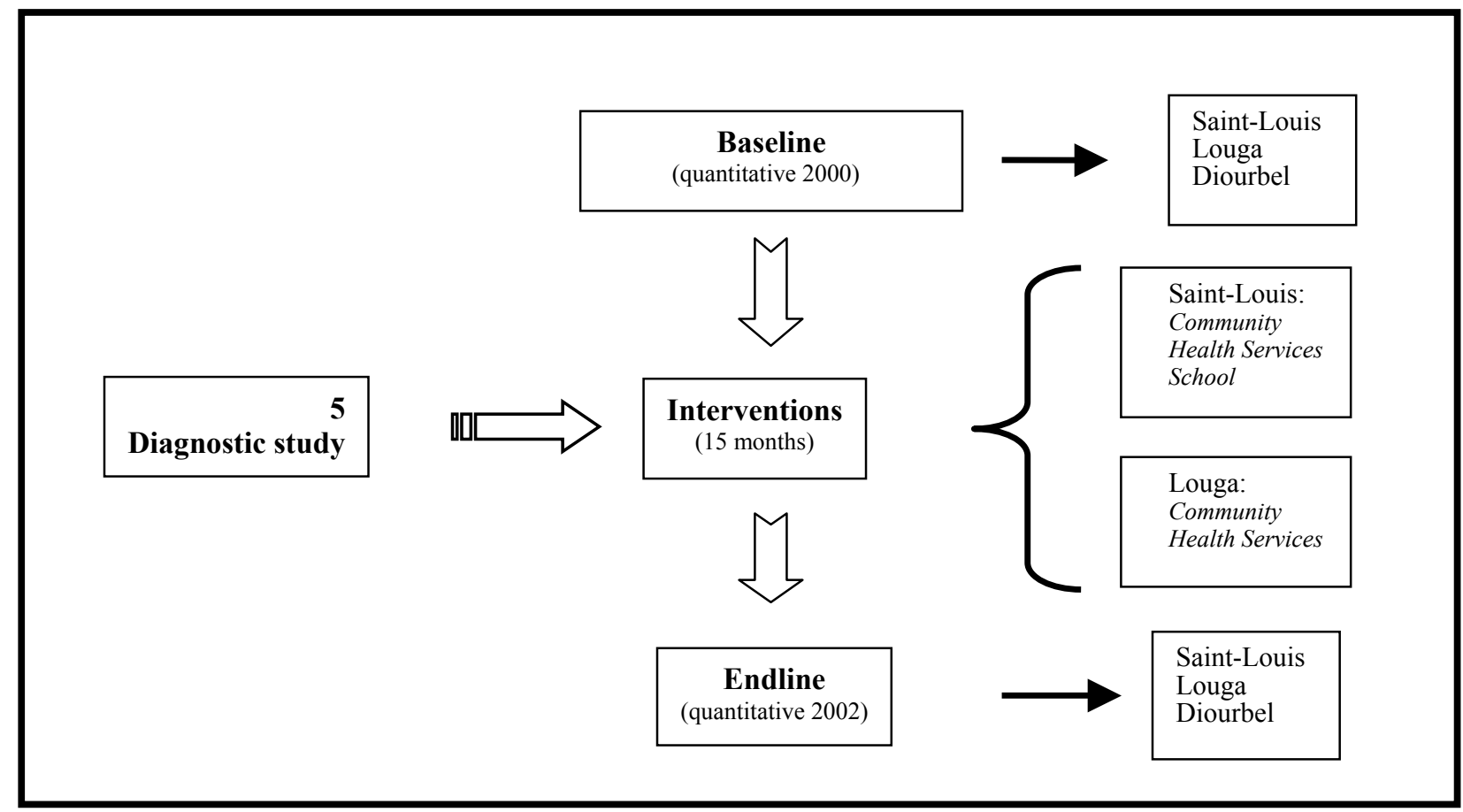

The target population for the endline household survey remained the same as in the baseline survey. A stratified two-stage cluster sampling procedure was used to select the sample ageeligible households because a cohort representing 25 percent of the original sample size needed to be re-interviewed at endline. Households in each of the 60 baseline sample DRs were listed and stratified into whether they were selected at baseline or not. From the stratum of sample baseline households, 15 households from each sample DR were randomly selected. The remaining 10 households were selected at random from those not included for baseline interviews. As in the baseline survey, all age-eligible young adults were asked to participate in the interviews. (See Annex B for implications of the selection procedures on the construction of sampling and analysis weights). 


\section{Sample size}

A total of 2,893 adolescents and 1,683 parents were interviewed at baseline, and 2,738 adolescents and 1,409 parents at endline. At the endline the response rates of adolescents decreased, particularly among boys 15 to 19 years old (see Table 1). The endline survey took place during the international World Cup soccer tournament, reducing the chance of finding boys at home, as not all households have a TV. Boys were often visiting friends or relatives in homes that had TV to watch the matches (see response rates in Annex A, Table A-1).

Table 1: Sample Size

\begin{tabular}{lcccccc}
\hline \hline & \multicolumn{2}{c}{ Saint-Louis } & \multicolumn{2}{c}{ Louga } & \multicolumn{2}{c}{ Diourbel } \\
\cline { 2 - 7 } & Baseline & Endline & Baseline & Endline & Baseline & Endline \\
\hline Boys & & & & & & \\
$10-14$ & 231 & 219 & 274 & 263 & 248 & 222 \\
$15-19$ & 173 & 183 & 225 & 201 & 198 & 147 \\
Girls & & & & & & \\
$10-14$ & 278 & 235 & 262 & 306 & 276 & 229 \\
$15-19$ & 231 & 239 & 258 & 262 & 239 & 232 \\
Parents & & & & & & \\
All & 568 & 519 & 537 & 421 & 578 & 469 \\
\hline \hline
\end{tabular}

\section{Summary of analyses and analytical strategies}

The various types of analyses conducted are as follows:

1) Bivariate analysis of personal characteristics of study participants and their parents by intervention groups and time of interviews (baseline and endline). This was done to assess whether selected characteristics of study participants, especially those that are associated with key outcomes of interest, were more or less the same among sample participants from the various intervention groups at both the baseline and endline surveys. Because interventions were randomized to groups rather than individuals, the usual balance in both known and unknown characteristics of study participants that individual-level randomization induces could not be assured; hence the need to perform tests of association of personal characteristics by intervention group and time of interview.

2) Unadjusted analysis of the association of selected outcomes with intervention groups and time of interviews.

3) Adjusted analysis of the association of selected outcomes with intervention groups and time of interviews. With some imbalance in personal characteristics that affect outcomes, the unadjusted assessment of the association of selected outcomes with intervention groups and time of interviews was extended to account for potential confounding or modification of effects of the intervention with some of the characteristics of study participants.

Data for analyses 1) and 2) above was summarized in terms of unweighted counts of study participants and weighted summary statistics including means, proportions or percentages, and standard deviations. For analysis 2), the overall strategy was to analyze jointly the outcomes of interest at baseline and endline surveys for all of the three intervention groups. In this strategy, 
the measure of intervention effect is the difference in levels of outcomes at baseline and endline between those in the intervention and control groups (see Annex B for a detailed description of calculating the measure of intervention effect). An alternative strategy was to initially establish that outcome levels at baseline between intervention and control groups are statistically equivalent. Then, the difference in outcomes between intervention and control groups at endline was calculated and considered to be the measure of effect of the intervention.

\section{Description of the Interventions}

The interventions were introduced after a long period of preparation, during which several curricula, information, education, and communication (IEC) materials, and a management information system (MIS) were developed. The service delivery phase lasted only 15 months. The $\mathrm{MOH}$ implemented the health service and community components, while the school component was implemented by GEEP. Given the socio-cultural context of Senegal, most actors educating youth, e.g., teachers, peer educators, and supervisors, put more emphasis on values clarification and abstinence as a mean of protection rather than condom promotion. The service delivery component did not have a condom distribution strategy. ${ }^{1}$

\section{Community Interventions}

The project envisioned that by making parents key participants, they would be better informed about adolescence and related reproductive health issues, be sensitive to the needs and issues of their adolescent children, and also be more willing for their children to participate in project activities. Another objective was to improve the knowledge, attitudes, and behaviors of out-ofschool adolescents.

\section{Sensitization of adults}

Over 3,555 parents, religious, administrative, and community leaders attended conferences and meetings convened by project staff. Discussion groups with adults on adolescent reproductive health topics were led by IEC agents of the Ministry of Health and the Ministry of Social Affairs. The adults contacted ranged from the parents of adolescents to members of organized groups such as women's groups. These programs did not follow a set or regular pattern of activities as they were based on the interest expressed by the adults in the community. During the meetings, a range of topics were discussed, including the puberty process, communication strategies between parents and adolescent children, differing concerns between parents and adolescents, adolescent health, and the nature of the services available.

\section{Conducting classes on adolescence in the community}

This was the primary activity of peer educators. Peer educators were chosen by their youth community-based organization (CBO). They were trained by the technical committee and equipped after signing a contract between the association and the district. They organized classes covering the 17 sessions of the life skills curriculum, Grandir en Harmonie [Growing in Harmony], developed with support from Family Health International (FHI). Adolescents recruited by peer educators, ranging in age from 10 to 19 , gathered into groups of 10 to 20 , and the peer educator conducted the class. The format of the classes was jointly decided by the peer educator and the participants and had sufficient flexibility to accommodate differing needs. For

\footnotetext{
${ }^{1}$ For more information, see the report on the process documentation, Diop et al. 2003.
} 
example, the venue of the class in some instances was based on the convenience of the participants. Examples of different venues used include a youth association office, youth information centers, community meeting spaces, or participants' homes. Second, as the entire curriculum of eight modules was covered over 17 sessions, the group met according to a plan they had jointly agreed upon.

These classes were based on the "edutainment" model (education and entertainment) and used the medium of games and play to illustrate concepts and ideas. Music and role-play were also some of the techniques used. ${ }^{2}$ Adolescents (18,358 total number) who completed the entire curriculum were given a badge of completion, pamphlets, or a T-shirt.

\section{IEC activities at community events}

Peer educators used opportunities provided by community festivals and religious holidays to conduct IEC activities. As these opportunities varied by site and season, there was no fixed schedule of events. Examples of community events include festivals for jazz and blues music, theatre festivals, music concerts, soccer and basketball matches, and camps held during vacations. At such gatherings, peer educators organized a booth where they displayed IEC materials from the project and handed out promotional material. They also initiated games and contests to publicize the message of adolescent reproductive health. The purpose of these activities was to inform adolescents and parents about the project and activities, recruit new adolescents to undergo the curriculum, allay parental fears about the curriculum, empower adolescents, and promote group education.

\section{Radio programming}

The medium of radio was also used to reach different audiences with adolescent reproductive health issues.

\section{Health Service Interventions}

Eight health service delivery clinics were identified to test the youth-friendly services strategy. Strengthening the link between community health services and schools was an important element of the intervention.

\section{Training}

A series of training workshops was held beginning with a training-of-trainers workshop using the WHO curriculum "Orientation of health providers on adolescent reproductive health". Then training was held for service providers working in the study clinics who would be serving adolescents, including nurses and midwives. The training was interactive and participatory with games, visualization exercises, debates, and group work.

The final group to receive training was Aide Ados [Adolescent Aides], young people identified within the facility by the district staff or in the neighborhood by the health provider as providers' aides to welcome, counsel, and refer adolescent within the health facility. They were also trained to conduct classes with groups of adolescents. They were under the supervision of the health post chief.

\footnotetext{
2 "Animation" is the term used for these activities.
} 


\section{Infrastructure modification}

Access and privacy were considered primary factors to facilitate adolescent use of health facilities. All the facilities participating in the study went through a COPE (Client Oriented, Provider Efficient) exercise to identify how services and the physical layout could be reorganized in a facility to make it adolescent-friendly. In some facilities, this involved the setting up of waiting rooms for the exclusive use of adolescents; in others, it involved adding doors that facilitated private access to the service provider.

\section{Information campaigns on reproductive health}

The providers' aides conducted classes on adolescence similar to the ones taught by peer educators in the community. They used the same curriculum for this purpose. These classes were usually conducted at the health facilities in the afternoon hours when no other services were provided. This ensured a degree of privacy and confidentiality for adolescents who were reluctant to visit health facilities. Some aides also conducted these classes at other venues, in response to requests from adolescents who did not wish to go to the health facilities. A total of 1,607 adolescents received care for reproductive health by health providers, 944 adolescents were counseled, 545 participated in classes within the health facility, and 828 participated in classes outside the health facility.

\section{School Interventions}

Six schools (two primary, two secondary, and two high schools) were chosen by GEEP for the introduction of the reproductive health curriculum.

\section{Curriculum development}

The curriculum Le Devenir Accompagné: Santé Reproductive et Adolescents [Accompanying the Future: Adolescents and Reproductive Health] was developed to be suitable for students in primary, secondary, and high school. It was also designed to be used by teachers either as material for class assignments or for didactic classroom teaching. After gaining the approval of the Ministry of Education, the six module-curriculum was presented to the stakeholders in the region who had participated in the planning meetings. The third and final step involved the presentation of the curriculum nationally to a wider range of stakeholders involving donors and cooperating agencies (January 2001).

\section{Training}

In the next step, training was held for those who would be conducting activities - teachers, student animator leaders (LEAs) ${ }^{3}$ or teachers' aides who are peer educators, and nurses posted at the school clinics. Prior to the project, teachers had not been trained on how to communicate with students regarding adolescence and the various issues around it. Hence, this activity was not only necessary but also innovative. Twenty-six teachers were given an introduction to the new curriculum, the theory behind its development, its aims, and how to use it. Teachers were organized in small working groups according to the level (primary, secondary, or high school) they taught, and they participated in group exercises about how they would introduce the materials in their classes. The training was conducted by GEEP and Ministry of Education

\footnotetext{
${ }^{3}$ Leader Elèves Animateurs (LEAs) are student volunteers and typically help the teachers in various tasks (teachers' aides). Teachers' aides are also members of family life education (FLE) clubs.
} 
headquarters staff. These staff were members of the core group who had developed the curriculum. Involving this group in training ensured that the philosophy behind the curriculum was transmitted to the teachers, and training capacity in the new curriculum was institutionalized.

Fifty-two teachers' aides were trained, and family life education clubs organized conferences and seminars. Five school nurses underwent the same training as other health providers based in the public sector clinics.

\section{Activities at school events}

The curriculum was taught within classes by inserting it in existing courses (e.g., reproduction within biology) when it was appropriate, or as a separate topic when it did not fit in the regular program (e.g., rights in French classes). The schools conducted a number of events outside of school hours that were avenues for providing information on reproductive health and services. These events were usually school functions attended by students and their families. A total of 5,053 students participated in the GEEP curriculum on reproductive health. In addition, community peer educators were asked to reinforce primary school interventions. They conducted group classes with 980 students in 18 schools under the supervision of 35 teachers. The synergy between health services and the community intervention was well established, but the linkages with between schools and the two other components were not maximized.

\section{Limitations of the study}

\section{Contamination between sites}

Maintaining the integrity of the control site was not easy. Activities on adolescent reproductive health were introduced in Diourbel, the control site, during the implementation of the research, particularly media campaigns. In addition reproductive health IEC activities increased in the general population during the period, including an outreach strategy that targeted the entire community. Louga was not supposed to implement a school-based intervention; however, given the difficulty in this city of working within the community, peer educators frequently contacted groups of students and conducted group classes outside schools.

\section{Sampling and area of intervention}

Saint-Louis is geographically large, and the 20 neighborhoods chosen in the survey sample to receive the intervention were difficult to cover with only one peer educator per neighborhood. In addition peer educators worked where adolescents were ready to participate, so they covered other neighborhoods following demand. In Louga, a smaller city, a better match was obtained between the survey area and the intervention area.

\section{Coverage of curriculum theme}

Issues of sexuality, masturbation, contraception, and condom use were found to be too sensitive even by peer educators. They were less well covered than the topics of values, abstinence, and fidelity. The menstrual cycle, a very technical theme, was not easy to handle by peer educators. In addition a debate took place among project advisors about the risks for adolescents of receiving this knowledge from non-medical personnel. It was thought that adolescents might 
tend to use knowledge of the menstrual cycle as a means of family planning, putting themselves at risk of pregnancy or STIs. The MOH does not recommend this method.

\section{Length of intervention}

Fifteen months of intervention - interrupted by school vacations, rainy seasons, and political events - did not permit a larger number of youth to be reached. However the length of the intervention was sufficient to see some effect.

\section{RESULTS}

\section{Socio-demographic characteristics}

\section{Adolescents}

Using two samples, collected at baseline and endline, to measure changes attributable to the intervention assumes that these samples have similar socio-demographic characteristics. Beyond the description of the two samples, some comparison tests between the baseline and endline were carried out to verify their similarity over time. Comparisons for the key socio-demographic variables are presented in Table 2.

\section{Distribution by sex and age}

Table 2 shows that proportions remained the same at endline in Saint-Louis and Diourbel; in Louga, the proportion of girls increased from 50 percent in 2000 to 56 percent in $2002(\mathrm{p}=0.02)$. The average age was about 14 years for both boys and girls, and did not change significantly from one survey to the next.

The 10-14 year age group was better represented than the 15-19 year age group, except for the girls in Saint-Louis, where the proportion of the 10-14 year age group dropped from 55 percent in 2000 to 49 percent in $2002(\mathrm{p}=0.04)$. The change in the age distribution did not create a significant change in the average age of the girls in Saint-Louis.

Almost all the adolescents targeted from the three areas were unmarried (single). Divorced and separated adolescents were grouped in the "single" category, although their numbers were small. There was a slight decrease at the endline in the proportion of single adolescents in Diourbel, from 98 percent in 2000 versus 95 percent in $2002(\mathrm{p}=0.00)$.

In the areas studied, more than half the adolescents had attained elementary education in both surveys. At the endline survey, more than a quarter of those in Saint-Louis and Louga, and about one-tenth of those in Diourbel, had higher than elementary education. A slight but significant decline in the proportion attaining elementary level occurred in Louga (60\% in 2000 versus 55\% in 2002; $p=0.02$ ), was offset by a larger significant increase in those attaining a secondary or higher level of education. In all sites there were small but significant declines in the proportions reporting attending Koranic studies between the baseline and endline surveys. The proportion of those who were not schooled (in either French or Koranic studies) was about one-fifth at both baseline and endline surveys in Diourbel, and about 10 percent in Louga. At Saint-Louis, the proportion of young illiterate people doubled ( $6 \%$ in 2000 versus $11 \%$ in $2002 ; p=0.00$ ). 
Table 2: Socio-demographic characteristics of adolescents (percent)

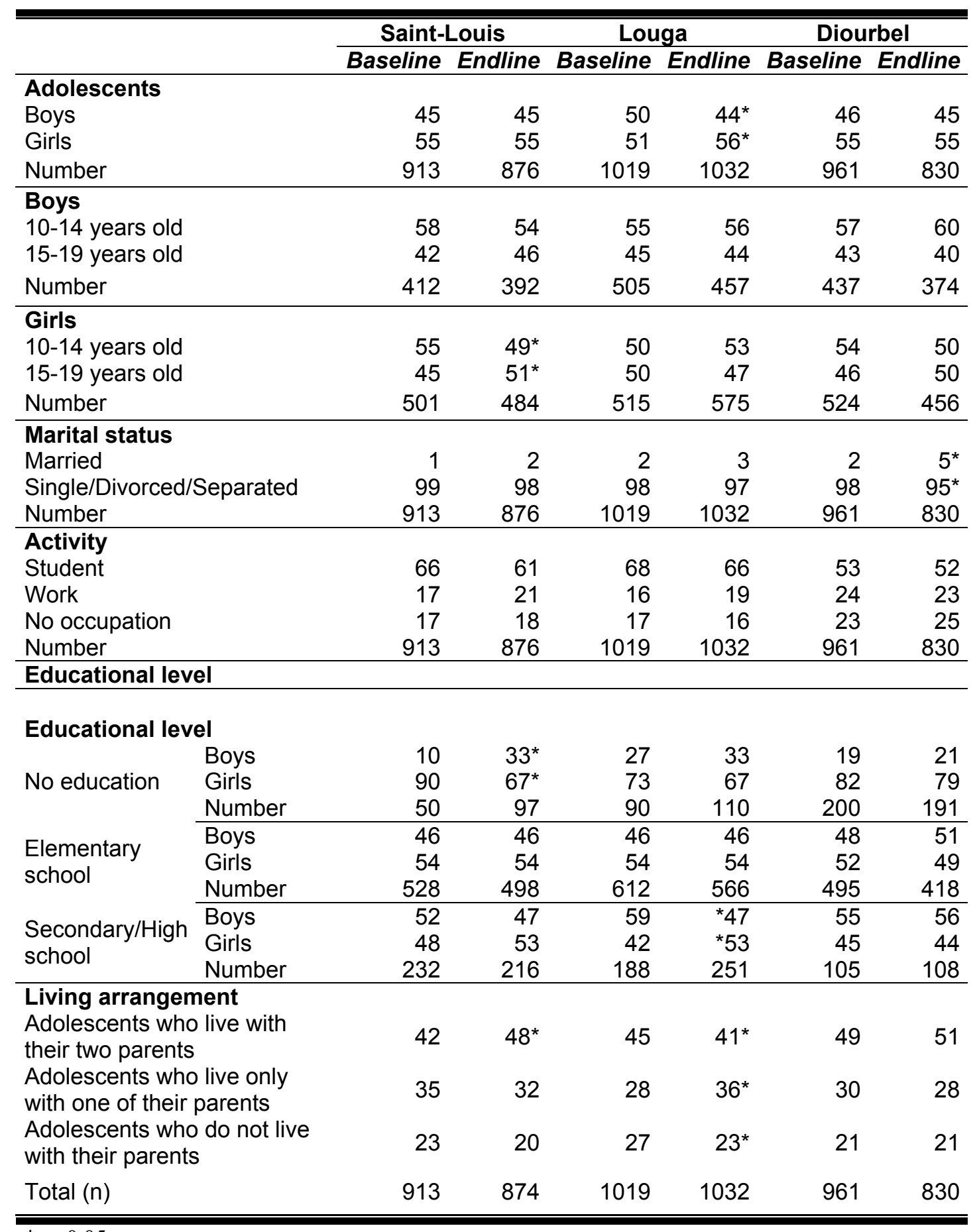

$* \mathrm{p}<0.05$

The proportion of illiterate girls was higher than boys in the three areas during the two surveys. The difference was greatest in Diourbel, where of the one-fifth reporting no education, about 80 percent were girls. However, in Saint-Louis there was a marked decrease in the proportion of young girls who were uneducated relative to boys, dropping from 90 percent in 2000 to 67 percent in $2002(\mathrm{p}=0.00)$. 
Educational attainment is relatively balanced by sex at the primary level. In Saint-Louis and Louga (and in Diourbel at baseline), the proportion of girls with primary education was slightly higher than boys. Among adolescents who had attained secondary education or were still pursuing studies, the proportion of boys and girls changed from baseline to endline, with higher proportions of girls at this level at endline in both Saint-Louis and Louga. Only Louga saw a significant change ( $42 \%$ in 2000 versus $53 \%$ in $2002 ; \mathrm{p}=0.02)$.

Koranic instruction is a very popular activity in the three sites, and many young people are sent to the Dahra. Among the small proportion attending Koranic education, girls formed the majority both during the initial and final surveys in Saint-Louis. In Diourbel, boys formed the majority in both surveys; however, they showed a significant decrease between 2000 and 2002 compared to girls, falling from 70 percent to 56 percent $(\mathrm{p}=0.02)$. In Louga, the boys formed the majority in 2000, whereas in 2002 their proportion was equal to that of girls ( $72 \%$ in 2000 and $49 \%$ in $2002 ; p=0.00)$. The national religious pattern is clearly reflected in the sample data, with virtually all respondents reporting being Muslim. In all study sites and during both surveys, more than half the adolescents were students. In Saint-Louis the proportion of pupils dropped from 66 percent in 2000 to 61 percent in $2002(p=0.01)$. In Louga the proportion of female students increased from 44 percent in 2000 to 52 percent in $2002(\mathrm{p}=0.01)$.

In Saint-Louis, the proportion of adolescents having some professional activity rose significantly from 17 percent to 21 percent $(\mathrm{p}=0.01$ ). In all sites, slightly more than half of those reporting some activity were males. In contrast, females formed the vast majority of those neither in school nor reporting economic activity. In Louga there was an increase in the proportion of girls among all non-occupied adolescents (from $80 \%$ in 2000 to $89 \%$ in $2002 ; p=0.02$ ), while in Diourbel the increase was from 76 percent to 89 percent $(\mathrm{p}=0.00)$.

In all areas nearly half or slightly more of the adolescents lived with their mother and father; this proportion rose in Saint-Louis from 42 percent to 48 percent $(\mathrm{p}=0.01)$. In Louga the proportion living with one parent (or with a guardian) increased from 28 percent to 36 percent $(\mathrm{p}=0.00)$, while the proportion of those not staying with their parents decreased from 27 percent to 23 percent $(\mathrm{p}=0.03)$.

\section{Conclusion}

From this analysis, the samples from the two surveys were comparable on most sociodemographic characteristics. The changes that were seen are related to the fact that the sample is two years older. Adolescents experienced transition to the labor market, marriage, and migration. There is no significant difference across the three sites except for the ethnic composition, with more Serer in Diourbel than the others sites. However, in terms of reproductive health behaviors, the Serers are no different than Wolofs.

\section{Parents}

Table 3 shows that about 70 percent of the parents interviewed were female, as they are the ones who were found at home by interviewers. This discrepancy between men and women is attributed both to the practice of polygamy, with more wives in the household, and to the absence of men either temporarily or for longer durations due to migration, particularly in Louga and Diourbel. The distribution of the sample by sex stayed more or less the same in Saint-Louis, but it changed in Louga where fewer men were interviewed during the endline. 
Table 3: Socio-demographic characteristics of parents

\begin{tabular}{|c|c|c|c|c|c|c|c|}
\hline & & \multicolumn{2}{|c|}{ Saint-Louis } & \multicolumn{2}{|c|}{ Louga } & \multicolumn{2}{|c|}{ Diourbel } \\
\hline & & Baseline & Endline & Baseline & Endline & Baseline & Endline \\
\hline $\operatorname{Sex}(\%)$ & $\begin{array}{l}\text { Men } \\
\text { Women } \\
\text { Number }\end{array}$ & $\begin{array}{r}29 \\
71 \\
568 \\
\end{array}$ & $\begin{array}{r}29 \\
71 \\
519 \\
\end{array}$ & $\begin{array}{r}30 \\
70 \\
537 \\
\end{array}$ & $\begin{array}{l}22^{*} \\
78^{*} \\
421 \\
\end{array}$ & $\begin{array}{r}28 \\
72 \\
578 \\
\end{array}$ & $\begin{array}{r}31 \\
69 \\
469 \\
\end{array}$ \\
\hline \multirow{2}{*}{$\begin{array}{l}\text { Mean of age } \\
\text { (years) }\end{array}$} & $\begin{array}{l}\text { Men } \\
\text { Number }\end{array}$ & $\begin{array}{r}50.5 \\
164 \\
\end{array}$ & $\begin{array}{r}52.5 \\
150 \\
\end{array}$ & $\begin{array}{r}49.5 \\
162 \\
\end{array}$ & $\begin{array}{r}48.3 \\
94 \\
\end{array}$ & $\begin{array}{r}54.6 \\
147 \\
\end{array}$ & $\begin{array}{r}47.4 \\
144 \\
\end{array}$ \\
\hline & $\begin{array}{l}\text { Women } \\
\text { Number }\end{array}$ & $\begin{array}{l}42.2 \\
404 \\
\end{array}$ & $\begin{array}{c}44.2^{*} \\
369 \\
\end{array}$ & $\begin{array}{l}41.0 \\
372 \\
\end{array}$ & $\begin{array}{l}41.9 \\
327 \\
\end{array}$ & $\begin{array}{l}40.6 \\
394 \\
\end{array}$ & $\begin{array}{l}40.4 \\
325 \\
\end{array}$ \\
\hline \multirow{5}{*}{$\begin{array}{l}\text { Educational } \\
\text { level (\%) }\end{array}$} & $\begin{array}{l}\text { Without } \\
\text { education }\end{array}$ & 48 & 46 & 55 & 58 & 78 & 80 \\
\hline & Elementary & 27 & 31 & 20 & 24 & 13 & 13 \\
\hline & $\begin{array}{l}\text { Secondary } \\
\text { \& higher }\end{array}$ & 24 & 23 & 23 & 19 & 8 & 7 \\
\hline & Other & 1 & 0 & 1 & 0 & 2 & 0 \\
\hline & Number & 568 & 519 & 537 & 421 & 578 & 469 \\
\hline
\end{tabular}

On average, men were older than women. In Diourbel, however, the average age of men interviewed decreased (from 55 years in 2000 to 47 years in 2002; $\mathrm{p}=0.00$ ). This difference is attributed to migratory habits and also the fieldwork before the rainy season during the endline. In the other areas differences were not significant. On the other hand, in Saint-Louis there was an increase in women's average age (from 42 years in 2000 to 44 years in 2002; $\mathrm{p}=0.01$ ).

As found among the adolescents, the dominant ethnic group is Wolof, followed by Pulaar and Serer. Other ethnic groups such as Mandingo, Maure, and Diola were scarcely represented.

The level of education of parents is low, especially in Louga and Diourbel. In the latter site approximately 80 percent of parents had no schooling (influenced by both the high proportion of women among the parents, and more conservative attitudes about women's education during earlier generations). There were more educated parents in Saint-Louis than in Louga and Diourbel, and they have a better knowledge of French and Arabic than of local languages (data not shown). In Diourbel, the parents are less literate in French, the main language of school instruction.

\section{Exposure to reproductive health programs}

The proportion of adolescents who had received information on reproductive health in school increased significantly during the period in all three sites. There were significant increases among boys aged 10-14 in Saint-Louis, from five percent to 31 percent, in Louga from 10 percent to 35 percent, and to a lesser extent in Diourbel, from seven percent to 20 percent. Significant increases were also observed among older boys in both Saint-Louis and Louga. The proportion of girls aged 10-14 who reported having reproductive health information at school increased the most in Louga from three percent to 31 percent, followed by Saint-Louis and 
Diourbel (all significant at $\mathrm{p}<0.05$ ). As seen with the males, there was a similar increase also among females 15-19 in Saint-Louis and in Louga, with the greater increase in Louga (see Table 4).

Table 4: Distribution of adolescents who received information on reproductive health at school

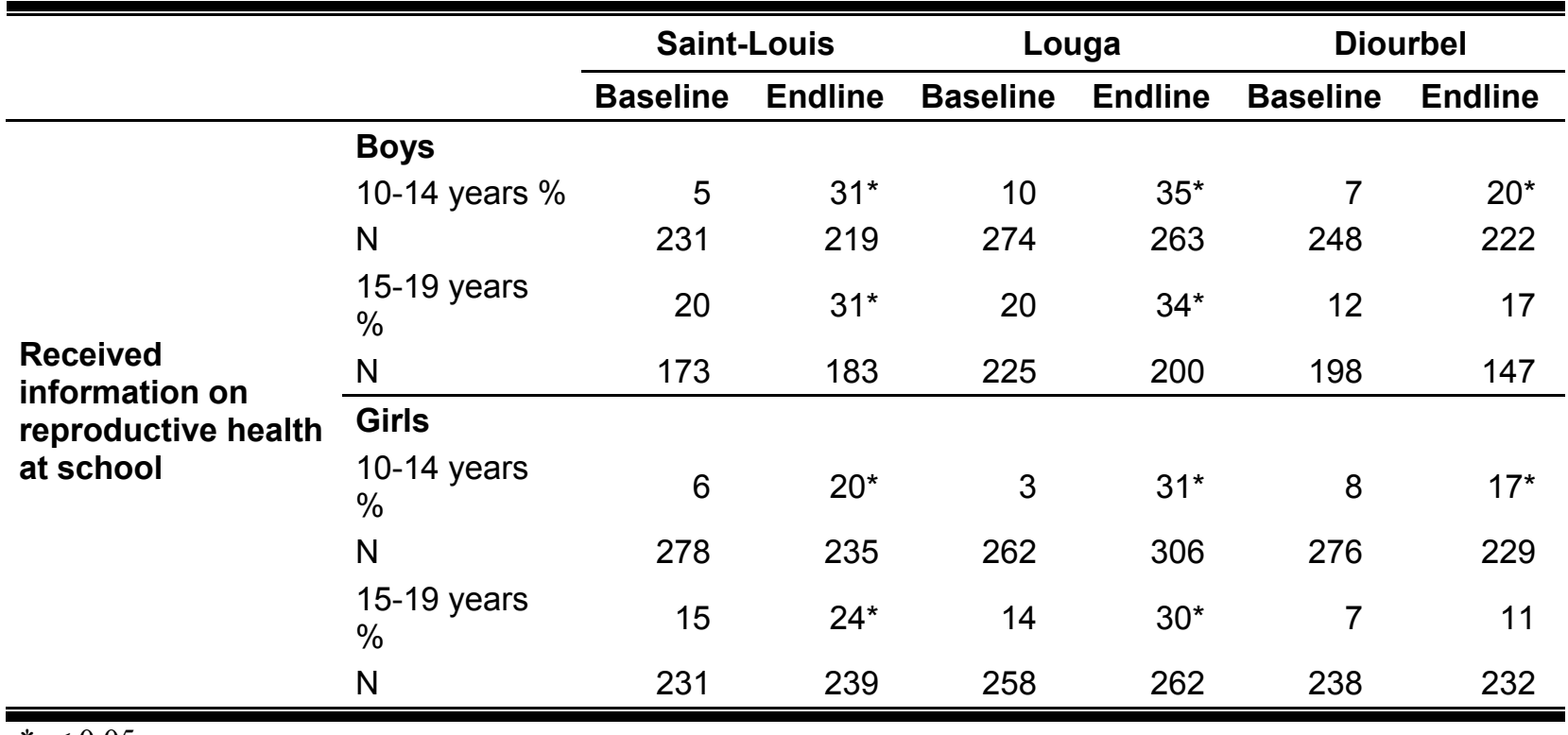

$* \mathrm{p}<0.05$

A similar trend was found for those who were exposed to reproductive health programs outside school (see Table 5). In all sites, regardless of sex or age group, the proportion of adolescents who benefited from the information increased. Both boys and girls in Louga in the 10-14 year age group showed increases of more than 30 percentage points, compared with 20 point gains in the other sites. Increases were even greater among the older adolescents, with significantly larger proportions reporting exposure to some reproductive health information in venues other than school in all study sites.

Table 5. Distribution of adolescents who received information on reproductive health outside school

\begin{tabular}{|c|c|c|c|c|c|c|c|}
\hline & & \multicolumn{2}{|c|}{ Saint-Louis } & \multicolumn{2}{|c|}{ Louga } & \multicolumn{2}{|c|}{ Diourbel } \\
\hline & & Baseline & Endline & Baseline & Endline & Baseline & Endline \\
\hline \multirow{6}{*}{$\begin{array}{l}\text { Received } \\
\text { information on } \\
\text { reproductive } \\
\text { health outside of } \\
\text { school }\end{array}$} & Boys & & & & & & \\
\hline & $\begin{array}{l}10-14 \text { years } \\
\%\end{array}$ & 7 & $28^{*}$ & 10 & $41^{*}$ & 12 & $33^{*}$ \\
\hline & $\mathrm{N}$ & 231 & 219 & 273 & 263 & 243 & 222 \\
\hline & $\begin{array}{l}15-19 \text { years } \\
\%\end{array}$ & 16 & $46^{*}$ & 18 & $60^{*}$ & 18 & $46^{*}$ \\
\hline & $\mathrm{N}$ & 173 & 183 & 222 & 200 & 195 & 147 \\
\hline & Girls & & & & & & \\
\hline
\end{tabular}




\begin{tabular}{lrrrrrr}
\hline \hline $10-14$ years & 6 & $26^{*}$ & 6 & $41^{*}$ & 9 & $27^{*}$ \\
$\%$ & 277 & 235 & 260 & 306 & 270 & 229 \\
$N$ & 17 & $49^{*}$ & 23 & $56^{*}$ & 21 & $54^{*}$ \\
$15-19$ years & 230 & 239 & 257 & 262 & 234 & 232 \\
\hline & & & & & \\
$\mathrm{N}$ & &
\end{tabular}

$* \mathrm{p}<0.05$

Several factors may account for the higher proportions of adolescents reporting exposure to reproductive health information outside school than in school. First, slightly less than half the sample was currently enrolled in school. Second, regardless of enrollment status, virtually all youth may have had the opportunity to be exposed to some community or media interventions.

The small differences between the project and control sites imply that adolescent reproductive health activities were undertaken to some degree in all areas. Exposure to a reproductive health program in school was higher in Saint-Louis and in Louga than in Diourbel. For the 10-14 year age group, exposure to a reproductive health program outside school was proportionally higher in Louga than in Saint-Louis or Diourbel. This may be due to the spatial layout of the town, with compact neighborhoods.

\section{Sources of information on reproductive health}

There was a significant change in sources of information, which showed a fairly important effect of the interventions. During the evaluation, adolescents reported specialists and the media as main sources of information. The specialist group consisted of teachers, peer educators, managerial and social development staff, or health care providers trained by the project. The role of specialists in disseminating this information rose significantly from 13 percent to 51 percent in Saint-Louis, and from 30 percent to 67 percent in Louga (see Figure 2). A small, non-significant increase was also found in Diourbel. Friends and family significantly decreased as a source of information in all sites. Exposure through the media in Diourbel rose dramatically from 5 percent to 73 percent.

Figure 2: Sources of reproductive health information

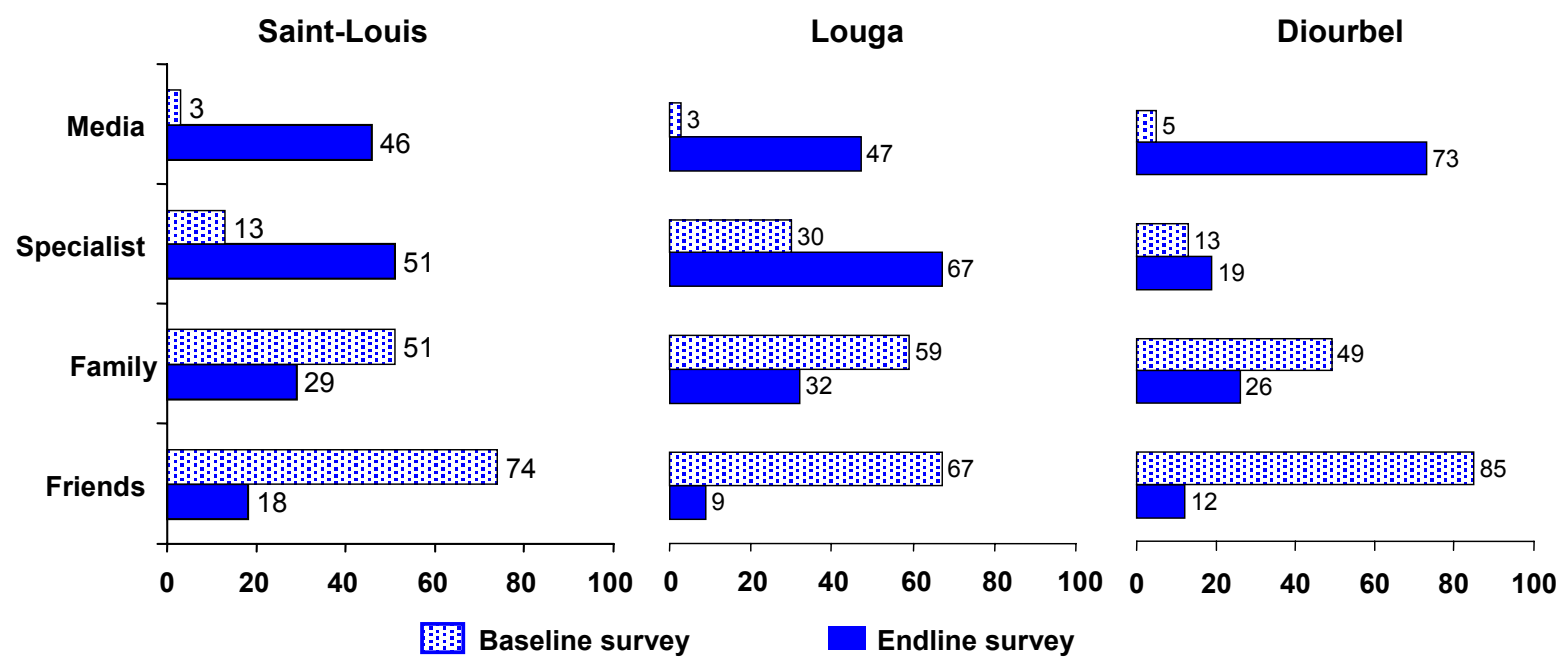


Exposure to classes organized by peer educators in the community was 14 percent in SaintLouis, 28 percent in Louga and only two percent in Diourbel. Adolescents in the 15-19 year age group were more likely to be reached by these classes than those aged $10-14$ years $(17 \%$ and $10 \%$ respectively). In Louga, significantly fewer girls were reached than boys. In the context of Senegal, girls of this age are highly controlled by the family, and they have less mobility than boys.

Table 6 clearly shows that contraception is a topic that adolescents would like to learn more about. Sexuality and issues related to reproduction were also frequently mentioned. About onethird of the adolescents in Diourbel also showed interest in learning more about STIs including HIV/AIDS.

Table 6: Percent distribution of reproductive health topics that adolescents want to learn more about

\begin{tabular}{lccc}
\hline \hline & Saint-Louis & Louga & Diourbel \\
\cline { 2 - 4 } & Endline & Endline & Endline \\
\hline Contraception & 81 & 90 & 81 \\
Reproduction & 35 & 38 & 29 \\
Sexuality and its consequences & 28 & 43 & 26 \\
Values & 20 & 21 & 16 \\
STI/HIVIAIDS & 18 & 19 & 32 \\
Human body functions & 11 & 5 & 9 \\
Puberty & 9 & 12 & 10 \\
Other reproductive health topics & 1 & 0 & 1 \\
Total (N) & 801 & 1002 & 740 \\
\hline \hline
\end{tabular}

Preferred sources for reproductive health information were varied as seen in Table 7. The family stands out as the most favored source, although the proportion of adolescents who actually seek information from their family is lower, as reflected in Figure 2. School and media are also cited by more than one-third of the adolescents, but no more than one-fourth of the adolescents mentioned health centers as a preferred source. There was an increase in adolescents who preferred information centers created by the project (youth counseling centers and information booths within youth associations), which rose from virtually no mention in the baseline to 17 percent in Saint-Louis and to 22 percent in Louga at the endline. 
Table 7: Percent distribution of adolescents by preferred sources of information on reproductive health

\begin{tabular}{lcccccc}
\hline & \multicolumn{2}{c}{ Saint-Louis } & \multicolumn{2}{c}{ Louga } & \multicolumn{2}{c}{ Diourbel } \\
\cline { 2 - 7 } & Baseline & Endline & Baseline & Endline & Baseline & Endline \\
\hline Educationalists/Peer & & & & & & \\
educator/IEC Agent & 11 & 14 & 5 & 18 & 8 & 2 \\
Family & 35 & 38 & 35 & 48 & 37 & 46 \\
Friends & 6 & 13 & 6 & 12 & 8 & 13 \\
Adolescent counseling centers & $\mathrm{NA}$ & 17 & $\mathrm{NA}$ & 22 & $\mathrm{NA}$ & 11 \\
Health centers & 21 & 17 & 23 & 26 & 19 & 13 \\
School & 35 & 31 & 27 & 39 & 34 & 31 \\
Media & 0 & 31 & 0 & 42 & 2 & 40 \\
No preference & 9 & 7 & 16 & 2 & 14 & 5 \\
Total $(\mathrm{n})$ & 911 & 873 & 1017 & 1032 & 958 & 829 \\
\hline \hline
\end{tabular}

\section{Conclusion}

The evaluation showed that the project interventions succeeded in exposing adolescents to information on reproductive health in Saint-Louis and Louga, and that youth in Diourbel were also exposed to reproductive health information from non-project sources. Both age groups were reached at school, but more boys reported receiving information than girls. Outside school, the 15-19 year age group was the more widely reached group. The observed increase in information disseminated by specialists (i.e. teachers, social development agents, IEC agents, and peer educators) may assure better quality of information conveyed. Increased information provided by the media and decreased information obtained from friends may also signal that more accurate information is now being provided. Adolescents would like to get more information on contraception, as well as other topics of sexuality and reproduction. The preferred channels of communication include the family, schools, and the media.

Two issues influence interpretation of the evaluation:

- The proportion of students reached was higher in Louga than in Saint-Louis, although the opposite had been expected. Louga also reported higher exposure to reproductive health information outside of school, presumably through community interventions. The recruitment process that peer educators used to organize community classes also reached schools.

- In Diourbel, the proportion of adolescents who received reproductive health information indicates that intensive and large-scale activities were carried out in this area, making it difficult to use these results for control purposes. In Diourbel, community leaders' awareness was raised during dissemination of the baseline study results, which brought together about one hundred political, administrative and health sector leaders, youth associations, and NGOs. 


\section{Parents' attitudes toward reproductive health programs}

Women participated more than men during community meetings in Louga and Saint-Louis, since women are organized in social groups whereas men are not. Parents' knowledge of the programs carried out in schools increased in the three sites, with the level rising significantly to around 40 percent in the two intervention areas and 25 percent in Diourbel where regular family life education clubs activities were taking place.

Among women, the increase in level of knowledge was higher in Louga and Saint-Louis than in Diourbel, which nevertheless also saw a significant rise. The level of approval for adolescents who receive reproductive health services dropped in Saint-Louis among both men and women, but rose among women in Diourbel and in Louga (from 76\% to 96\%) (see Table 8). Most of the parents who approved of adolescents receiving services wanted their children to benefit from the program, a positive development. All the women in the intervention sites supported this, but there was no marked difference in Diourbel between men and women.

Table 8: Parents' knowledge of reproductive health programs at school and support for the programs (\%)

\begin{tabular}{|c|c|c|c|c|c|c|c|}
\hline & & \multicolumn{2}{|c|}{ Saint-Louis } & \multicolumn{2}{|c|}{ Louga } & \multicolumn{2}{|c|}{ Diourbel } \\
\hline & & Baseline & Endline & Baseline & Endline & Baseline & Endline \\
\hline \multirow{4}{*}{$\begin{array}{l}\text { Know about the FLE } \\
\text { programs at school }\end{array}$} & Men & 14 & $40^{*}$ & 14 & $40^{*}$ & 4 & $28^{*}$ \\
\hline & $\mathrm{N}$ & 165 & 152 & 161 & 96 & 163 & 136 \\
\hline & Women & 5 & $42^{*}$ & 4 & $41^{*}$ & 6 & $25^{*}$ \\
\hline & $\mathrm{N}$ & 403 & 367 & 376 & 325 & 415 & 333 \\
\hline \multirow{4}{*}{$\begin{array}{l}\text { Approve of their children } \\
\text { receiving services }\end{array}$} & Men & 92 & $82^{*}$ & 74 & $93^{*}$ & 85 & $93^{*}$ \\
\hline & $\mathrm{N}$ & 165 & 152 & 161 & 96 & 163 & 136 \\
\hline & Women & 96 & $91^{*}$ & 76 & $96^{*}$ & 91 & 95 \\
\hline & $\mathrm{N}$ & 403 & 367 & 376 & 325 & 415 & 333 \\
\hline \multirow{4}{*}{$\begin{array}{l}\text { Want their children to } \\
\text { benefit }\end{array}$} & Men & 92 & $91^{*}$ & 90 & $99^{*}$ & 95 & 98 \\
\hline & $\mathrm{N}$ & 165 & 152 & 161 & 96 & 163 & 136 \\
\hline & Women & 100 & $97^{*}$ & 93 & $100^{*}$ & 98 & 100 \\
\hline & $\mathrm{N}$ & 403 & 367 & 376 & 325 & 415 & 333 \\
\hline
\end{tabular}

$* \mathrm{p}<0.05$

\section{Parents' attitude on the content of reproductive health programs}

Table 9 shows that the level of approval of reproductive health programs remained high, although it varied according to the reproductive health topic. A significant change was seen among mothers in Saint-Louis, where approval of providing information about contraception increased from 53 percent to 66 percent $(\mathrm{p}<0.05)$. Overall, however, this was the topic for which parents were most conservative. Approval of all other topics reached 90 percent or more for both mothers and fathers in all study sites, with few significant changes between the surveys. In all sites, parents wanted to receive more information about adolescents reproductive health for themselves. 
Table 9: Parents' attitudes towards reproductive health programs according to topic (\%)

\begin{tabular}{|c|c|c|c|c|c|c|c|}
\hline & & \multicolumn{2}{|c|}{ Saint-Louis } & \multicolumn{2}{|c|}{ Louga } & \multicolumn{2}{|c|}{ Diourbel } \\
\hline & & Baseline & Endline & Baseline & Endline & Baseline & Endline \\
\hline \multirow{4}{*}{ Anatomy/physiology } & Men & 99 & 98 & 98 & $91^{*}$ & 98 & 98 \\
\hline & $\mathrm{N}$ & 154 & 139 & 154 & 95 & 150 & 132 \\
\hline & Women & 98 & 98 & 99 & $94^{*}$ & 98 & 98 \\
\hline & $\mathrm{N}$ & 387 & 361 & 366 & 323 & 404 & 324 \\
\hline \multirow{4}{*}{ Sexuality } & Men & 90 & 93 & 91 & 85 & 93 & 87 \\
\hline & $\mathrm{N}$ & 154 & 139 & 154 & 95 & 150 & 132 \\
\hline & Women & 85 & $94^{*}$ & 95 & 95 & 96 & $91^{*}$ \\
\hline & $\mathrm{N}$ & 387 & 361 & 366 & 323 & 404 & 324 \\
\hline \multirow{4}{*}{$\begin{array}{l}\text { Early/unwanted } \\
\text { pregnancy }\end{array}$} & Men & 99 & 97 & 96 & 96 & 98 & $95^{*}$ \\
\hline & $\mathrm{N}$ & 154 & 139 & 154 & 95 & 150 & 132 \\
\hline & Women & 99 & 98 & 98 & $100^{*}$ & 96 & 97 \\
\hline & $\mathrm{N}$ & 387 & 361 & 366 & 323 & 404 & 324 \\
\hline \multirow{4}{*}{ Contraception } & Men & 62 & 72 & 67 & 65 & 56 & 54 \\
\hline & $\mathrm{N}$ & 154 & 139 & 154 & 95 & 150 & 132 \\
\hline & Women & 53 & $66^{*}$ & 68 & 66 & 56 & 52 \\
\hline & $\mathrm{N}$ & 387 & 361 & 366 & 323 & 404 & 324 \\
\hline \multirow{4}{*}{ STI/HIVIAIDS } & Men & 100 & 98 & 99 & 97 & 97 & 97 \\
\hline & $\mathrm{N}$ & 154 & 139 & 154 & 95 & 150 & 132 \\
\hline & Women & 98 & 96 & 99 & 100 & 97 & 98 \\
\hline & $\mathrm{N}$ & 387 & 361 & 366 & 323 & 404 & 324 \\
\hline
\end{tabular}

$* \mathrm{p}<0.05$

\section{Conclusion}

Fewer than half the parents were familiar with reproductive health programs for adolescents, although approval of adolescents receiving services and benefiting from such programs was high and increased significantly in the two intervention sites. Women's approval was higher than men's. Contraception was the most sensitive topic. Parents wanted to get more information on these topics so that they could play a bigger role in their children's lives. Higher proportional changes and more significant increases show that greater change was achieved in Saint-Louis and Louga than in Diourbel. The interventions had a positive impact on parents' attitudes towards reproductive health programs for adolescents.

\section{Communication on reproductive health}

The first hypothesis of this study proposed that the intervention areas would have a more favorable environment for adolescents to access reproductive health at the end of the project than at baseline. Parent-child communication was used as a proxy indicator to evaluate the community's support for communications around reproductive health.

\section{Parents' perceptions of communication with adolescents}

There was a decline in the proportion of parents who did not discuss reproductive health issues with their children after the intervention (see Table 10). There were significant declines among both mothers and fathers in all study sites, with the exception of men in Saint-Louis (who showed a non-significant drop). Women were more willing to discuss these issues than men. 
Table 10: Parents' views on discussing reproductive health with their children (\%)

\begin{tabular}{llccccccc}
\hline \hline & & \multicolumn{2}{c}{ Saint-Louis } & \multicolumn{2}{c}{ Louga } & \multicolumn{2}{c}{ Diourbel } \\
\cline { 2 - 8 } & & Baseline & Endline & Baseline & Endline & Baseline & Endline \\
\hline \multirow{2}{*}{$\begin{array}{l}\text { Does not discuss } \\
\text { reproductive health }\end{array}$} & $\mathrm{N}$ & 41 & 37 & 48 & $25^{*}$ & 32 & $20^{*}$ \\
with the child & $\mathrm{N}$ & 165 & 152 & 161 & 96 & 163 & 136 \\
\cline { 2 - 9 } & Women & 26 & $15^{*}$ & 29 & $16^{*}$ & 19 & $12^{*}$ \\
\hline \hline
\end{tabular}

${ }^{*} \mathrm{p}<0.05$

\section{Adolescents' perceptions of communication with parents}

There were no significant changes among adolescents in their perception of the ease of discussing reproductive health with their father or male guardian, regardless of age group or sex. There were significant declines in all sites among older girls reporting it was easy to speak with mothers or female guardians; this was also the case among older boys in Saint-Louis. The only group reporting increased ease in speaking with mothers was younger boys in Louga. In most cases, fewer than 20 percent of the youth felt it was easy to speak with their fathers, and fewer than half felt it was easy to speak with mothers, reflecting long-standing social and cultural taboos against these topics.

It is possible that this ambivalent attitude about communicating with parents also can be attributed to changing adolescent expectations. The interventions towards youth emphasized the need to talk about reproductive health within the family setting, yet constraints remain to actually doing so on the part of both the parents and the youth.

\section{Level of communication on reproductive health}

During the baseline study, the proportion of adolescents in the 10-14 age group who did not talk with anyone about reproductive health was high, ranging from 55 to 69 percent. It dropped in all study sites in the endline survey (see Table 11). There were also important and significant declines among younger boys in Saint-Louis and Louga, as well as girls in both age groups in Louga and Saint-Louis.

The data show no consistent pattern reporting with whom adolescents communicate most. ${ }^{4}$ Louga is the only site where the proportion of adolescents who said that they discussed reproductive health with their friends had increased significantly between the two surveys (with the exception for boys in the 15-19 year age group).

\footnotetext{
${ }^{4}$ See Table A3 in Annex A.
} 
Table 11: Adolescents reporting no communication on reproductive health (\%)

\begin{tabular}{llcccccc}
\hline \hline & \multicolumn{2}{c}{ Saint-Louis } & \multicolumn{2}{c}{ Louga } & \multicolumn{2}{c}{ Diourbel } \\
\cline { 2 - 7 } & & Baseline & Endline & Baseline & Endline & Baseline & Endline \\
\hline & Boys & & & & & & \\
& $10-14$ years & 55 & $41^{*}$ & 62 & $37^{*}$ & 68 & $41^{*}$ \\
& $\mathrm{~N}$ & 231 & 219 & 274 & 263 & 248 & 222 \\
Does not & $15-19$ years & 16 & 17 & 28 & 20 & 34 & $16^{*}$ \\
communicate & $\mathrm{N}$ & 173 & 183 & 225 & 200 & 198 & 147 \\
\cline { 2 - 8 } with anybody & Girls & & & & & & \\
& $10-14$ years & 55 & $38^{*}$ & 60 & $39^{*}$ & 69 & $32^{*}$ \\
& $\mathrm{~N}$ & 276 & 235 & 262 & 306 & 275 & 229 \\
& $15-19$ years & 11 & $18^{*}$ & 25 & $16^{*}$ & 32 & $17^{*}$ \\
& $\mathrm{~N}$ & 231 & 239 & 258 & 262 & 236 & 232 \\
\hline \hline
\end{tabular}

$* \mathrm{p}<0.05$

Regardless of the desire to speak with parents, the proportion of adolescents who discussed reproductive health with their father or male guardian remained low with less than 16 percent among males and six percent among females. There were significant increases among younger boys in Diourbel and among all girls in Saint-Louis, but they did not exceed the prevailing levels.

Both boys and girls were more likely to speak with their mothers or female guardians about reproductive health than their fathers or male guardians, but the rates still do not exceed 24 percent among male adolescents or 43 percent among females. Indeed, the only groups to register significant increases were younger boys and girls in Diourbel. Indeed, older girls in Saint-Louis and Louga were significantly less likely to speak with their mothers following the intervention.

Shyness persists in discussing these personal topics. In general, fewer than 20 percent of adolescents report initiating discussions, while up to 50 percent report that most often it is others who do so. Around one-third indicate that it depends - sometimes they raise the topic, and sometimes it is others.

Younger boys and girls in Saint-Louis appear to have gained some confidence, with significantly more reporting that they took the initiative in discussing reproductive health; this was also true for younger boys in Diourbel. Among older boys in Louga and older girls in Diourbel, fewer reported taking initiative at the endline compared with the baseline.

Large and significant increases took place at all sites among both boys and girls in discussing STIs including HIV/AIDS, although the level barely exceeds 25 percent among all the youth. Love relations also showed positive and significant increases across sites for all adolescents, particularly in Diourbel. Although discussions on reproductive health have increased, it is still haphazard. After the interventions, the frequency of discussions on reproductive health increased significantly in the three areas.

\section{Influence of direct exposure to the interventions}

The previous analyses sought to gauge the impact of the interventions on the population as a whole, without considering that not all adolescents or parents were directly influenced by the interventions. The following analysis tests the direct effect of the interventions by separating the 
adolescents into those who were exposed to reproductive health information at school or outside school during the previous 12 months and those who were not exposed to the project interventions.

Both boys and girls in Saint-Louis and Louga who were exposed to the interventions speak more with their friends, fathers, mothers, and others than those who were not exposed. The differences for the boys aged 10-14 in Louga are more evident (83\% for those exposed compared to 36\% who were not) than in Saint-Louis (67\% compared to 52\%) (see Figure 3). The increase in the proportion for those aged 15-19 was also greater in Louga than in Saint-Louis for both boys and girls. In summary, adolescents who were informed on reproductive health communicated significantly more with various people, while those who were not exposed did not.

\section{Figure 3: Communication on reproductive health according to exposure to interventions}

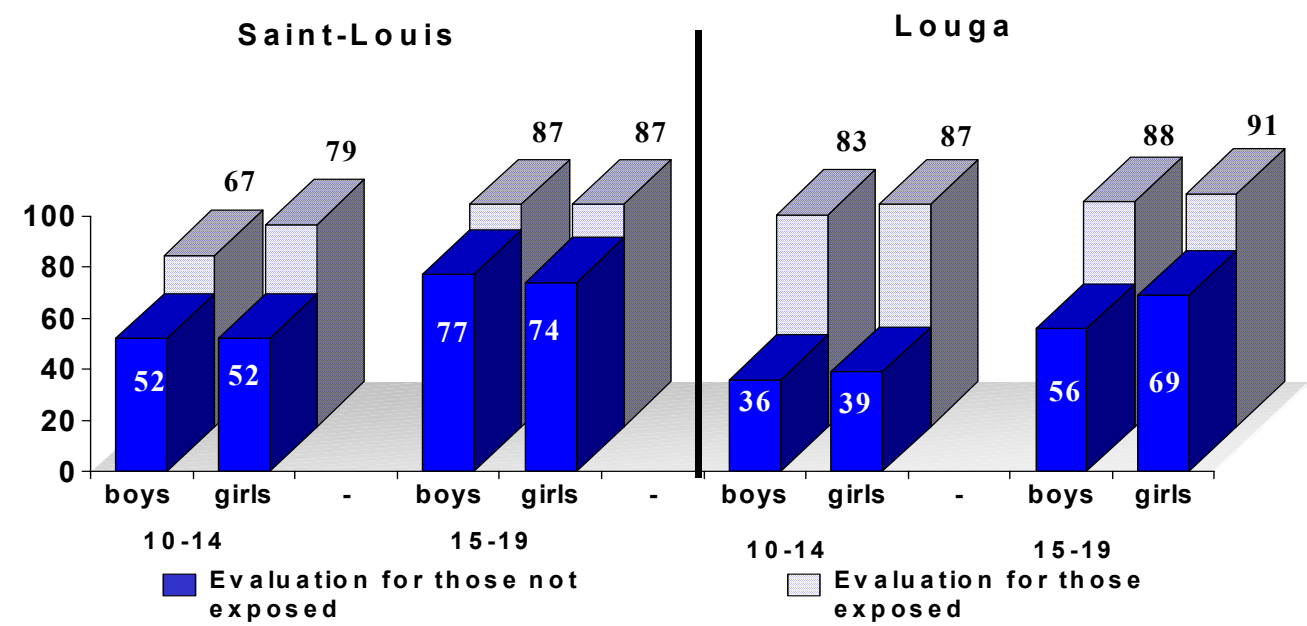

\section{Conclusion}

The possibility of discussing reproductive health requires establishing a climate that encourages communication. Communication, both on the parents' and adolescents' part, has improved. Adolescents sought more information from adults and other qualified sources than from their friends. Nevertheless, a family atmosphere conducive to communication remains lacking, and at the same time adolescents' expectations for more open communication have risen.

Adolescents, especially the younger ones, showed few significant differences in their choice of a discussion partner. Older girls generally spoke with friends and mothers. The older adolescents were more likely to initiate the conversation on reproductive health while the 10-14 year age group had a passive approach. However, both age groups more often reported that someone else began the discussion. Adolescents most frequently discuss topics related to STI/HIV/AIDS and love relationships. Adolescents who were exposed to reproductive health interventions seek more communication and information. 
It is not possible to draw clear conclusions on the effectiveness of the interventions on communication by comparing the different areas, as significant changes at comparable levels have taken place in all three areas. Improving communication, particularly for the younger age group, has to be seriously considered by program managers. Intervention programs aimed at younger adolescents need to be initiated.

Communication between parents and children was chosen as an indicator to show improvement in community support. Interventions to improve the social environment not only aimed to improve family communication but also to obtain support from political leaders, administrative heads, religious and community leaders.

\section{Knowledge and attitudes towards reproductive health}

\section{Knowledge of puberty}

Of the adolescents who knew of changes that signal puberty among females, the only significant changes occurred among girls in Louga (see Table 12). The recognition of ejaculation as an initial sign of fertility among boys rose for boys of all ages in Saint-Louis, and among boys aged 15-19 and girls of all ages in Louga. Knowledge of the menstrual cycle remained unchanged, except among boys aged 10-14 years in Louga where there was a small increase, and in Diourbel where there was a small but significant decrease. Overall, younger boys and girls know very little about puberty, and virtually no change was seen as a result of the interventions. Knowledge among older adolescents is slightly better, but remains low and did not improve after the interventions.

A comment on the teaching process is necessary. Beyond the complexity of understanding the menstrual cycle itself, there were personal prejudices among some of the teachers in the way the topic was taught, who feared that adolescents might consider it as an effective family planning method. 
Table 12. Knowledge of puberty among all adolescents

\begin{tabular}{|c|c|c|c|c|c|c|c|}
\hline & & \multicolumn{2}{|c|}{ Saint-Louis } & \multicolumn{2}{|c|}{ Louga } & \multicolumn{2}{|c|}{ Diourbel } \\
\hline & & Baseline & Endline & Baseline & Endline & Baseline & Endline \\
\hline \multirow{10}{*}{$\begin{array}{l}\text { Know the signs marking } \\
\text { the beginning of } \\
\text { womanhood for girls }\end{array}$} & Boys & & & & & & \\
\hline & $\begin{array}{l}10-14 \\
\text { years }\end{array}$ & 5 & 6 & 2 & 3 & 1 & 3 \\
\hline & $\mathrm{N}$ & 231 & 219 & 274 & 263 & 248 & 222 \\
\hline & $\begin{array}{l}15-19 \\
\text { vears }\end{array}$ & 32 & 33 & 20 & 32 & 22 & 21 \\
\hline & $\mathrm{N}$ & 173 & 183 & 225 & 200 & 198 & 147 \\
\hline & Girls & & & & & & \\
\hline & $\begin{array}{l}10-14 \\
\text { years }\end{array}$ & 9 & 11 & 6 & $14^{*}$ & 9 & 11 \\
\hline & $\mathrm{N}$ & 278 & 235 & 262 & 306 & 276 & 229 \\
\hline & $\begin{array}{c}15-19 \\
\text { years }\end{array}$ & 44 & 52 & 28 & $57^{*}$ & 44 & 42 \\
\hline & $\mathrm{N}$ & 231 & 239 & 258 & 262 & 238 & 232 \\
\hline \multirow{10}{*}{$\begin{array}{l}\text { Know the ability to } \\
\text { ejaculate marks the } \\
\text { beginning of being able } \\
\text { to be a father for boys }\end{array}$} & Boys & & & & & & \\
\hline & $\begin{array}{l}10-14 \\
\text { years }\end{array}$ & 1 & $4^{*}$ & 1 & 4 & 1 & 3 \\
\hline & $\mathrm{N}$ & 231 & 219 & 274 & 263 & 248 & 222 \\
\hline & $\begin{array}{l}15-19 \\
\text { years }\end{array}$ & 18 & $32^{*}$ & 15 & $28^{*}$ & 16 & 21 \\
\hline & $\mathrm{N}$ & 173 & 183 & 225 & 200 & 198 & 147 \\
\hline & Girls & & & & & & \\
\hline & $\begin{array}{l}10-14 \\
\text { years }\end{array}$ & 1 & 1 & 1 & $4^{*}$ & 0 & 1 \\
\hline & $\mathrm{N}$ & 278 & 235 & 262 & 306 & 276 & 229 \\
\hline & $\begin{array}{l}15-19 \\
\text { years }\end{array}$ & 16 & 25 & 7 & $27^{*}$ & 12 & 18 \\
\hline & $\mathrm{N}$ & 231 & 239 & 258 & 262 & 238 & 232 \\
\hline \multirow{10}{*}{$\begin{array}{l}\text { Knowledge of menstrual } \\
\text { cycle }\end{array}$} & Boys & & & & & & \\
\hline & $\begin{array}{l}10-14 \\
\text { years }\end{array}$ & 2 & 2 & 2 & $6^{*}$ & 3 & $1^{*}$ \\
\hline & $\mathrm{N}$ & 231 & 219 & 274 & 263 & 248 & 222 \\
\hline & $\begin{array}{l}15-19 \\
\text { years }\end{array}$ & 18 & 21 & 25 & 26 & 17 & 14 \\
\hline & $\mathrm{N}$ & 173 & 183 & 225 & 200 & 198 & 147 \\
\hline & Girls & & & & & & \\
\hline & $\begin{array}{l}10-14 \\
\text { years }\end{array}$ & 5 & 3 & 4 & 8 & 3 & 4 \\
\hline & $\mathrm{N}$ & 278 & 235 & 262 & 306 & 276 & 229 \\
\hline & $\begin{array}{l}15-19 \\
\text { years }\end{array}$ & 37 & 33 & 36 & 42 & 32 & 25 \\
\hline & $\mathrm{N}$ & 231 & 239 & 258 & 262 & 238 & 232 \\
\hline
\end{tabular}

$* \mathrm{p}<0.05$ 


\section{Influence of direct exposure to interventions}

Figure 4 shows that adolescents exposed to the interventions either in or out of school are more aware of the onset of maturity for girls in both intervention areas. Adolescents are more likely to know fertility signs for girls, and knowledge is higher in the 15-19 age group. It reaches a maximum of 64 percent for girls in Louga (41\% for those not exposed). The level for boys also rose, with 42 percent in Saint-Louis for those exposed to the interventions versus 16 percent who were not exposed, and 38 percent for those exposed to interventions in Louga compared to 16 percent for those not exposed. Boys and girls aged 10-14 years who where exposed also have better knowledge than those who were not exposed. Specifically, 16 percent of exposed girls compared with seven percent of non-exposed girls in Saint-Louis, and 17 percent of exposed girls compared with eight percent of non-exposed girls in Louga. For boys, knowledge was 10 percent among the exposed compared with two percent of the non-exposed in Saint-Louis.

Figure 4: Knowledge of puberty according to exposure to interventions

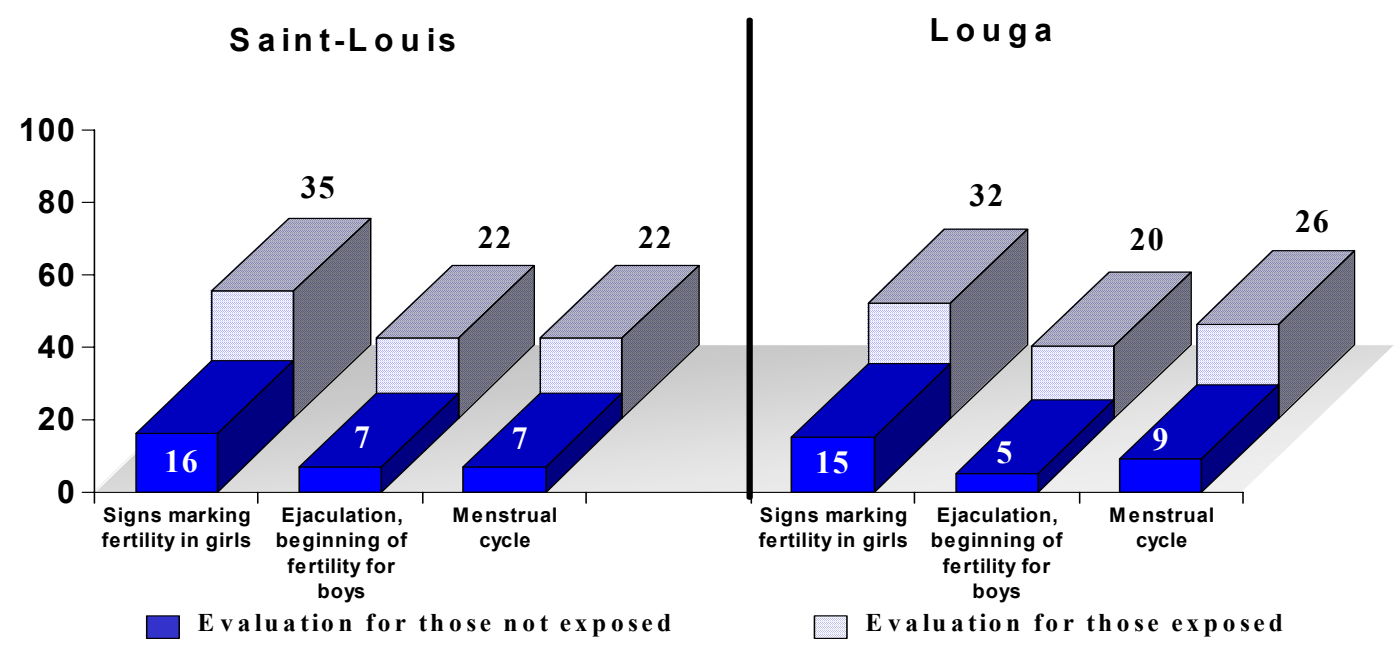

Actual exposure to the intervention results in similar trends for other knowledge indicators. Knowledge that a boy can impregnate a girl when he ejaculates increased significantly among all those exposed: 22 percent versus seven percent in Saint-Louis, and 20 percent versus five percent in Louga. Thirty-five percent of the girls exposed to interventions in Louga were aware of this stage in boys' development compared to 10 percent of those who were not exposed.

The time during the menstrual cycle when a girl can become pregnant is also better known by adolescents exposed to interventions (26\% versus $9 \%$ in Louga, and $22 \%$ versus $7 \%$ in SaintLouis). However, the levels of knowledge are relatively low for the 10-14 age group, rising to 12 percent for girls exposed to the intervention in Louga compared with three percent among those not exposed. These figures were significantly higher for girls compared to boys, and higher for the 15-19 age group, with a high of 49 percent for girls exposed in Louga versus 25 percent for boys. 


\section{Knowledge of risks related to adolescent sex}

Table 13 shows that adolescents know risks associated with adolescent sexual relations; more than 80 percent in all sites could list multiple risks. The already high knowledge levels increased significantly among both boys and girls in Louga and among girls in Diourbel. In Saint-Louis, there was a significant increase among boys aged 15-19 years and girls aged 10-14 years in the awareness of the health risks for girls who become pregnant. Knowledge also improved among older girls in Diourbel. Older girls in Louga reported a significant decline in their knowledge of pregnancy risks. There was little variation in the high knowledge of risks of abortion, and there were no significant changes between the two surveys.

Table 13: Knowledge of risks by adolescents according to the area of study and time of interview

\begin{tabular}{|c|c|c|c|c|c|c|c|}
\hline & & \multicolumn{2}{|c|}{ Saint-Louis } & \multicolumn{2}{|c|}{ Louga } & \multicolumn{2}{|c|}{ Diourbel } \\
\hline & & Baseline & Endline & Baseline & Endline & Baseline & Endline \\
\hline \multirow{2}{*}{$\begin{array}{l}\text { Know the risks when an } \\
\text { adolescent has sexual } \\
\text { intercourse }\end{array}$} & $\begin{array}{l}\text { Boys } \\
\mathrm{N}\end{array}$ & $\begin{array}{c}90 \\
257\end{array}$ & $\begin{array}{c}86 \\
259\end{array}$ & $\begin{array}{c}89 \\
332\end{array}$ & $\begin{array}{l}94^{*} \\
308\end{array}$ & $\begin{array}{c}84 \\
283\end{array}$ & $\begin{array}{c}87 \\
229\end{array}$ \\
\hline & $\begin{array}{l}\text { Girls } \\
\mathrm{N}\end{array}$ & $\begin{array}{c}88 \\
337\end{array}$ & $\begin{array}{c}90 \\
330\end{array}$ & $\begin{array}{c}91 \\
354\end{array}$ & $\begin{array}{l}95^{*} \\
398\end{array}$ & $\begin{array}{c}83 \\
353\end{array}$ & $\begin{array}{l}92^{*} \\
328\end{array}$ \\
\hline \multirow{10}{*}{$\begin{array}{l}\text { Know the health risks for } \\
\text { girls who become pregnant } \\
\text { and the child }\end{array}$} & Boys & & & & & & \\
\hline & $\begin{array}{l}10-14 \\
\text { vears }\end{array}$ & 71 & 83 & 84 & 74 & 79 & 84 \\
\hline & $\mathrm{N}$ & 83 & 77 & 107 & 105 & 97 & 79 \\
\hline & $15-19$ & $80^{*}$ & $92^{*}$ & 90 & 91 & 85 & 83 \\
\hline & $\mathrm{N}$ & 176 & 182 & 225 & 202 & 189 & 150 \\
\hline & Girls & & & & & & \\
\hline & $\begin{array}{l}10-14 \\
\text { years }\end{array}$ & 67 & $80^{*}$ & 77 & 83 & 80 & 88 \\
\hline & $\mathrm{N}$ & 114 & 83 & 100 & 129 & 122 & 100 \\
\hline & $\begin{array}{l}15-19 \\
\text { years }\end{array}$ & 86 & 91 & 95 & $86^{*}$ & 78 & $90^{*}$ \\
\hline & $\mathrm{N}$ & 224 & 248 & 255 & 270 & 241 & 229 \\
\hline \multirow{10}{*}{$\begin{array}{l}\text { Know the health risk of } \\
\text { abortion }\end{array}$} & Boys & & & & & & \\
\hline & $\begin{array}{l}10-14 \\
\text { years }\end{array}$ & 88 & 90 & 91 & 94 & 91 & 90 \\
\hline & $\mathrm{N}$ & 83 & 78 & 105 & 106 & 95 & 80 \\
\hline & $\begin{array}{l}15-19 \\
\text { years }\end{array}$ & 92 & 96 & 96 & 97 & 97 & 95 \\
\hline & $\mathrm{N}$ & 176 & 183 & 223 & 202 & 187 & 150 \\
\hline & Girls & & & & & & \\
\hline & $\begin{array}{l}10-14 \\
\text { years }\end{array}$ & 85 & 82 & 92 & 96 & 90 & 92 \\
\hline & $\mathrm{N}$ & 114 & 83 & 101 & 129 & 118 & 100 \\
\hline & $\begin{array}{l}15-19 \\
\text { years }\end{array}$ & 94 & 96 & 99 & 99 & 92 & 98 \\
\hline & $\mathrm{N}$ & 224 & 248 & 254 & 270 & 241 & 228 \\
\hline
\end{tabular}

$* \mathrm{p}<0.05$ 
Knowledge of the risks for those who engage in sexual relations is higher for adolescents (both girls and boys) exposed to the interventions than for those not directly exposed (see Figure 5). As might be expected, risks are better known among the older adolescents than the younger ones. For example 99 percent of girls 15-19 knew at least one risk, compared with only 41 percent of the 10-14 year age group. Significant differences were also seen among boys knowing the risks of pregnancy. Almost all boys (97\%) aged 15-19 years in Louga who were exposed to the intervention knew the risks, compared with 75 percent of those not exposed (data not shown). In Saint-Louis the same pattern was observed. Knowledge of risks is better known by those who were exposed to the intervention.

Figure 5: Analysis of risks of sexual relations by exposure to interventions: all youth

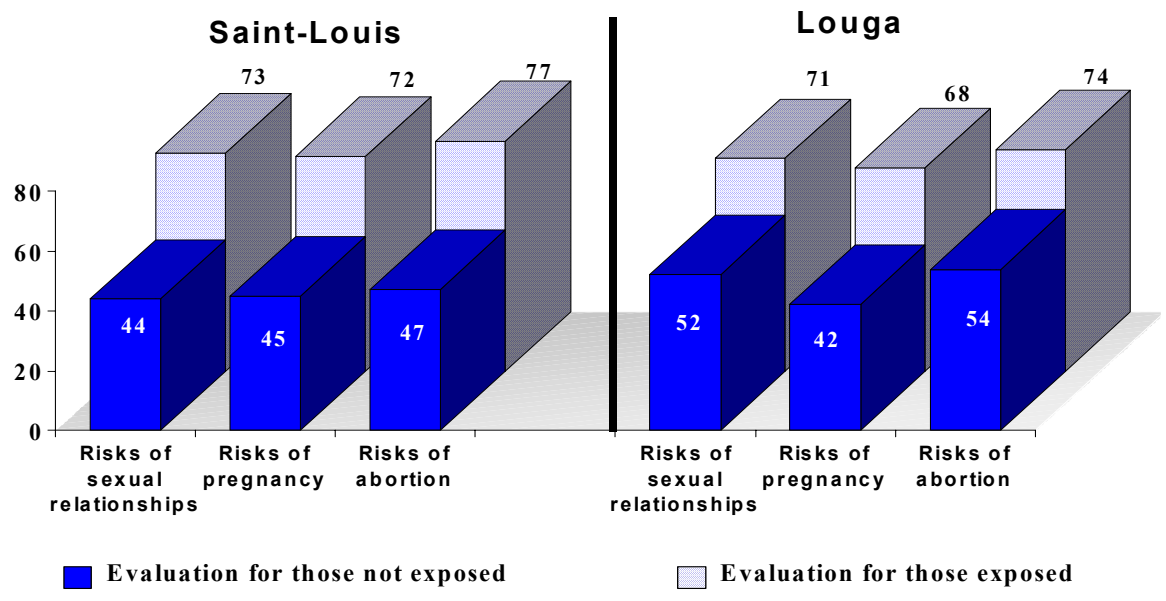

\section{Conclusion}

The analysis of the knowledge of puberty and the risks associated with early sexuality show that levels of information are generally low for physiological changes, but high for risk assessment. Adolescents exposed to the program were more likely to understand the menstrual cycle (though knowledge levels remained modest), even though understanding of the actual mechanism is not easy for young adolescents. The level of knowledge about puberty and the risks associated with sexuality were greater among the adolescents who were exposed to the interventions, especially those aged 15-19 years.

In comparing the three areas of study, there was positive increase in levels of knowledge on puberty especially in Louga. No significant increase was noted in Diourbel. Knowledge about risks related to early sexuality, pregnancy, or abortion was already high but improved significantly in all sites.

The low level of knowledge on issues concerning fertility and physiological signs that mark the onset of puberty, particularly in the younger age group, requires attention from parents and program managers. Young adolescents are concerned about their bodily changes related to puberty and need to be better informed about this topic. 


\section{Knowledge of contraception and condoms}

Information on contraception was evaluated at three levels: knowledge of methods of preventing pregnancy (general knowledge), spontaneous knowledge or knowledge after description of each of these methods (specific knowledge), and practical knowledge on how to use the known method. Data were not collected from adolescents aged 10-12 because during the pilot test of the questionnaire this group could not answer several questions. Only the pill and the condom were considered in this analysis as they are the most common methods that adolescents use.

Table 14: Percent trends in contraception general knowledge

\begin{tabular}{|c|c|c|c|c|c|c|c|}
\hline & & \multicolumn{2}{|c|}{ Saint-Louis } & \multicolumn{2}{|c|}{ Louga } & \multicolumn{2}{|c|}{ Diourbel } \\
\hline & & Baseline & Endline & Baseline & Endline & Baseline & Endline \\
\hline \multirow{9}{*}{$\begin{array}{l}\text { Knowledge about the } \\
\text { existence of contraception }\end{array}$} & Boys & & & & & & \\
\hline & $\begin{array}{l}10-14 \\
\text { years }\end{array}$ & 30 & $42^{*}$ & 45 & $58^{*}$ & 38 & 42 \\
\hline & $\mathrm{N}$ & 231 & 219 & 271 & 263 & 248 & 222 \\
\hline & $\begin{array}{l}15-19 \\
\text { years }\end{array}$ & 72 & $84^{*}$ & 80 & $90^{*}$ & 76 & 82 \\
\hline & $\begin{array}{l}\text { N } \\
\text { Girls }\end{array}$ & 173 & 183 & 224 & 200 & 197 & 147 \\
\hline & $\begin{array}{l}10-14 \\
\text { vears }\end{array}$ & 31 & 31 & 34 & $50^{*}$ & 33 & 33 \\
\hline & $\mathrm{N}$ & 277 & 235 & 261 & 306 & 275 & 229 \\
\hline & $\begin{array}{l}15-19 \\
\text { years }\end{array}$ & 74 & $85^{*}$ & 77 & $86^{*}$ & 63 & 69 \\
\hline & $\mathrm{N}$ & 231 & 239 & 258 & 262 & 237 & 232 \\
\hline
\end{tabular}

$* \mathrm{p}<0.05$

General knowledge of contraceptive methods rose significantly among boys in both age groups in Saint-Louis and Louga (see Table 14). While the percentage point changes were similar, boys in Louga were better informed at baseline and increased to a relatively higher level of knowledge by endline. For girls, there were significant improvements in knowledge in Louga among both age groups, and in the 15-19 age group in Saint-Louis. No significant change was observed in Diourbel for either boys or girls, regardless of age.

Some improvements in specific knowledge of methods were seen. In Louga, knowledge of the pill increased significantly for boys in both age groups: 45 percent to 58 percent for those aged 13-14, and 52 percent to 66 percent for those aged 15-19 $(\mathrm{p}<0.05)$. No significant changes were seen among boys in Saint-Louis and Diourbel. Knowledge about the pill also increased significantly among older girls in Saint-Louis.

Significant increases in knowledge about condoms occurred in all sites, among both sexes and age groups. By the time of the endline survey, more than two-thirds of the adolescents, and in most cases more than 90 percent, were familiar with the condom (see Table 15). Among the boys, the greatest increase in knowledge was recorded for both age groups in Saint-Louis, and among younger boys in Diourbel. Among the girls, the largest proportionate increases were seen in Louga, particularly among the younger girls, but similar increases were also noted in SaintLouis and Diourbel. 


\begin{tabular}{|c|c|c|c|c|c|c|c|}
\hline & & \multicolumn{2}{|c|}{ Saint-Louis } & \multicolumn{2}{|c|}{$\begin{array}{l}\text { Louga } \\
\end{array}$} & \multicolumn{2}{|c|}{ Diourbel } \\
\hline & & Baseline & Endline & Baseline & Endline & Baseline & Endline \\
\hline \multirow{9}{*}{$\begin{array}{l}\text { Knowledge of } \\
\text { condoms }\end{array}$} & Boys & & & & & & \\
\hline & $13-14$ & 53 & $91^{*}$ & 72 & $94^{*}$ & 59 & $86^{*}$ \\
\hline & $\mathrm{N}$ & 81 & 81 & 111 & 106 & 98 & 79 \\
\hline & $\begin{array}{l}15-19 \\
\text { vears }\end{array}$ & 75 & $96^{*}$ & 87 & $97^{*}$ & 83 & $97^{*}$ \\
\hline & $\begin{array}{l}\text { N } \\
\text { Girls }\end{array}$ & 173 & 183 & 225 & 201 & 198 & 147 \\
\hline & $\begin{array}{c}13-14 \\
\text { years }\end{array}$ & 40 & $70^{*}$ & 48 & $91^{*}$ & 43 & $68^{*}$ \\
\hline & $\mathrm{N}$ & 117 & 84 & 102 & 137 & 118 & 101 \\
\hline & $\begin{array}{l}15-19 \\
\text { vears }\end{array}$ & 70 & $92^{*}$ & 74 & $97^{*}$ & 60 & $84^{*}$ \\
\hline & $\mathrm{N}$ & 231 & 239 & 258 & 262 & 239 & 232 \\
\hline
\end{tabular}

$* \mathrm{p}<0.05$

The proportion of boys in Louga aged 13-14 who knew how to use the pill correctly increased significantly from 10 percent to 22 percent and from 27 percent to 37 percent for those aged 1519. Among girls, knowledge of pill use improved in Saint-Louis (from $8 \%$ to $18 \%$ for those aged $13-14$, and from $25 \%$ to $40 \%$ for the $15-19$ age group), and Louga (from $8 \%$ to $18 \%$ for $13-14$ age group, and from $31 \%$ to $40 \%$ for $15-19$ year olds).

Knowledge about the part of the body where the condom is placed increased significantly among younger boys in Louga (from 14\% to 30\%), and older boys in Saint-Louis (from 22\% to 32\%). Among girls, the increase was significant only in Saint-Louis, from four percent to 16 percent among younger girls, and from 22 percent to 31 percent for the older ones (data not shown).

Table 16: Percent knowledge of correct condom use (boys aged 13 to 19 years)

\begin{tabular}{lcccccc}
\hline \hline & \multicolumn{2}{c}{ Saint-Louis } & \multicolumn{2}{c}{ Louga } & \multicolumn{2}{c}{ Diourbel } \\
\cline { 2 - 7 } & Baseline & Endline & Baseline & Endline & Baseline & Endline \\
\hline $\mathrm{N}$ & 254 & 264 & 336 & 306 & 296 & 226 \\
\hline Verify the date of expiration & 10 & $24^{*}$ & 7 & $26^{*}$ & 12 & $25^{*}$ \\
$\begin{array}{l}\text { Open the wrapper carefully } \\
\text { Press the tip of the condom }\end{array}$ & 18 & 19 & 24 & $33^{*}$ & 22 & 17 \\
$\begin{array}{l}\text { Roll the condom on the penis } \\
\text { Remove the condom after }\end{array}$ & 23 & $12^{*}$ & 18 & 22 & 5 & 3 \\
$\begin{array}{l}\text { ejaculation } \\
\text { Wrap up and dispose of the }\end{array}$ & 11 & 12 & 20 & 14 & 22 & 15 \\
$\begin{array}{l}\text { condom } \\
\text { Use a new condom at each }\end{array}$ & 18 & 17 & 40 & ${ }^{*} 29$ & 27 & 22 \\
encounter & 18 & $* 23$ & 11 & ${ }^{*} 24$ & 13 & $* 34$ \\
\hline \hline
\end{tabular}

To better understand more detailed awareness about condom use, adolescents were asked to list the steps that they considered important for correct use. In all sites, significant improvements were seen in knowledge of some steps (see Table 16). In Louga and Diourbel, several significant 
declines also were observed. Across all sites the most consistent increases were seen in knowing to use a new condom with each act of intercourse, and to check the expiration date.

\section{Attitudes toward the use of contraception}

With the exception of older boys in Diourbel, there were no significant changes in attitudes regarding contraceptive use by married adolescents. Generally, around half of the adolescents approved of such use (see Table 17).

Table 17: Percent approving use of contraception by adolescents

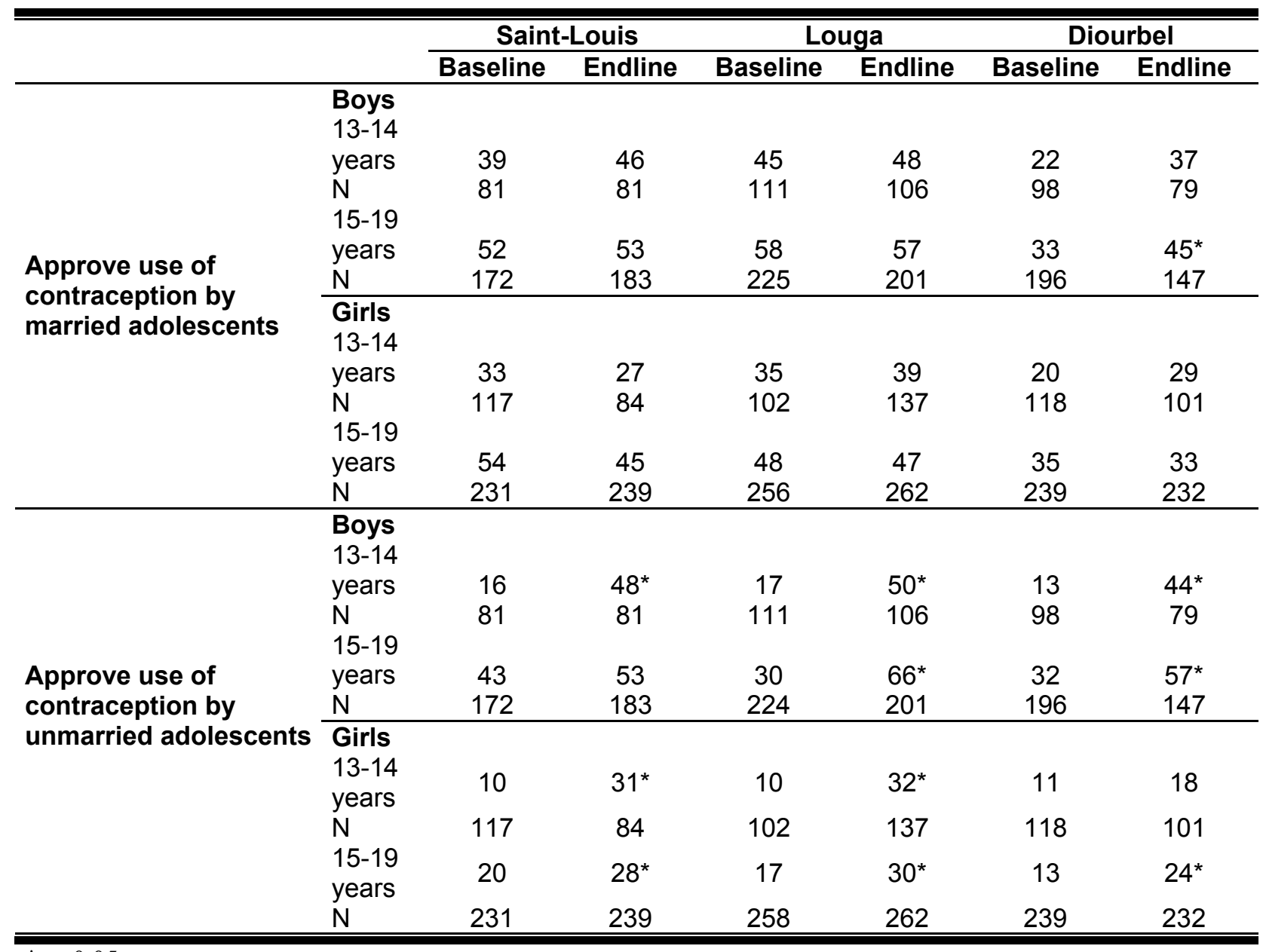

${ }^{*} \mathrm{p}<0.05$

On the other hand, attitudes towards use of contraception by unmarried teenage couples changed significantly in all the areas of study and in all the groups except for girls aged 13-14 in Diourbel and boys 15-19 in Saint-Louis. By the time of the endline survey, there was little difference in the proportions approving use by either married or unmarried adolescents among the male adolescents. Among the girls, approval of use by unmarried adolescents increased, but generally did not reach the levels approving use by married adolescents. It appears that during the intervention period, adolescents acquired more tolerant attitudes about use of contraception by unmarried adolescents. More than half of the adolescents approved use by the sexually active. In 
Saint-Louis the proportion of those who approved was 59 percent, in Louga 66 percent, and in Diourbel, 53 percent. The proportions approving contraception under different circumstances differed by site.

\section{Influence of direct exposure to the interventions}

General knowledge of contraceptive methods was higher among the adolescents exposed to the intervention for both sexes and age groups. The biggest difference was observed in Saint-Louis among girls aged 10-14 years. Of those exposed to the intervention, 52 percent knew about at least one method of contraception, compared to 17 percent of those who were not exposed. Among the older girls, 84 percent of those exposed knew a method, compared with 63 percent who were not exposed. Similar levels were found among the older girls in Louga also (81\% and $63 \%$ respectively).

At Louga there was a significant difference between those boys who were informed and those who were not. Among those aged 10-14 years the difference was 23 percent and four percent, respectively; for those aged 15-19 years, the difference was 72 percent and 54 percent respectively.

Knowledge of the condom, either spontaneously or after prompting, showed a significant difference for both boys and girls aged 13-14 years in both intervention sites. In Saint-Louis a significantly larger proportion of girls aged 15-19 who were exposed to the intervention had knowledge of the condom than their counterparts who did not benefit from the intervention. Among younger boys in Louga, seven percent of those who received information had practical knowledge of the pill, compared to zero percent for those who did not receive the information. For girls in the same age group, the proportions were four percent and 0.4 percent respectively, whereas for the older groups they were 25 percent and six percent respectively.

The direct effects of the program are confirmed with regard to practical knowledge of the condom and pill. In both intervention areas, all age groups registered significant gaps between those adolescents who were involved in the program and those who were not (see Figure 6). 
Figure 6: Theoretical and practical knowledge of the pill and condoms according to exposure to the intervention for all adolescents

S a in $t-L$ ou is

Louga

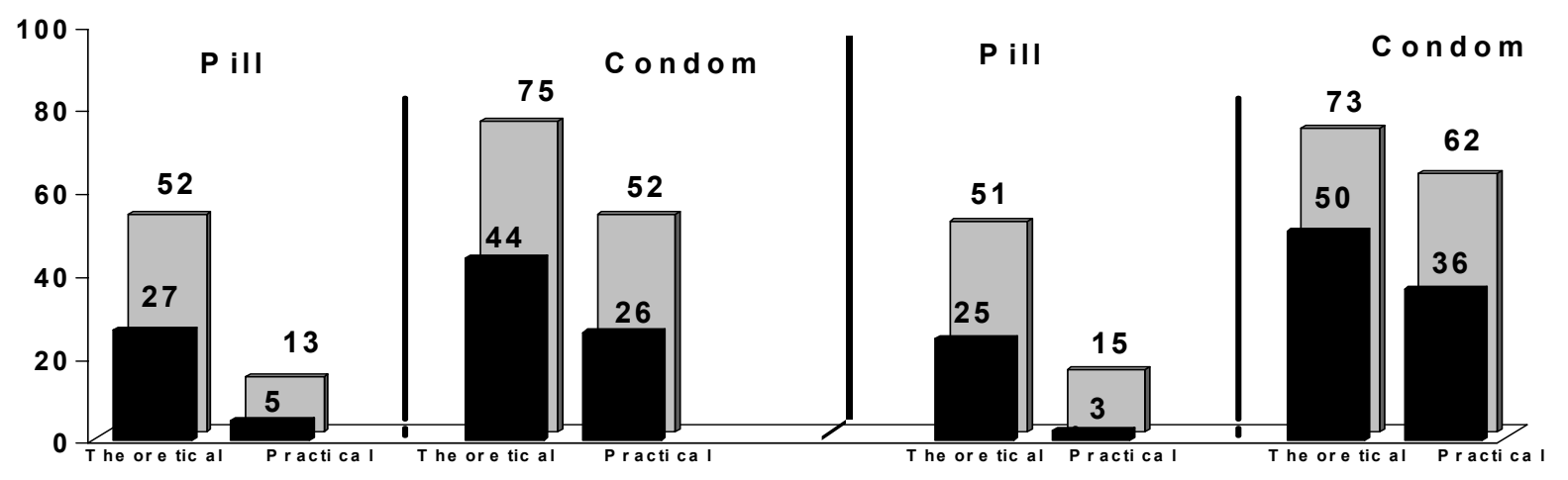

Not exposed

Exposed

\section{Conclusion}

General knowledge of contraceptive methods improved between the two surveys in Saint-Louis and in Louga but not in Diourbel. Better knowledge of correct condom use was noted in SaintLouis. Attitudes towards the use of these methods became more tolerant vis-a-vis unmarried adolescents, particularly in Saint-Louis and Louga. The effect of the program was confirmed by comparing the adolescents who were involved in the program with those who were not in the same locality. In all cases, those adolescents who were exposed during the interventions had better results than their counterparts.

\section{Knowledge of HIVIAIDS}

In the three study sites, nearly all the adolescents knew of HIV/AIDS. At Louga a small but significant increase in knowledge occurred. There were only minor fluctuations according to sex and age, and for this reason the data are not presented by these variables.

Other STIs were largely unknown, although there was some improvement was made between the baseline study and the endline in Saint-Louis and Louga (see Table 18). Girls had better knowledge than boys and the 13-14 year olds were practically ignorant in this area.

Table 18: Knowledge of STI/HIVIAIDS (\%)

\begin{tabular}{lcccccc}
\hline & \multicolumn{2}{c}{ Saint-Louis } & \multicolumn{2}{c}{ Louga } & \multicolumn{2}{c}{ Diourbel } \\
\cline { 2 - 7 } & Baseline & Endline & Baseline & Endline & Baseline & Endline \\
\hline Knowledge of & 97 & 97 & 96 & $98^{*}$ & 94 & 92 \\
HIVIAIDS & 13 & $18^{*}$ & 12 & $18^{*}$ & 11 & 12 \\
Knowledge of STIs & 911 & 876 & 1011 & 1032 & 955 & 830 \\
$\mathrm{~N}$ & & & &
\end{tabular}

${ }^{*} \mathrm{p}<0.05$ 
Knowledge of ways to protect against HIV/AIDS has changed over time. Before the interventions, abstinence and the use of condoms, were considered the two main means of protection against HIV/AIDS (see Figure 7). After the intervention there was a significant reduction in reference to the condom (60\% in 2000 compared to $43 \%$ in 2002) and faithfulness to one partner (55\% compared to $46 \%$ ). There was a dramatic increase in reference to avoiding objects contaminated by blood, going from one percent to 30 percent. Abstinence remained the best-known means of protection, with three-quarters of the adolescents citing it, a slight increase over the baseline.

Figure 7: Knowledge of means of protection against HIVIAIDS

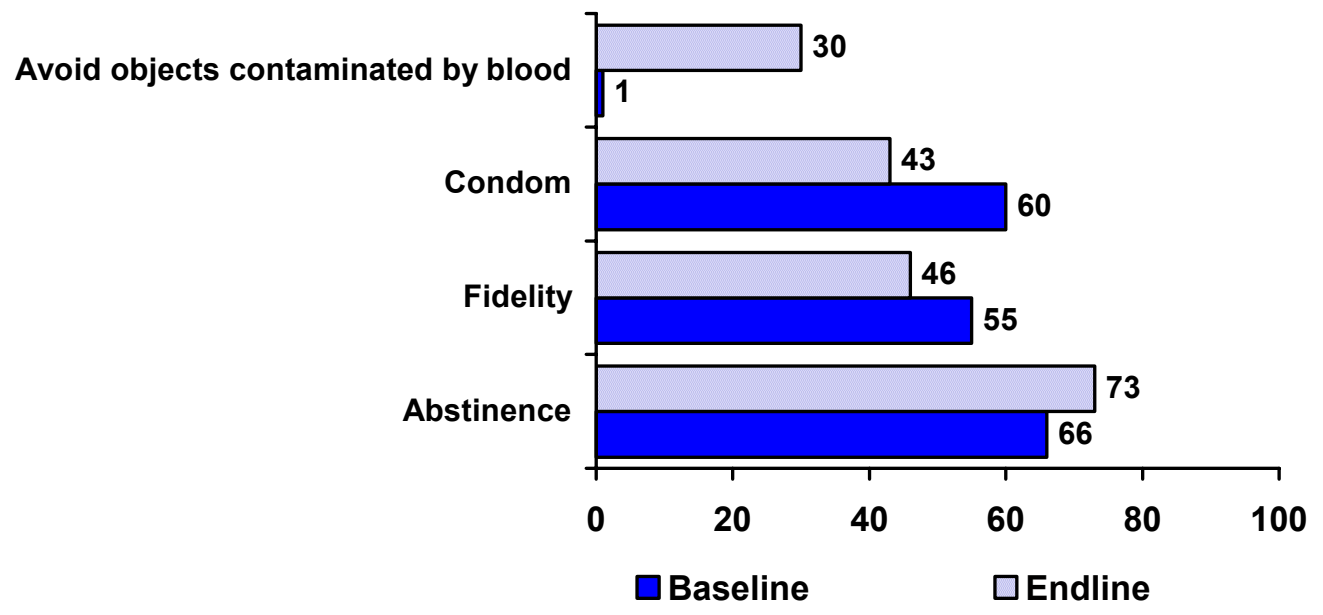

\section{Influence of direct exposure to the interventions}

Those who were not involved in the program also had good knowledge of HIV/AIDS (94\% in Saint-Louis and $96 \%$ in Louga). The advent of the program allowed more adolescents to be informed, and as a result more than 99 percent of adolescents who were exposed to the program knew about the existence of HIV/AIDS (see Figure 8). There was also improvement in the knowledge of other STIs among the adolescents who were influenced by the program. In SaintLouis there was a three-fold increase, and in Louga a five-fold increase in knowledge of other STIs among those exposed to the interventions compared to those who were not exposed. 
Figure 8: Knowledge of STI/HIVIAIDS according to exposure to the intervention

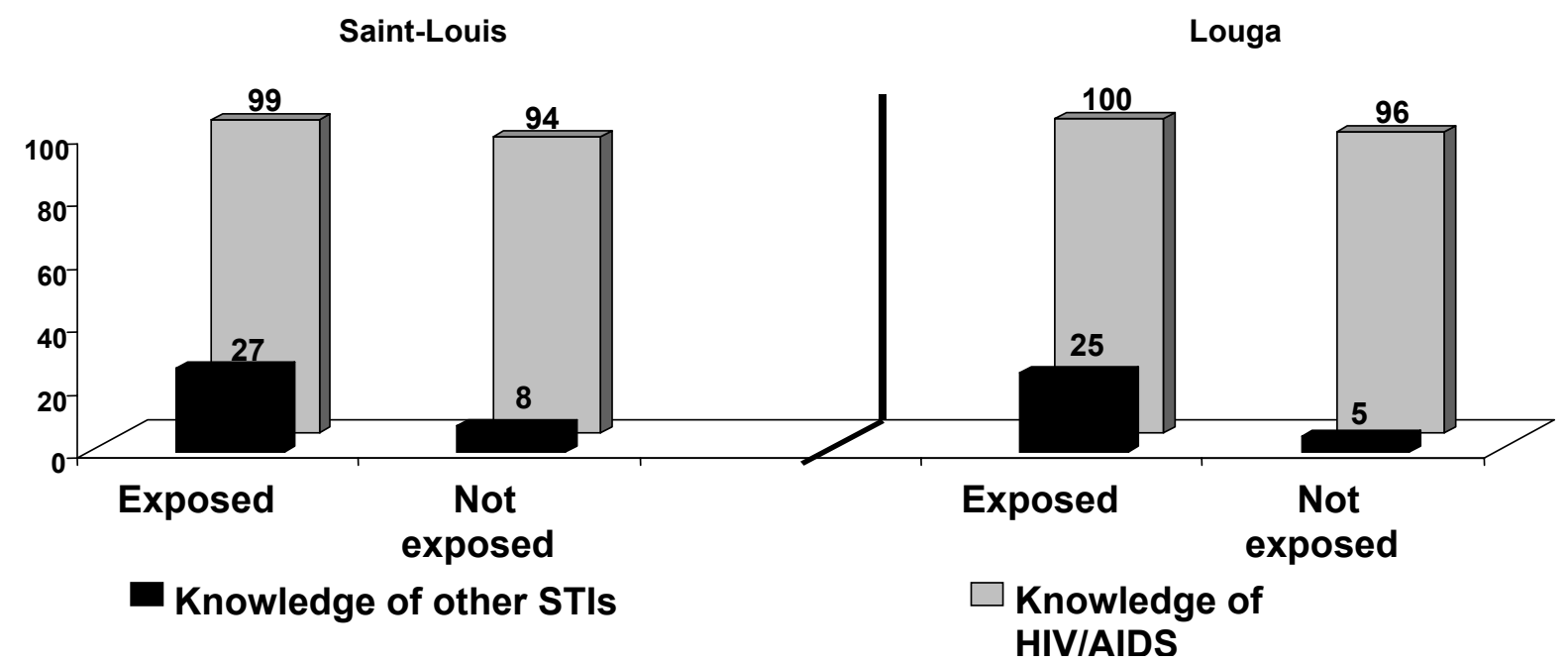

\section{Conclusion}

Knowledge of HIV/AIDS was quite widespread before the implementation of the interventions; however, the interventions allowed this knowledge to be reinforced. Other STIs were less well known. Before the intervention one out of 10 adolescents knew about the existence of other STIs in the three areas of study. After the intervention knowledge improved significantly to nearly one in five adolescents in both Saint-Louis and in Louga.

The methods of protection against STI/HIV/AIDS cited by the adolescents were for the most part those recommended by the program to fight against HIV/AIDS. Before the interventions the adolescents cited abstinence and the condom as the principle means of protection. At the endline this perception had changed. Notably the idea of faithfulness to one partner and the avoidance of sharp objects contaminated by blood became more important, especially among the sexually active adolescents (data not shown).

\section{Sexual Activity}

Sexual practice by adolescents was one of the key indicators of interest for the interventions, with the goal of delaying sexual debut, or if sexually experienced, reducing risk by limiting the number of partners or by using condoms. Analysis was limited to non-married adolescents. Overall, there were few significant changes in the proportion of adolescents reporting ever having had sexual activity between the baseline and endline surveys. In Louga, there was a significant increase among the younger boys. This may be due to increased reliability of reporting. An even smaller but significant increase was also found among the older girls in SaintLouis.

Table 19 shows that the average age of first intercourse increased in Saint-Louis (by about one year, from 13.7 to 14.6), and remained unchanged in Louga and Diourbel (about 13.5). It is important to note the large gap that exists between the proportion of adolescents aged 10-14 years who reported having sexual experience and those aged 15-19 years. The proportion increased overall from about six percent for boys aged 10-14 years to more than 30 percent for 
boys aged 15-19 years. Considering that the average age for first sexual encounters (for those already sexually active) is about 14 years, it can be well understood that puberty is a period during which exposure to early sexuality increases, often before adolescents are well informed about the consequences.

It is also important to emphasize the very small proportion of adolescents, both boys and girls, who have had any sexual activity. Virtually none of the younger girls, and only a small proportion of the younger boys, have experienced sexual initiation. Among older girls, only 10 percent have had sex at least once, as well as less than one-third of the older boys.

Table 19: Sexual experience (\%) and mean age of first sexual experience

\begin{tabular}{|c|c|c|c|c|c|c|c|c|}
\hline & & & \multicolumn{2}{|c|}{ Saint-Louis } & \multicolumn{2}{|c|}{ Louga } & \multicolumn{2}{|c|}{ Diourbel } \\
\hline & & & Baseline & Endline & Baseline & Endline & Baseline & Endline \\
\hline \multirow{5}{*}{$\begin{array}{l}\text { Have ever had } \\
\text { sexual experience }\end{array}$} & \multirow{3}{*}{ Boys } & $\begin{array}{l}10-14 \\
\text { years }\end{array}$ & 5 & 5 & 6 & $12^{*}$ & 11 & 7 \\
\hline & & $\begin{array}{l}N \\
15-19\end{array}$ & 231 & 219 & 273 & 263 & 247 & 222 \\
\hline & & $\begin{array}{l}\text { years } \\
\mathrm{N}\end{array}$ & $\begin{array}{c}32 \\
173 \\
\end{array}$ & $\begin{array}{c}29 \\
183 \\
\end{array}$ & $\begin{array}{c}36 \\
225\end{array}$ & $\begin{array}{c}33 \\
200 \\
\end{array}$ & $\begin{array}{c}42 \\
196 \\
\end{array}$ & $\begin{array}{l}25^{*} \\
147\end{array}$ \\
\hline & \multirow[t]{2}{*}{ Girls } & $\begin{array}{l}10-14 \\
\text { years } \\
\mathrm{N} \\
15-19\end{array}$ & $\begin{array}{c}0 \\
277\end{array}$ & $\begin{array}{c}1 \\
235\end{array}$ & $\begin{array}{c}1 \\
260\end{array}$ & $\begin{array}{c}1 \\
306\end{array}$ & $\begin{array}{c}1 \\
276\end{array}$ & $\begin{array}{c}1 \\
229\end{array}$ \\
\hline & & $\begin{array}{l}\text { years } \\
\mathrm{N}\end{array}$ & $\begin{array}{c}4 \\
230\end{array}$ & $\begin{array}{c}9^{*} \\
239\end{array}$ & $\begin{array}{c}11 \\
258\end{array}$ & $\begin{array}{c}17 \\
262\end{array}$ & $\begin{array}{c}11 \\
238\end{array}$ & $\begin{array}{c}18 \\
232\end{array}$ \\
\hline \multicolumn{9}{|c|}{ Age of first sexual experience } \\
\hline & & Mean & 13.70 & $14.61^{*}$ & 14.02 & 13.51 & 13.35 & 13.36 \\
\hline \multirow{2}{*}{\multicolumn{2}{|c|}{ Both }} & SE & 0.279 & 0.284 & 0.197 & 0.500 & 0.249 & 0.305 \\
\hline & & $\mathrm{N}$ & 59 & 74 & 98 & 107 & 105 & 52 \\
\hline
\end{tabular}

${ }^{*} \mathrm{p}<0.05$ SE: Standard error of mean

Whether or not first intercourse was desired showed significant change at all sites. However these variations were not of the same nature. The proportion of adolescents who declared that they wanted their first sexual experience decreased in Saint-Louis, while it increased in Louga and Diourbel (see Table 20). The small size of the sample did not allow for a more detailed analysis by age and sex.

The main reasons given for first sexual experience changed in Saint-Louis and Louga. In both places, the proportion reporting that their first experience was tried out of curiosity significantly declined, while those reporting it was a result of love increased. If it is true that sexual experimentation for curiosity has declined, it indicates greater awareness of sexual risk-taking, and efforts to reduce that risk. What is not clear is whether adolescents are simply re-classifying their rationale for first sex as love in their own minds, thinking this is safer and more socially acceptable than acknowledging the drive of curiosity.

In terms of sexual partner, the behavior of the adolescents changed significantly during the period at all sites. At the baseline, the adolescents mostly had casual sexual partners whereas at the endline the first partner was more likely to be the regular sexual partner. 
Table 20: Percent distribution of adolescents having desired first intercourse, reasons for first intercourse, and subsequent status of first sexual partner

\begin{tabular}{lccccccc}
\hline \hline & & \multicolumn{2}{c}{ Saint-Louis } & \multicolumn{2}{c}{ Louga } & \multicolumn{2}{c}{ Diourbel } \\
\cline { 2 - 8 } & & Baseline & Endline & Baseline & Endline & Baseline & Endline \\
\hline Desired their first & $\%$ & 82 & $59^{*}$ & 67 & $81^{*}$ & 54 & $67^{*}$ \\
intercourse & $\mathrm{N}$ & 79 & 92 & 134 & 143 & 140 & 96 \\
\hline $1^{\text {st }}$ experience for love & $\%$ & 25 & $46^{*}$ & 40 & $60^{*}$ & 33 & 38 \\
$1^{\text {st }}$ experience for curiosity & $\%$ & 69 & $39^{*}$ & 49 & $34^{*}$ & 46 & 53 \\
$1^{\text {st }}$ experience under & $\%$ & 6 & 16 & 11 & 7 & 22 & $9^{*}$ \\
duress & $\mathrm{N}$ & 63 & 74 & 103 & 109 & 109 & 55 \\
& $\%$ & 43 & $61^{*}$ & 47 & $58^{*}$ & 40 & $54^{*}$ \\
\hline \multirow{2}{*}{ Regular partner } & $\mathrm{N}$ & 59 & 74 & 94 & 109 & 100 & 55 \\
& & & & & & & \\
\hline \hline
\end{tabular}

* Significant difference $p<0.05$

The proportion of adolescents having had sexual intercourse during the six months preceding the interview did not change in any site, and there were no significant variations between sites in the number of sexual partners in the prior six months (see Table 21). Combining the samples from Louga and Saint-Louis, there was a decrease in the number of sexual partners from 2.1 to 1.5 between baseline and endline, while in Diourbel the number of sexual partners did not change.

Table 21: Distribution of adolescents (both boys and girls) according to their sexual activities during the 6 months preceding the study

\begin{tabular}{lccccccc}
\hline \hline & \multicolumn{2}{c}{ Saint-Louis } & \multicolumn{2}{c}{ Louga } & \multicolumn{2}{c}{ Diourbel } \\
\cline { 3 - 8 } & & Baseline & Endline & Baseline & Endline & Baseline & Endline \\
\hline $\begin{array}{l}\text { Had sexual } \\
\text { encounter during } \\
\text { the last 6 months }\end{array}$ & & & & & & & \\
\hline \\
\multirow{3}{*}{ Use of protection } & First sex & 29 & 23 & 31 & 19 & 16 & $4^{*}$ \\
& Last sex & 49 & $34^{*}$ & 42 & $30^{*}$ & 33 & $16^{*}$ \\
& $\mathrm{~N}$ & 71 & 89 & 122 & 129 & 126 & 88 \\
\hline \hline
\end{tabular}

$* \mathrm{p}<0.05$

It is important to note that only about half of the small proportion of sexually active adolescents reported having had sexual activity during the prior six months in Saint-Louis, and even fewer were sexually active in Louga. Clearly, secondary abstinence, or limiting sexual activity following sexual initiation, is an important part of the reproductive behavior of adolescents in Senegal.

In Table 21 the proportion of adolescents having used protection at the time of their first intercourse did not vary significantly in Saint-Louis or in Louga, while in Diourbel there was a significant decline in the proportion reporting use of protection. In all sites, the proportion reporting using protection at most recent intercourse declined significantly, although the levels are higher than that reported for first intercourse. 


\section{Influence of direct exposure to the interventions}

The comparison between those adolescents influenced by the interventions and the others yields three findings. First, in Saint-Louis the interventions reached more sexually active adolescents, particularly younger boys. For all the other groups, the differences were not significant. Secondly, there were no changes in the proportion reporting sexual experience in the prior six months. Third, protection during sexual intercourse appeared to be more widely used by those adolescents in Saint-Louis who had been exposed to the interventions than for the others. Among the adolescents who were not exposed, use of protection remained negligible both for the first and most recent intercourse (7\% and 3\% respectively). In marked contrast, those who had been exposed and were sexually active used methods of protection in 30 percent of the cases at their first intercourse and in 50 percent of the cases in their latest intercourse in Saint-Louis. No comparable differences were seen in Louga.

\section{Protective behavior}

While it is encouraging that nearly one-third of sexually active adolescents reported having used protection at last intercourse, the declines seen in the study sites are of concern (see Table 22). This is perhaps linked to an increased perception of having sex for love, of reporting having sex with regular partners rather than casual partners, and a higher importance attributed to fidelity as a means of protection against STIs including HIV/AIDS. This situation argues for the creation of efforts to better inform sexually active adolescents of the need to protect themselves against unwanted pregnancies as well as STIs. Having one sexual partner does not protect against unwanted pregnancy, even if it is a means reducing the risk of STIs.

The direct effect of the interventions on the adolescents who were exposed seems to show a different pattern. Higher proportions of adolescents who were well informed about reproductive health through the interventions declared themselves to be using protection than those who did not benefit from the information, particularly at their most recent intercourse.

The fact that sexual intercourse (especially recent) did not increase after the interventions were introduced shows that it is possible to give adolescents accurate and in-depth information about reproductive health without them engaging in sex. It is important to note that the interventions placed emphasis on abstinence and also on responsible sexuality. 
Table 22: Protective behavior and sexual experience of adolescents

\begin{tabular}{|c|c|c|c|c|c|}
\hline & & \multicolumn{2}{|c|}{ Saint-Louis } & \multicolumn{2}{|c|}{ Louga } \\
\hline & & Exposed & $\begin{array}{c}\text { Not } \\
\text { Exposed }\end{array}$ & Exposed & $\begin{array}{c}\text { Not } \\
\text { Exposed }\end{array}$ \\
\hline \multirow{10}{*}{ Had already had sexual experience } & Boys & & & & \\
\hline & $\begin{array}{l}10-14 \\
\text { years }\end{array}$ & 10 & $1^{*}$ & 14 & 9 \\
\hline & & 101 & 118 & 153 & 110 \\
\hline & $\begin{array}{l}15-19 \\
\text { years }\end{array}$ & 31 & 24 & 32 & 37 \\
\hline & $\mathrm{N}$ & 116 & 67 & 148 & 53 \\
\hline & Girls & & & & \\
\hline & $\begin{array}{l}10-14 \\
\text { years }\end{array}$ & 3 & 1 & 1 & 1 \\
\hline & & 95 & 140 & 178 & 128 \\
\hline & $\begin{array}{l}15-19 \\
\text { vears }\end{array}$ & 7 & 12 & 15 & 21 \\
\hline & $\mathrm{N}$ & 150 & 89 & 182 & 80 \\
\hline \multicolumn{6}{|l|}{ All adolescents } \\
\hline \multirow{2}{*}{$\begin{array}{l}\text { Had at least one sexual experience during the } \\
\text { last } 6 \text { months }\end{array}$} & $\%$ & 63 & 60 & 56 & 44 \\
\hline & $\mathrm{N}$ & 58 & 28 & 87 & 44 \\
\hline \multirow{2}{*}{$\begin{array}{l}\text { Used protection against unwanted pregnancy } \\
\text { and/or against STIs at the time of first } \\
\text { experience }\end{array}$} & $\%$ & 30 & $7^{*}$ & 16 & 23 \\
\hline & $\mathrm{N}$ & 58 & 28 & 87 & 44 \\
\hline \multirow{2}{*}{$\begin{array}{l}\text { Used protection against unwanted pregnancy } \\
\text { and/or against STls at the time of their latest } \\
\text { intercourse }\end{array}$} & $\%$ & 50 & $3^{*}$ & 26 & 38 \\
\hline & $\mathrm{N}$ & 58 & 28 & 87 & 44 \\
\hline
\end{tabular}

$* \mathrm{p}<0.05$

\section{Knowledge and use of health facilities}

Awareness of health facilities that can offer reproductive health services to adolescents was a strong component of the intervention. The reorganized youth-friendly facilities were referred to in each session of the curriculum and in all IEC materials. Knowledge of health facilities that offer reproductive health services to adolescents increased among both boys and girls in both age groups in Saint-Louis and Diourbel (see Table 23). Generally knowledge was higher among the older adolescents than among the younger ones, but the differences were not great between the two sexes. The relative increase in knowledge was greater for girls than for boys in both age groups. In Saint-Louis, the older adolescents showed greater improvements in knowledge than the younger ones, while the opposite was the case in Diourbel. The increased knowledge in Saint-Louis may reflect awareness of a recently opened health center in the community.

While knowledge of facilities that offer reproductive health services was relatively high, use of these centers was quite low. Significant increases were reported at all sites (excluding all girls in Louga and older boys in Saint-Louis), yet the actual levels of use remained low. Among the younger adolescents, only in Diourbel did their use of services exceed 10 percent. Among the older age group use of health facilities barely reached 20 percent. 
Table 23: Adolescents' knowledge and use of reproductive health services (\%)

\begin{tabular}{|c|c|c|c|c|c|c|c|c|}
\hline & & & \multicolumn{2}{|c|}{ Saint-Louis } & \multicolumn{2}{|c|}{ Louga } & \multicolumn{2}{|c|}{ Diourbel } \\
\hline & & & Baseline & Endline & Baseline & Endline & Baseline & Endline \\
\hline \multirow{10}{*}{$\begin{array}{l}\text { Knowledge of } \\
\text { health facilities }\end{array}$} & Boys & & & & & & & \\
\hline & $10-14$ & $\%$ & 28 & $39^{*}$ & 53 & 54 & 41 & *58 \\
\hline & years & $\mathrm{N}$ & 231 & 219 & 272 & 263 & 247 & 222 \\
\hline & $15-19$ & $\%$ & 48 & $63^{*}$ & 74 & 80 & 58 & *67 \\
\hline & years & $\mathrm{n}$ & 173 & 183 & 225 & 200 & 195 & 147 \\
\hline & Girls & & & & & & & \\
\hline & $10-14$ & $\%$ & 24 & $48^{*}$ & 47 & 47 & 29 & $58^{*}$ \\
\hline & years & $\mathrm{N}$ & 277 & 235 & 258 & 306 & 274 & 229 \\
\hline & $15-19$ & $\%$ & 48 & $73^{*}$ & 67 & 74 & 46 & $66^{*}$ \\
\hline & years & $\mathrm{n}$ & 230 & 239 & 257 & 262 & 238 & 232 \\
\hline \multirow{9}{*}{ Use of services } & Boys & & & & & & & \\
\hline & $10-14$ & $\%$ & 1 & $7^{*}$ & 2 & $9^{*}$ & 0 & $10^{*}$ \\
\hline & years & $\mathrm{N}$ & 81 & 219 & 110 & 263 & 98 & 222 \\
\hline & $15-19$ & $\%$ & 6 & 7 & 8 & $13^{*}$ & 9 & $12^{*}$ \\
\hline & years & $\mathrm{n}$ & 173 & 183 & 225 & 200 & 193 & 147 \\
\hline & $10-14$ & $\%$ & 1 & $7^{*}$ & 1 & 4 & 0 & $15^{*}$ \\
\hline & years & $\mathrm{N}$ & 117 & 235 & 102 & 306 & 118 & 229 \\
\hline & $15-19$ & $\%$ & 8 & $18^{*}$ & 12 & 14 & 8 & $20^{*}$ \\
\hline & years & $\mathrm{N}$ & 229 & 239 & 257 & 262 & 237 & 232 \\
\hline
\end{tabular}

$* \mathrm{p}<0.05$

\section{Reasons for visit to health facilities}

The question on the reasons for a visit to a health facility was only asked at the endline survey. Respondents reported that half of the visits to the health facilities were to seek treatment of illnesses that were not related to reproductive health; the balance were for reproductive health reasons (see Figure 9). Among these visits, most adolescents wanted information on sexuality $(22 \%)$, demonstrating that health facilities have now begun to play a role in supplying information to adolescents. Another 15 percent of the visits were for gynecological examinations or prenatal consultations. 
Figure 9: Percent distribution of adolescents according to the reasons for the latest visit to a health center

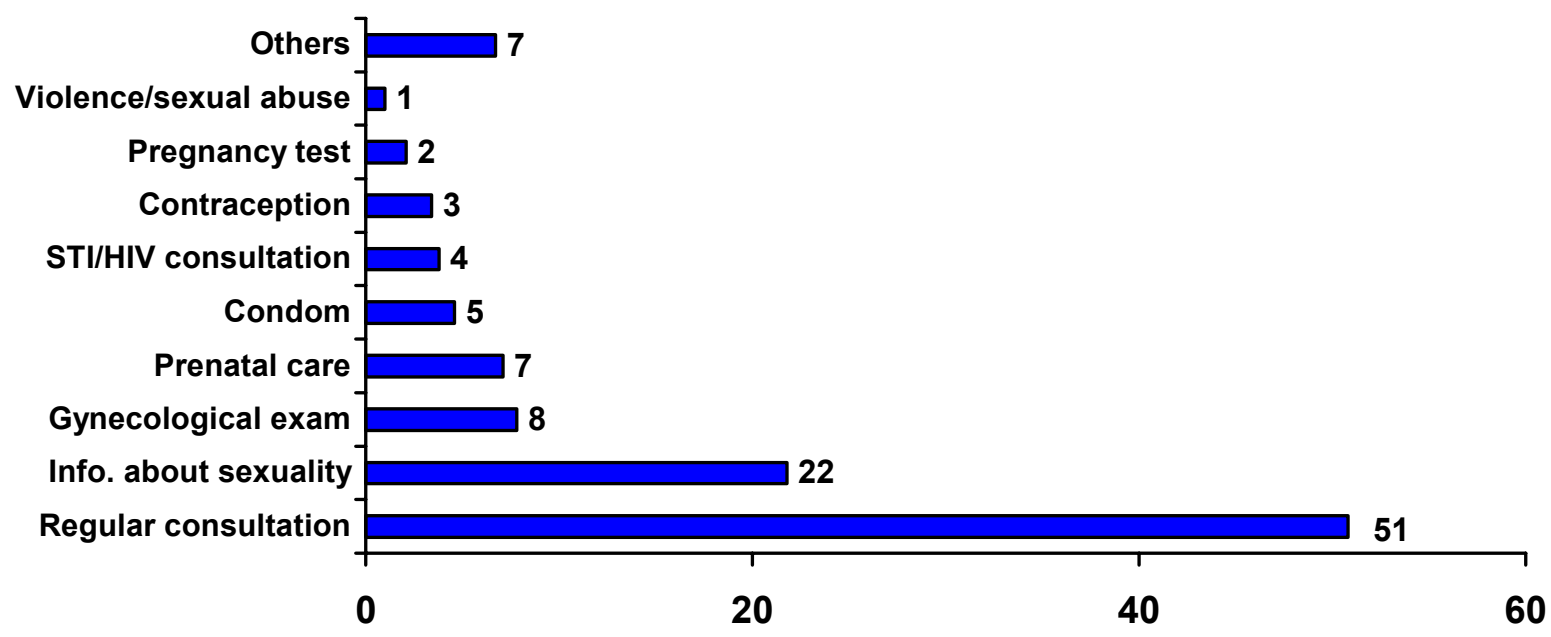

\section{Adolescents' perception of health facilities}

Adolescents' perception of the reception they would receive at the health center is a good indicator of their disposition to visit them in case of need. A large proportion of adolescents who did not visit health facilities reported no need. At the end of the interventions, this perception that they do not need to visit health facilities improved among all youth in Saint-Louis, among older boys and all girls in Louga, and only among girls in Diourbel.

There is a significant increase in all age groups responding to the question "Do you think you would be well received in a pharmacy if you went there to buy contraceptives?", except for boys 10-14 years old in Louga and Diourbel and boys 15-19 years old in Diourbel (see Table 24). The greatest progress was noted in Saint-Louis among the girls aged 10-14, where the proportion of those who had a positive perception of their reception in the pharmacies increased from 10 percent to 41 percent.

Youth were asked whether they thought they would be well received if they visited a health facility for treatment of STIs. With the exception of the younger males in Diourbel, significant increases in positive perceptions were seen among all youth at all sites, with the improvements of similar magnitude. 
Table 24: Attitudes about visits to health facilities

\begin{tabular}{|c|c|c|c|c|c|c|c|c|}
\hline & & & \multicolumn{2}{|c|}{ Saint-Louis } & \multicolumn{2}{|c|}{ Louga } & \multicolumn{2}{|c|}{ Diourbel } \\
\hline & & & Baseline & Endline & Baseline & Endline & Baseline & Endline \\
\hline \multirow{10}{*}{$\begin{array}{l}\text { Think that they would } \\
\text { be well received at a } \\
\text { pharmacy while } \\
\text { seeking } \\
\text { contraception }\end{array}$} & Boys & & & & & & & \\
\hline & $10-14$ & $\%$ & 14 & $46^{*}$ & 44 & 56 & 31 & 44 \\
\hline & years & $\mathrm{N}$ & 81 & 81 & 110 & 105 & 96 & 79 \\
\hline & $15-19$ & $\%$ & 44 & $60^{*}$ & 52 & $73^{*}$ & 52 & 53 \\
\hline & years & $\mathrm{N}$ & 173 & 183 & 225 & 200 & 195 & 146 \\
\hline & Girls & & & & & & & \\
\hline & $10-14$ & $\%$ & 10 & $41^{*}$ & 34 & $47^{*}$ & 14 & $29^{*}$ \\
\hline & years & $\mathrm{N}$ & 116 & 84 & 102 & 136 & 117 & 99 \\
\hline & $15-19$ & $\%$ & 26 & $43^{*}$ & 32 & $51^{*}$ & 26 & $38^{*}$ \\
\hline & years & $\mathrm{N}$ & 173 & 182 & 257 & 262 & 239 & 230 \\
\hline \multirow{10}{*}{$\begin{array}{l}\text { Think they would be } \\
\text { well treated at a } \\
\text { health facility for } \\
\text { STIs }\end{array}$} & Boys & & & & & & & \\
\hline & $10-14$ & $\%$ & 19 & $49^{*}$ & 46 & *62 & 37 & 51 \\
\hline & years & $\mathrm{N}$ & 81 & 81 & 110 & 105 & 96 & 79 \\
\hline & $15-19$ & $\%$ & 39 & $54^{*}$ & 51 & *80 & *43 & ${ }^{*} 60$ \\
\hline & years & $\mathrm{N}$ & 173 & 182 & 225 & 200 & 195 & 146 \\
\hline & Girls & & & & & & & \\
\hline & $10-14$ & $\%$ & 11 & $38^{*}$ & 33 & $60^{*}$ & 14 & $43^{*}$ \\
\hline & years & $\mathrm{N}$ & 116 & 84 & 102 & 136 & 117 & 99 \\
\hline & $15-19$ & $\%$ & 23 & $50^{*}$ & 41 & $59^{*}$ & 26 & $53^{*}$ \\
\hline & years & $\mathrm{N}$ & 173 & 182 & 257 & 262 & 239 & 230 \\
\hline
\end{tabular}

$* \mathrm{p}<0.05$

The question on perceived reception at health facilities for adolescents seeking contraceptives was only asked during the endline survey. Overall, the responses are consistent with the perceptions reported for those seeking STI services, with 40 to 60 percent of adolescents anticipating respectful service (see Figure 10). Levels were slightly higher at the intervention sites compared with the control site, particularly in Louga, partly due to the youth-friendly services during the intervention. 
Figure 10: Proportion of adolescents who think that they would be well received at a health facility while seeking contraceptive products

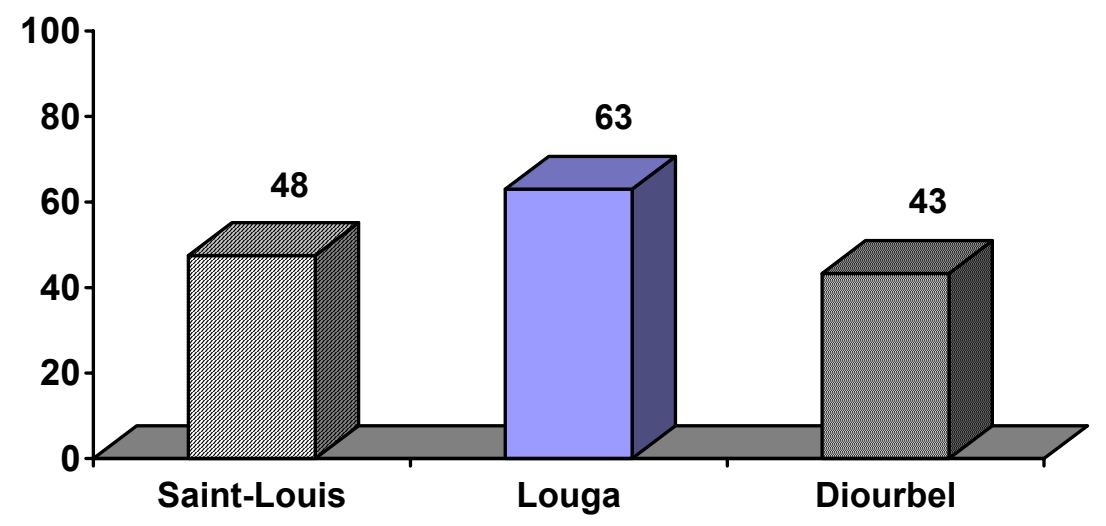

\section{Influence of direct exposure to the interventions}

The adolescents who had been exposed to the interventions were more familiar with the existence of the health services than those who were not (see Figure 11). In Saint-Louis as well as in Louga, three-quarters of the adolescents exposed to the intervention reported knowing a health facility compared with only one-third of those who were not exposed.

Similarly, the adolescents exposed to the intervention tended to frequent these health facilities more than the others. Generally adolescents informed about reproductive health were twice as likely to attend a health facility as those not informed, although the levels remained quite low.

\section{Figure 11: Knowledge and use of health facilities}

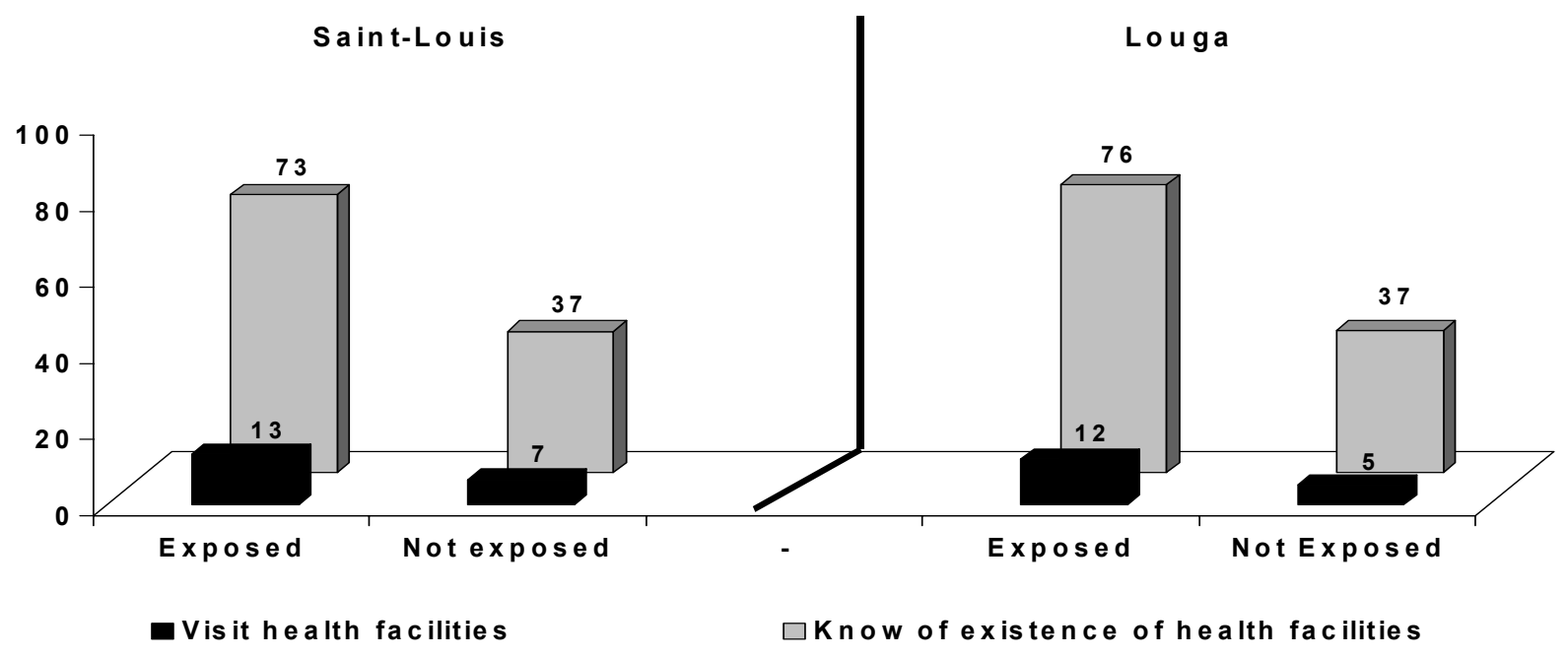




\section{Conclusion}

Before the introduction of the interventions, more adolescents in Louga knew about the facilities than those in Diourbel and Saint-Louis. At baseline boys were somewhat more informed of the existence of these facilities than girls, but levels were similar by the endline. After the interventions, the knowledge of health facilities increased in Saint-Louis and in Diourbel but not in Louga, where the levels were already quite considerable. Youth visits to health facilities were rare before the interventions in the three areas. At the end of the interventions there was a significant rise reported in these visits particularly in Saint-Louis and Diourbel, but the level remained modest, below 20 percent. In comparing those adolescents exposed to the interventions with those who were not, both knowledge and visits were twice as high among those exposed.

Half of the adolescent visits to the health facilities were for treatment of common illness, but the second most important reason for visits was to seek information on sexuality. This shows the evolving perception of adolescents toward health facilities and pharmacies as welcoming sources of treatment for STIs and sources of contraceptive supplies. Improvements were seen in all sites, though changes were less pronounced in Diourbel.

\section{Multivariate results}

The effects of interventions implemented in sites A and B (Louga and Saint-Louis, respectively) were assessed by comparing the difference in outcomes (either as means or proportions) at baseline and endline levels in each site with the difference in outcomes at baseline and endline in site $\mathrm{C}$ (Diourbel). However, this assessment of intervention effects did not account for the characteristics of study participants. Thus, to assess whether these characteristics affected the intervention effects, multivariable models (in particular logistic regression models) were estimated.

The procedure included two stages, the first of which consisted of creating a basic model where the following were the explanatory variables:

- Project site (Louga, Saint-Louis) with Diourbel as a reference

- Time (baseline, endline) with the baseline as a reference

- Interaction variables, combining site and time

In the second stage, other factors were added to the model, including

- Sex ('boy' with 'girl' as reference)

- Age ('15-19 years' with '10-14 years' as reference)

- Marital status ('married' with 'single' as reference)

- Education ('formal education', 'informal education' with 'uneducated' as reference)

- Academic status ('student' with 'non-student' as reference)

- Religious practice ('practice religion', with 'does not practice religion' as reference)

- Living with parents ('lives with at least one parent' with 'does not live with parent' as reference)

These factors were first introduced in the basic model individually to measure their own effect before being put together to measure their collective effect. 
As seen throughout this report, the interventions carried out in Louga and Saint-Louis made it possible to influence a large proportion of adolescents. However, despite its status as a control site, Diourbel also benefited from similar activities beyond the control of the research design.

Annex A, Table A-4 shows the final model fitted for each of five outcomes selected: exposure to reproductive health information at the school; exposure to reproductive health information outside the school; ever had sex; secondary abstinence among those who ever had sex; and communication with parents on reproductive health. Shown are the odds ratios and their 95 percent confidence intervals for each of the factors included in a final model for a specific outcome. The odds ratio for the interaction of time by site indicates a measure of effect of interventions on a specific outcome. (These are reported in Table A-4 as EL to BS OR in Louga, EL to BS OR in Saint-Louis, and EL to BS OR in Diourbel. The EL to BS OR in Diourbel has a value of one, as this the comparison group).

If the value of the odds ratio is greater than 1 (with the 95 percent confidence interval excluding one), then the estimate of change in outcome over time in an intervention site is greater than the estimate of change over time in the control site, indicating positive effects of the site interventions on an outcome variable. On the other hand, if one is within the 95 percent confidence interval, then changes over time in an intervention site are statistically equivalent to changes over time in the control site, i.e. there was no intervention effect. Should the odds ratio be less than one, and with one excluded from the 95 percent confidence interval, then changes over time in the intervention sites are less than the changes over time in the control site. The odds ratios associated with the control variables can be similarly interpreted except the comparison group is the reference cell specified. For example, an odds ratio of greater than 1 for males reporting sex in the last six months indicates that males are more likely than females (the reference category) to report having sex in the last six months.

In this discussion, the substantive implications of the odds ratios presented in the Annex are discussed. Also indicated is whether the unadjusted estimates of effects differ in significance or substantive implications from the adjusted estimates, i.e. whether the participants' characteristics influence the intervention effects (in this presentation, the unadjusted estimates of effects are those obtained in the first stage of modeling where no characteristics of study participants are included in the model.) The effects of the other covariates on the overall level of response are also indicated.

\section{Exposure to the programs at the school}

This model was developed to learn whether there were any distinct groups that received information on reproductive health at school during the interventions. Considering this, the successive addition of factors to the basic model gave the following results:

- A greater proportion of boys than girls were exposed to the school interventions.

- Adolescents aged 15-19 years were exposed more than those aged 10-14; this trend was especially evident when comparing Saint-Louis and Diourbel.

- Single adolescents were influenced more at school than married ones.

- Adolescents who practice their religion regularly were more exposed than those who did not.

- Adolescents living with one or both parents were also exposed more than those who were not living with a parent. 


\section{Conclusion}

The adjusted estimate of the effect of interventions in Saint-Louis on reproductive health information in school is statistically significant while the unadjusted estimate is not. This indicates that effects are associated with some characteristics of the study participants (living with parents, practicing a religion, single status, 15-19 year age group).

\section{Exposure to the programs outside school}

Sexual activity occurs more among older boys than among girls or younger adolescents. It was also noted that educated adolescents had a tendency to have recent sexual activity than those who were not educated. On the other hand, students who were attending school and were exposed to the intervention were less likely to have recent sexual activity. Factors related to religious beliefs and practices and living with at least one biological parent were also protective. Adoption of secondary abstinence is higher in Louga (intervention site) than in Diourbel (control site). In Louga, adolescents who had sexual experience were less likely to have had intercourse during the prior six months than those in Diourbel; in addition adolescents in Louga have fewer sexual partners than those in Diourbel.

The proportion of adolescents who discuss reproductive health topics with their parents increased in all sites from baseline to endline. However, the increase observed in Saint-Louis is less than the increase in Diourbel. It was the same for the adolescents in Louga in relation to those of Diourbel. Although the proportion of adolescents aged 15-19 who discussed reproductive health with their parents at baseline was greater than those aged 10-14, the 10-14 year olds increased their likelihood of talking to parents over time than those aged 15-19. The relative differences in proportion between adolescents currently in school and the others increased after the interventions.

At Saint-Louis those currently in school had less of a tendency to discuss reproductive health with their parents compared with the non-students; the opposite situation was noted in Diourbel before and after the interventions. Adolescents who reported religious practice were more likely to report talking to parents about reproductive health than adolescents who did not report religious practice, especially at baseline. However, the differences between those with religious practice and without religious practice were less at endline than at baseline. At Louga and SaintLouis, the difference in proportions of adolescents talking to parents about reproductive health was larger than the difference found in Diourbel.

Living with parents does not seem to bring more possibilities of discussing reproductive health issues with them than living with guardians. In effect, the adolescents living with at least one of their biological parents do not have a greater probability of discussing reproductive health with that parent than other adolescents with their guardians. (This is true of the bivariate results, but when controlled for other covariates, those living with parents were about 20 percent more likely to talk to their parents about reproductive health than adolescents not living with their parents.) This confirms the results of the bivariate analysis which had shown a significant drop of the perception of adolescents about the ease of discussing reproductive health issues with their parents/guardians. This analysis helps to conclude that it is up to the parents to create a favorable environment in the midst of families for the establishment of a dialogue with the adolescent on topics such as reproductive health. The unadjusted and adjusted estimate of effects of interventions did not differ substantively with the differences over time in the intervention sites of Louga and Saint-Louis than in the control site, Diourbel. 
The proportion of adolescents who discuss reproductive health principally with their parents increased in all sites, but less in Louga and Saint-Louis than in Diourbel. However, disparities were observed between adolescents. On the one hand, the proportion of adolescents age 10-14 who discussed reproductive health with their parents increased more than those age 15-19. On the other hand, students had less of a tendency to discuss reproductive health with their parents than those who were not students in Saint-Louis; Diourbel had the opposite situation. The results from the analysis confirmed the need for parents to be more open towards their adolescents so that they build an environment conducive for dialogue.

\section{COST ANALYSIS ${ }^{5}$}

The project period was divided into three phases: the preparatory phase, the intervention phase, and the service delivery phase. The first two phases occurred in the beginning and are related to the start up of the project; the last phase relates to the period when the beneficiaries were reached.

\section{Methodology}

The cost analysis was conducted from the perspective of an agency providing reproductive health information or services to adolescents. The methodology includes information on costs of all new activities or additions to an existing set of activities; it excludes activities that are already underway such as the existing range of services provided at health clinics.

Activities in the design and intervention phase typically occur just once at the initiation of the new program. Hence, the costs are incurred only once and are of the nature of fixed or start-up costs. Subsequent to the start-up phase, activities in the service delivery phase commence; these activities occur repeatedly as they are ongoing activities. The costs incurred for these activities are recurring or variable costs. For example, they vary by the number of times an activity occurs or by the number of individuals involved in the activity. Cost estimates for undertaking activities in each of the three phases are estimated. The model assumes a two-year reference period: one year for the design and intervention phase, and one year for the service delivery phase.

There are two principal criteria for including items in the cost analysis: first, the item was a new activity or an addition to the existing set of activities; and second, the activity was conducted for the sole purpose of providing reproductive health information or services for adolescents. A range is provided for the cost estimates to indicate differences in the intensity with which a program is conducted. The range is represented by the figures on the minimum and maximum lines at the bottom of Table 25 .

\footnotetext{
${ }^{5}$ For more detailed information about the cost analysis, refer to the technical report by RamaRao and Diop (2003).
} 


\section{Data collection}

Forms for collecting data on costs were specially designed. Separate forms were designed for different activities during the implementation phase: training, meetings, or conducting activities. The persons who conducted the various activities was recorded in these forms as well as the costs incurred for the activity. For activities that recur in the implementation phase, the data are available for the months in which they occurred.

Efforts were made to list resources that were donated for the conduct of any activity. These included the time of various individuals, physical space provided by specific agencies, or materials. The value of these resources is estimated by the price that they would have cost in an open market. For example, the value of labor donated was estimated in one of two ways; by the price charged in the labor market for similarly skilled labor, or by its opportunity cost or the cost foregone in conducting the present activity.

\section{Number of cost estimates}

Three cost models were developed-one each for the community, clinic, and school components. As two components occur in one intervention site (Site A, Louga), and all three components occur in the other (Site B, Saint-Louis), a total of five estimates are presented. Each model presents the overall costs of conducting a variety of activities in the design or preparation phase, the implementation phase, and the service phase. ${ }^{6}$ Activities related to overall planning and coordination of the project are common to all the three models, while others are specific to each model.

Table 25 presents the findings of the cost of providing reproductive health information and services of two alternate packages. One package consists of using two different mechanismscommunity outreach and health clinics (as tested in Site A, Louga); the other comprises three mechanisms - community outreach, health clinics, and schools (as tested in Site B, Saint-Louis). The analysis presented here is an aggregated one that subsumes the specific activities that were conducted in the planning, training, and service delivery phases to obtain an overall summarized view.

\footnotetext{
${ }^{6}$ For detail on the specific activities conducted and costs attached to them refer to RamaRao and Diop (2003).
} 
Table 25: Summarized Costs of All Interventions by Site

\begin{tabular}{|c|c|c|c|c|}
\hline \multirow[t]{2}{*}{ Activities } & \multicolumn{2}{|c|}{ Site A (Louga) } & \multicolumn{2}{|c|}{ Site B (Saint-Louis) } \\
\hline & $\begin{array}{c}\text { Financial } \\
\text { (CFA) }\end{array}$ & $\begin{array}{c}\text { Non- Financial } \\
(\text { CFA })\end{array}$ & $\begin{array}{c}\text { Financial } \\
(\text { CFA) }\end{array}$ & $\begin{array}{c}\text { Non-Financia } \\
\text { (CFA) }\end{array}$ \\
\hline $\begin{array}{l}\text { Community } \\
\text { Planning } \\
\text { Training } \\
\text { Services-Minimum } \\
\text { Services-Maximum } \\
\text { Supervision-Minimum } \\
\text { Supervision-Maximum } \\
\text { Grand total: Minimum }{ }^{1} \\
\text { CFA } \\
\text { US \$ } \\
\text { Grand total: Maximum² } \\
\text { CFA } \\
\text { US \$ }\end{array}$ & $\begin{array}{c}9913251 \\
3718776 \\
2236000 \\
5360000 \\
493713 \\
927426 \\
\\
16361740 \\
\mathbf{2 7 , 2 7 0} \\
19919453 \\
\mathbf{3 3 , 1 9 9}\end{array}$ & $\begin{array}{c}3681563 \\
1077438 \\
50000 \\
50000 \\
480000 \\
2795000 \\
\\
\mathbf{5 2 8 9 0 0 1} \\
\mathbf{8 , 8 1 5} \\
\mathbf{7 6 0 4 0 0 1} \\
\mathbf{1 2 , 6 7 3}\end{array}$ & $\begin{array}{c}9757981 \\
4331214 \\
2398000 \\
4745150 \\
1155993 \\
1519986 \\
\\
\mathbf{1 7 6 4 3 1 8 8} \\
\mathbf{2 9 , 4 0 5} \\
\mathbf{2 0 3 5 4 3 3 1} \\
\mathbf{3 3 , 9 2 4}\end{array}$ & $\begin{array}{c}3612000 \\
1077438 \\
460000 \\
1410000 \\
630000 \\
1260000 \\
\\
\mathbf{5 7 7 9 4 3 8} \\
\mathbf{9 , 6 3 2} \\
\mathbf{7 3 5 9 4 3 8} \\
\mathbf{1 2 , 2 6 6}\end{array}$ \\
\hline $\begin{array}{l}\text { Health Clinic } \\
\text { Planning } \\
\text { Training } \\
\text { Services-Minimum } \\
\text { Services-Maximum } \\
\text { Supervision-Minimum } \\
\text { Supervision-Maximum } \\
\text { Grand total: Minimum }{ }^{1} \\
\text { CFA } \\
\text { US \$ } \\
\text { Grand total: Maximum² } \\
\text { CFA } \\
\text { US \$ }\end{array}$ & $\begin{array}{c}7691873 \\
5212088 \\
336000 \\
448000 \\
193713 \\
423426 \\
\\
13433674 \\
\mathbf{2 2 , 3 8 9} \\
\mathbf{1 3 7 7 5 3 8 7} \\
\mathbf{2 2 , 9 5 9}\end{array}$ & $\begin{array}{c}964541 \\
4399750 \\
0 \\
0 \\
480000 \\
1020000 \\
\\
\mathbf{5 8 4 4 2 9 1} \\
\mathbf{9 , 7 4 0} \\
\mathbf{6 3 8 4 2 9 1} \\
\mathbf{1 0 , 6 4 0}\end{array}$ & $\begin{array}{c}8397935 \\
6892511 \\
588000 \\
756000 \\
351993 \\
673986 \\
\\
16230439 \\
\mathbf{2 7 , 0 5 1} \\
\mathbf{1 6 7 2 0 4 3 2} \\
\mathbf{2 7 , 8 6 7}\end{array}$ & $\begin{array}{c}894978 \\
4399750 \\
0 \\
0 \\
630000 \\
1260000 \\
\\
\mathbf{5 9 2 4 7 2 8} \\
\mathbf{9 , 8 7 5} \\
\\
\mathbf{6 5 5 4 7 2 8} \\
\mathbf{1 0 , 9 2 5}\end{array}$ \\
\hline $\begin{array}{l}\text { School } \\
\text { Planning } \\
\text { Training } \\
\text { Services-Minimum } \\
\text { Services-Maximum } \\
\text { Supervision-Minimum } \\
\text { Supervision-Maximum } \\
\text { Grand total: Minimum }{ }^{1} \\
\text { CFA } \\
\text { US \$ } \\
\text { Grand total: Maximum² } \\
\text { CFA } \\
\text { US \$ }\end{array}$ & & & $\begin{array}{c}10948729 \\
2368333 \\
725000 \\
775000 \\
129000 \\
608000 \\
\\
14171062 \\
\mathbf{2 3 , 6 1 8} \\
\mathbf{1 4 7 0 0 0 6 2} \\
\mathbf{2 4 , 5 0 0} \\
\end{array}$ & $\begin{array}{c}139125 \\
0 \\
0 \\
0 \\
600000 \\
1200000 \\
\\
739125 \\
1,232 \\
1339125 \\
\mathbf{2 , 2 3 2} \\
\end{array}$ \\
\hline $\begin{array}{l}\text { All Interventions } \\
\text { Minimum } \\
\text { Maximum }\end{array}$ & $\begin{array}{l}50,018 \\
56,516 \\
\end{array}$ & $\begin{array}{l}18,197 \\
22,955 \\
\end{array}$ & $\begin{array}{l}80,074 \\
86,291 \\
\end{array}$ & $\begin{array}{l}20,739 \\
25,423 \\
\end{array}$ \\
\hline
\end{tabular}

${ }^{1}$ Sum of the following line items: Planning, training, services-minimum and supervision-minimum.

2 Sum of the following line items: Planning, training, services-maximum and supervision-maximum.

Exchange rate of 1 US $\$=600 \mathrm{CFA}$ 
In summary, the total cost of the package using community outreach and health clinics (Site A, Louga) is in the range of $\$ 68,215$ to $\$ 79,471$. On the other hand, providing the same services using all three mechanisms (community, health clinics, and schools - Site B, Saint Louis) is in the range of $\$ 100,813$ to $\$ 111,714$. Of the three mechanisms, reaching the youth at school is the least expensive (minimum of $\$ 24,850$ and maximum of $\$ 26,732$ ) while community outreach is the most expensive (range of $\$ 36,085$ to $\$ 45,872$ in Site A, Louga, and $\$ 39,037$ to $\$ 46,190$ in Site B, Saint-Louis). Reaching adolescents at clinics is just slightly less expensive than through outreach (range of \$32,139 to \$33,599 in Site A, Louga and \$36,926 to \$38,792 in Site B, SaintLouis).

One important finding is that most of the costs are incurred early on, typically in the planning and implementation phases; the costs of the service delivery phase are considerably lower. The start-up costs range from two-fifths to about three-quarters of the total costs. The primary reason for such high costs is that there were no existing models or guidelines of providing reproductive health information and services to adolescents to build on or modify. As a result, important stakeholders had to be identified and brought together for a number of consultative meetings and discussions. Furthermore, curricula had to be developed, pre-tested, and passed through the approval process. These activities can be considered as important investments for future programs to build on. Other costs that may occur in the future relate to the training of new batches of participants - peer educators, providers' aides, and teachers' aides. As the current batch of young people age and transition into the next phase of their lives - be it employment or further study - there will be a need for training new peer educators.

A second important finding is that once the initial costs are incurred, the costs of service delivery and supervision are much lower; they also provide an indication of the recurring costs for the existing level of demand in the foreseeable future. This is, however, predicated upon the existing service model and demand; should either or both of these parameters change, the recurring costs will also change.

Third, the analyses also reflected the variations in cost that can occur due to regional differences arising from differing economic conditions and markets. Thus, in general, costs were lower in Site A (Louga) than in Site B (Saint-Louis). However, these differentials are not wide and suggest that replicating the models in a different part of the country may not alter the costs substantially.

Fourth, there were opportunities for cost savings as the models were implemented as a package. There were several activities common to all three models which had to be undertaken; hence, the costs of these could be distributed across both the sites and three models. Examples of these activities include the preparations and discussions held at regional and national levels; the development and production of IEC material which could be used at all three venues of clinics, schools, and community outreach; the development, training, and production of radio programs which reinforced the information and messages provided by the three venues.

A fifth important finding is that there were significant donations of resources by a number of stakeholders to the project. These donations were in the form of time, physical space, and material resources. These contributions are important not only for their economic value but also for the interest and engagement in the project exhibited by the various stakeholders. Staff of technical and multilateral agencies contributed their time in the initial discussion of ideas at the country level, the development of materials, and conducting the various training workshops. 
Contributions were also made by the private, for-profit sector. For example, radio stations contributed radio time for airing the programs. These programs continued beyond the life of the project period because of interest and demand from the listening public. Finally, civil society groups donated space for holding meetings and discussion groups at the community level. The engagement of this diverse range of stakeholders built in ownership and ensured the success of this pilot venture. It also indicates the basis for ensuring sustainability in the future.

In conclusion, the cost analysis has presented three different models for providing reproductive health information and services and their costs. The analyses presented here suggest that on average an intervention, be it facility-based, school-based, or community-based, will be under $\$ 40,000$ for a period of two years to reach 33,494 adolescents and 2,268 parents through interpersonal activities. The numbers of youth and adults reached through mass activities such as radio programs, and events like concerts and festivals are difficult to estimate.

Pilot projects such as these provide a lot of information from the feasibility of doing the innovations, the lessons learned from the experience, the coverage of the intended beneficiaries, and costs. While information on costs is a useful input for policy makers and program managers in their decision-making process, it is but one parameter. Costs by themselves are not sufficient to indicate whether a specific program should be replicated or expanded. Other considerations such as the need for these services, the interest and willingness of stakeholders to participate, and the feasibility of providing them are perhaps more important.

\section{Limitations in the cost analysis}

There are some limitations that have to be noted. First, the analysis is restricted to costs, with no inclusion of effectiveness measures. As a result, it is not possible to gauge the different impacts of the three models and to choose the most cost-effective way of serving adolescents. Implicitly all three models are assumed to be equally effective. Moreover, the issue is complicated by the possibility that some youth may have been reached by all the interventions; for example, a school-going child may have been exposed to the messages at school, participated in the activities at the community level, and also visited a clinic. In such a scenario, it will be difficult to disentangle the individual effects of the three interventions; it will only be possible to provide comparisons of the two packages - one comprising of the three interventions and the other with two. The second limitation refers to the lack of inclusion of costs borne by the beneficiaries of the interventions. For example, opportunity and transport costs of those who attended the community outreach program or facilities have been ignored. Though difficult to capture, and overall a very small portion of the total costs of the project, it may be useful to estimate these outlays on the part of participants.

Finally, should there be interest in replication of this pilot project, sufficient resources have already been invested in the groundwork of testing different strategies to provide services for adolescents and young people that these investments can be harvested. 


\section{CONCLUSIONS}

\section{Feasibility}

The study demonstrated that it is possible to carry out interventions to improve adolescents' knowledge of reproductive health topics despite the sensitive nature of this question in Senegal's socio-cultural context. The interventions provided an opportunity not only to promote positive values such as abstinence until marriage and respect for adolescents of the other gender, but also to discuss responsible sexuality. The program did not attempt to promote or distribute condoms through the new mechanisms developed, given the newness of the reproductive health themes and the sensitive nature of adolescent reproductive health. Condoms and other contraceptives were available only through existing sources.

Mobilization of politicians, administrative heads, religious and community leaders was achieved, and they all showed a strong commitment for the program. Some of them assumed proactive roles that show potential support that could be tapped in the future. A multi-agency partnership between the health department, community, schools, and the media proved that a multi-sectorial approach is feasible when organized through an operational technical committee.

Young people's involvement, in making youth associations responsible and in clarifying the terms of collaboration by a contract, led to high levels of mobilization and very little dropout of peer educators. However, the local technical committee must be cautious to maintain a balance between mass mobilization activities, of which young people are fond, and inter-personal education activities, which are more effective for changing knowledge, attitudes, and behavior.

Peers educators' capacities in using management tools are limited, and the sensitization of the non-educated adolescents on reproductive health is more difficult and requires more time than for in-school adolescents. Clinic interventions using young people as providers' aides to welcome and counsel adolescents made facilities more attractive for young people. Community interventions required a lot of energy, time, and human resources.

\section{Costs}

The highest costs were incurred during the preparation stage at the beginning of the study, especially during the planning and setting up of the service delivery phase. Approximately 38 percent of total costs was related to implementing the community component, 31 percent for clinic component, and 28 percent for the school component. The costs borne in the service delivery phase were considerably lower. From the perspective of scaling up, costs would be approximately $\$ 40,000$ over a two years period, mainly for training and service delivery.

\section{Effectiveness}

The evaluation shows that the interventions led to greater exposure of adolescents to reproductive health information in Louga and in Saint-Louis. The 10-14 and 15-19 age groups were also influenced at school. However, the boys received more information than girls. Outside school, it was the adolescents aged 15-19 who were most influenced. 
Parents' attitudes towards reproductive health programs were more favorable after the interventions. Women were more influenced in part because they are more easily accessed through their community-based organizations. They developed more tolerant attitudes than the men. Communication on reproductive health topics increased within each group. However that improvement in communication does not increase parent-child communication. Other adults and trained specialists were more accessed by the adolescents.

The interventions also led to a significant improvement in the knowledge of puberty among the girls in Louga and in Saint-Louis, the risks related to early sexuality, and knowledge of contraceptives including condoms. Generally, adolescents aged 15-19 had a better knowledge of contraceptives than those aged 13-14 years.

This study showed that values such as abstinence are the main reference and source of protection among young people. Thus, secondary abstinence and being faithful to one partner were promoted more strongly than the use of condoms or other contraception among the sexually active adolescents. The interventions seem to have had an effect on limiting sexual activity but not on protection through the use of condoms or other contraceptive methods.

Adolescents directly exposed to the interventions had in general improved knowledge, attitudes, and behavior compared to those who were not exposed. This is promising for the future as more systematic intervention and exposure to reproductive health programs will be developed.

In summary the hypotheses on the greater improvement in the environment for youth in site A (Louga) and B (Saint-Louis) compared with site C (Diourbel) have been accepted for most indicators on knowledge and attitude. The hypothesis that there would be greater utilization of services in site A (Louga) and B (Saint-Louis) compared with site C (Diourbel) has not been supported. Only site B (Saint-Louis) showed a knowledge and use of health facilities greater than site C (Diourbel), and it is more pronounced for older adolescents. Site A (Louga) did not show any improvement.

The hypothesis that site B (Saint-Louis) will show greater improvement in school-based health education than site A (Louga) has not been fully supported. Indicators of knowledge and use of services and contraception show that site B (Saint-Louis) had greater improvement than site A (Louga), but for other indicators the two sites are similar. The school-based intervention was difficult to evaluate with this design.

\section{Research methods}

This study shows that it is difficult to maintain a control site when many organizations in Senegal are implementing interventions on reproductive health. In Diourbel, initially selected as a control site because it was not supporting interventions aimed at adolescents when the study started, activities targeting adolescents increased during the course of the two-year project period. These were implemented by the regional and district staff after the dissemination of the baseline results.

Policy relevant scientific research and a well-developed research design can be difficult to implement in reality. In Louga, no intervention was planned within the schools. However, this could not be achieved in reality because the implementing partners did not follow the requirement of the research design, but rather addressed a social demand by publicizing community activities in schools in order to recruit more adolescents. 
In the creation of evaluation tools, parent-child communication was identified as the sole indicator of a changing, more supportive social environment. Within Senegal's socio-cultural context this was a limited indicator. The strategies used for making the environment favorable influenced the targeted adolescents, politicians, administrative, religious heads, parents, and entire communities. Unfortunately the social changes obtained through these strategies were not evaluated.

\section{PROGRAM IMPLICATIONS}

- The topics of contraception in general and the condom in particular were addressed only superficially by the implementers. Yet the data show that these are subjects for which the adolescents wish to receive very straightforward information. It is necessary therefore to scrutinize the implementers' attributes, particularly the staff responsible for the program and departmental technical officers, to ensure they feel comfortable and competent to convey accurate, value-free information. In clarifying the content of messages on this topic, the program can gain momentum and efficiency. The implementers and the communities should also know that adolescents do not become more permissive when they learn about contraception; this study clearly demonstrated the opposite effect.

- On the issue of teaching adolescents about the menstrual cycle, a consensus was not reached. The implementers were anxious that in the Senegalese context, where contraceptive use is limited, adolescents would use information about the cycle to prevent pregnancy. As girls' menstrual cycles are subject to many fluctuations, it is more difficult to accurately assess fertile and infertile periods. If assessed incorrectly, a sexually active girl may become pregnant if relying on this as a contraceptive method. Discussions should be initiated and a consensus should be reached on how to convey this important information.

- The decline in using condoms or other contraceptives as a means of protection versus being faithful to one partner is an important result. Even if the message of being faithful to one partner is encouraged to reduce the risk of STIs including HIV/AIDS, it is important that IEC messages toward sexually active adolescents also emphasize dual protection against early pregnancy. Having only one sexual partner may protect them against STIs but not against pregnancy.

- The targeted male parents were poorly influenced because they are less frequently organized in groups and thus more difficult to reach collectively. Strategies aimed at influencing them are difficult to implement. It will be necessary to use the media and religious leaders if this strategy is to benefit male parents and youth.

- The young adolescents (10-14 years old) who were less intensely targeted by the interventions have shown the need to gain information on materials and services. During puberty they are in search of their personal identity. The data show that they are less sexually active, but among those who have become sexually active, the average age of initiation is 14 to 15 . Young adolescents need a complete and well-supported reproductive health program.

- Parent-child communication is still insufficient. Adolescents show an eagerness to discuss reproductive health with their parents and seek better education on these issues. 
Parents have expressed their wish to convey this information to their children, but they are limited due to their poor understanding of the subject, lack of opportunities to talk about it, and their fear of encouraging risky behaviors. It is necessary to establish a program with "parent schooling" so that they can learn more on this topic.

- The strategies aimed at schools were conservative and did not mobilize all the teachers and administrative heads. A specific program is needed to provide a favorable school environment towards reproductive health before addressing the targeted adolescents.

- The fact that sexual activity had not increased since the interventions were introduced shows that it is possible to inform adolescents in a straightforward manner about reproductive health without their engaging in early sexual activity with regrettable consequences, as communities fear. These results will help program leaders in the quest for a wide-scale expansion of reproductive health programs for adolescents. 


\section{ANNEX A}

Table A-1: Sample and response rates

\begin{tabular}{|c|c|c|c|c|c|c|}
\hline \multirow[b]{2}{*}{ Selected } & \multicolumn{2}{|c|}{ Saint-Louis } & \multicolumn{2}{|c|}{ Louga } & \multicolumn{2}{|c|}{ Diourbel } \\
\hline & Baseline & Endline & Baseline & Endline & Baseline & Endline \\
\hline \multicolumn{7}{|l|}{ Boys } \\
\hline 10 to 14 & 257 & 264 & 289 & 319 & 281 & 266 \\
\hline 15 to 19 & 194 & 241 & 257 & 256 & 234 & 211 \\
\hline \multicolumn{7}{|l|}{ Girls } \\
\hline 10 to 14 & 300 & 272 & 269 & 326 & 288 & 271 \\
\hline 15 to 19 & 246 & 280 & 265 & 292 & 255 & 282 \\
\hline \multicolumn{7}{|l|}{ Parents } \\
\hline Total & 633 & 616 & 625 & 440 & 739 & 565 \\
\hline \multicolumn{7}{|c|}{ Interviewed } \\
\hline \multicolumn{7}{|l|}{ Boys } \\
\hline 10 to 14 & 231 & 219 & 274 & & 248 & 222 \\
\hline 15 to 19 & 173 & 183 & 225 & & 198 & 147 \\
\hline \multicolumn{7}{|l|}{ Girls } \\
\hline 10 to 14 & 278 & 235 & 262 & & 276 & 229 \\
\hline 15 to 19 & 231 & 239 & 258 & & 239 & 232 \\
\hline \multicolumn{7}{|l|}{ Parents } \\
\hline Total & 568 & 519 & 537 & & 578 & 469 \\
\hline \multicolumn{7}{|c|}{ Totals } \\
\hline Total boys selected & 451 & 505 & 546 & & 515 & 477 \\
\hline Total girls selected & 546 & 552 & 534 & & 543 & 553 \\
\hline Total boys interviewed & 404 & 402 & 499 & & 446 & 369 \\
\hline Total girls interviewed & 509 & 474 & 520 & & 515 & 461 \\
\hline \multicolumn{7}{|c|}{ Response Rate (Percent) } \\
\hline \multicolumn{7}{|l|}{ Boys } \\
\hline 10 to 14 & 90 & 83 & 95 & & 88 & 84 \\
\hline 15 to 19 & 89 & 76 & 88 & & 85 & 70 \\
\hline Total & 90 & 80 & 91 & & 87 & 77 \\
\hline \multicolumn{7}{|l|}{ Girls } \\
\hline 10 to 14 & 93 & 86 & 97 & & 96 & 85 \\
\hline 15 to 19 & 94 & 85 & 97 & & 94 & 82 \\
\hline Total & 93 & 86 & 97 & & 95 & 83 \\
\hline \multicolumn{7}{|l|}{ Parents } \\
\hline Total & 90 & 84 & 86 & & 78 & 83 \\
\hline
\end{tabular}


Table A-2: Perception of adolescents on the discussion with their parents (\%)

\begin{tabular}{|c|c|c|c|c|c|c|c|}
\hline & & \multicolumn{2}{|c|}{ Saint-Louis } & \multicolumn{2}{|c|}{ Louga } & \multicolumn{2}{|c|}{ Diourbel } \\
\hline & & Baseline & Endline & Baseline & Endline & Baseline & Endline \\
\hline \multirow{9}{*}{$\begin{array}{l}\text { Easy to talk about } \\
\text { reproductive health } \\
\text { with father/tutor }\end{array}$} & $\begin{array}{r}\text { Boys } \\
10-14 \\
\text { years } \\
\text { old }\end{array}$ & 21.0 & 17.7 & 19.4 & 18.1 & 26.5 & 25.2 \\
\hline & $\mathrm{N}$ & 184 & 219 & 250 & 263 & 224 & 222 \\
\hline & $\begin{array}{r}15-19 \\
\text { years } \\
\text { old }\end{array}$ & 26.7 & 19.3 & 14.0 & 13.3 & 22.6 & 21.3 \\
\hline & $\mathrm{N}$ & 140 & 183 & 201 & 200 & 178 & 147 \\
\hline & $\begin{array}{r}\text { Girls } \\
10-14\end{array}$ & & & & & & \\
\hline & $\begin{array}{r}\text { years } \\
\text { old }\end{array}$ & 18.6 & 14.0 & 13.5 & 11.5 & 15.5 & 17.1 \\
\hline & $\mathrm{N}$ & 202 & 235 & 234 & 306 & 230 & 229 \\
\hline & $\begin{array}{r}15-19 \\
\text { years } \\
\text { old }\end{array}$ & 21.6 & 14.1 & 15.8 & 18.8 & 17.3 & 24.6 \\
\hline & $\mathrm{N}$ & 180 & 239 & 217 & 262 & 199 & 232 \\
\hline \multirow{10}{*}{$\begin{array}{l}\text { Easy to talk about } \\
\text { reproductive health } \\
\text { with mother/tutor }\end{array}$} & $\begin{array}{c}\text { Boys } \\
10-14\end{array}$ & & & & & & \\
\hline & $\begin{array}{r}\text { years } \\
\text { old }\end{array}$ & 28.2 & 26.1 & 21.8 & *30.6 & 28.6 & 34.3 \\
\hline & $N$ & 226 & 219 & 260 & 263 & 239 & 222 \\
\hline & $\begin{array}{r}15-19 \\
\text { years } \\
\text { old }\end{array}$ & 29.6 & ${ }^{*} 20.2$ & 19.9 & 31.4 & 25.5 & 21.3 \\
\hline & $\mathrm{N}$ & 170 & 183 & 212 & 200 & 187 & 147 \\
\hline & $\begin{array}{r}\text { Girls } \\
10-14\end{array}$ & & & & & & \\
\hline & $\begin{array}{r}\text { years } \\
\text { old }\end{array}$ & 38.1 & 42.5 & 35.3 & 41.6 & 36.2 & 48.0 \\
\hline & $N$ & 277 & 235 & 258 & 306 & 269 & 229 \\
\hline & $\begin{array}{r}15-19 \\
\text { years } \\
\text { old }\end{array}$ & 62.2 & *37.7 & 53.7 & *41.6 & 53.4 & *38.3 \\
\hline & $\mathrm{N}$ & 228 & 239 & 251 & 262 & 229 & 232 \\
\hline
\end{tabular}


Table A-3: Communication of adolescents on reproductive health according to their main source (in percentage)

\begin{tabular}{|c|c|c|c|c|c|c|c|}
\hline & & \multicolumn{2}{|c|}{$\begin{array}{l}\text { Saint-Louis } \\
\end{array}$} & \multicolumn{2}{|c|}{ Louga } & \multicolumn{2}{|c|}{ Diourbel } \\
\hline & & Baseline & Endline & Baseline & Endline & Baseline & Endline \\
\hline \multirow{10}{*}{$\begin{array}{l}\text { Communicate } \\
\text { with friends }\end{array}$} & Boys & & & & & & \\
\hline & 10-14 years & 15.2 & 14.5 & 15.1 & *28.9 & 17.1 & 13.3 \\
\hline & $\mathrm{N}$ & 231 & 219 & 274 & 263 & 248 & 222 \\
\hline & $\begin{array}{l}15-19 \text { years } \\
\text { old }\end{array}$ & 53.5 & 41.1 & 49.4 & 55.6 & 37.3 & 47.1 \\
\hline & $\mathrm{N}$ & 173 & 183 & 225 & 200 & 198 & 147 \\
\hline & Girls & & & & & & \\
\hline & $\begin{array}{l}10-14 \text { years } \\
\text { old }\end{array}$ & 7.2 & 10.5 & 6.4 & *17.1 & 8 & 10.8 \\
\hline & $\mathrm{N}$ & 276 & 235 & 262 & 306 & 275 & 229 \\
\hline & $15-19$ years & 32 & 30.6 & 25 & *41.4 & 22 & 26.2 \\
\hline & $\mathrm{N}$ & 231 & 239 & 258 & 262 & 236 & 232 \\
\hline \multirow{10}{*}{$\begin{array}{l}\text { Communicate } \\
\text { more with } \\
\text { his/her } \\
\text { father/tutor }\end{array}$} & Boys & & & & & & \\
\hline & $10-14$ years & 6.5 & 12.4 & 7.0 & 6.9 & 3.8 & *13.1 \\
\hline & $\mathrm{N}$ & 231 & 219 & 274 & 263 & 248 & 222 \\
\hline & $\begin{array}{l}15-19 \text { years } \\
\text { old }\end{array}$ & 9.6 & 15.7 & 4.1 & 3 & 9 & 12.4 \\
\hline & $\mathrm{N}$ & 173 & 183 & 225 & 200 & 198 & 147 \\
\hline & Girls & & & & & & \\
\hline & $\begin{array}{l}10-14 \text { years } \\
\text { old }\end{array}$ & 1.6 & ${ }^{*} 5.8$ & 3.3 & 3 & 2.1 & 5.3 \\
\hline & $\mathrm{N}$ & 276 & 235 & 262 & 306 & 275 & 229 \\
\hline & $\begin{array}{l}15-19 \text { years } \\
\text { old }\end{array}$ & 0.4 & ${ }^{*} 6$ & 2.4 & 4.5 & 4 & 5.5 \\
\hline & $\mathrm{N}$ & 231 & 239 & 258 & 262 & 236 & 232 \\
\hline \multirow{10}{*}{$\begin{array}{l}\text { Communicate } \\
\text { more with } \\
\text { his/her } \\
\text { mother/tutor }\end{array}$} & Boys & & & & & & \\
\hline & $\begin{array}{l}10-14 \text { years } \\
\text { old }\end{array}$ & 17.5 & 18.5 & 10.8 & 15.1 & 7.5 & *24 \\
\hline & $\mathrm{N}$ & 231 & 219 & 274 & 263 & 248 & 222 \\
\hline & $\begin{array}{l}15-19 \text { years } \\
\text { old }\end{array}$ & 7.9 & 13.3 & 10.7 & 12.1 & 13.6 & 13.7 \\
\hline & $\mathrm{N}$ & 173 & 183 & 225 & 200 & 198 & 147 \\
\hline & Girls & & & & & & \\
\hline & $\begin{array}{l}10-14 \text { years } \\
\text { old }\end{array}$ & 28.6 & 38.6 & 22.5 & 31.8 & 16.5 & *42.7 \\
\hline & $\mathrm{N}$ & 276 & 235 & 262 & 306 & 275 & 229 \\
\hline & $\begin{array}{l}15-19 \text { years } \\
\text { old }\end{array}$ & 38.3 & ${ }^{*} 27$ & 32.4 & ${ }^{*} 21.3$ & 32 & 32.8 \\
\hline & $\mathrm{N}$ & 231 & 239 & 258 & 262 & 236 & 232 \\
\hline
\end{tabular}


Table A-3: Communication of adolescents on reproductive health according to their main source (in percentage) (continued)

\begin{tabular}{|c|c|c|c|c|c|c|c|}
\hline & & \multicolumn{2}{|c|}{ Saint-Louis } & \multicolumn{2}{|c|}{$\begin{array}{c}\text { Louga } \\
\end{array}$} & \multicolumn{2}{|c|}{ Diourbel } \\
\hline & & Baseline & Endline & Baseline & Endline & Baseline & Endline \\
\hline \multirow{9}{*}{$\begin{array}{l}\text { Communicate } \\
\text { more with } \\
\text { other people }\end{array}$} & $\begin{array}{l}\text { Boys } \\
10-14 \text { years } \\
\text { old }\end{array}$ & 5.5 & *13.4 & 5.3 & *12.6 & 3.9 & 8.2 \\
\hline & $\mathrm{N}$ & 231 & 219 & 274 & 263 & 248 & 222 \\
\hline & $\begin{array}{l}15-19 \text { years } \\
\text { old }\end{array}$ & 13.3 & 13.3 & 7.9 & 9 & 5.9 & 11.3 \\
\hline & $\mathrm{N}$ & 173 & 183 & 225 & 200 & 198 & 147 \\
\hline & Girls & & & & & & \\
\hline & $\begin{array}{l}10-14 \text { years } \\
\text { old }\end{array}$ & 7.8 & 7.3 & 7.5 & 8.9 & 3.3 & *8.7 \\
\hline & $\mathrm{N}$ & 276 & 235 & 262 & 306 & 275 & 229 \\
\hline & $\begin{array}{l}15-19 \text { years } \\
\text { old }\end{array}$ & 17.5 & 18.1 & 15.1 & 17.1 & 10.4 & 18.6 \\
\hline & $\mathrm{N}$ & 231 & 239 & 258 & 262 & 236 & 232 \\
\hline
\end{tabular}

${ }^{*} \mathrm{p}<0.05$ 
Table A-4: Odds Ratios (OR) and confidence intervals of key explanatory variables

\begin{tabular}{|c|c|c|c|c|c|c|}
\hline \multirow[t]{3}{*}{ Explanatory Variables } & \multirow{2}{*}{\multicolumn{3}{|c|}{$\begin{array}{l}\text { Reproductive Health } \\
\text { Information at School } \\
\text { OR }\end{array}$}} & \multicolumn{3}{|c|}{$\begin{array}{l}\text { Reproductive Health } \\
\text { Information Out of School }\end{array}$} \\
\hline & & $95 \% \mathrm{Cl}$ & & \multirow{2}{*}{ OR } & \multirow{2}{*}{\multicolumn{2}{|c|}{$\frac{95 \% \mathrm{Cl}}{\mathrm{I}}$}} \\
\hline & & Lower & Upper & & & \\
\hline $\begin{array}{l}\text { Endline (EL) } \\
\text { Baseline (BS) }\end{array}$ & $\begin{array}{l}6.6 \\
1.0\end{array}$ & 3.9 & 11.1 & 4.0 & $\begin{array}{l}2.7 \\
1.0\end{array}$ & 5.7 \\
\hline EL to BS OR in St.-Louis & $1.7^{*}$ & 1.2 & 2.5 & 1.3 & 0.8 & 2.2 \\
\hline EL to BS OR in Louga & 2.5 & 1.6 & 3.9 & $1.6^{*}$ & 1.0 & 2.60 \\
\hline EL to BS OR in Diourbel & 1.0 & & & 1.0 & & \\
\hline $\begin{array}{l}\text { Male } \\
\text { Female }\end{array}$ & $\begin{array}{l}1.2 \\
1.0\end{array}$ & 1.0 & 1.4 & $\begin{array}{l}0.9 \\
1.0\end{array}$ & 0.8 & 1.1 \\
\hline $15-19$ years & $2.5^{\mathrm{a}}$ & 1.8 & 3.3 & 2.7 & 2.3 & 3.1 \\
\hline $10-14$ years & $1.0^{\mathrm{a}}$ & & & 1.0 & & \\
\hline $\begin{array}{l}\text { EL to BS OR among } 15-19 \\
\text { EL to BS OR among } 10-14\end{array}$ & $\begin{array}{l}0.4 \\
1.0\end{array}$ & 0.3 & 0.6 & & & \\
\hline Married & 0.4 & 0.2 & 0.7 & 1.2 & 0.8 & 1.8 \\
\hline Unmarried & 1.0 & & & 1.0 & & \\
\hline With formal schooling & $31.6^{b}$ & 14.9 & 66.9 & 1.2 & 1.0 & 1.6 \\
\hline With informal / Koranic schooling & $3.5^{b}$ & 1.6 & 7.9 & 1.0 & 0.7 & 1.4 \\
\hline No schooling & $1.0^{\mathrm{b}}$ & & & 1.0 & & \\
\hline Formal schooling (versus none) at St.-Louis & & & & 3.5 & 1.5 & 8.2 \\
\hline Formal schooling (versus none) in Louga & & & & 1.5 & 1.1 & 2.1 \\
\hline Formal schooling (versus none) in Diourbel & & & & 1.0 & & \\
\hline Informal schooling (versus none) at St.-Louis & & & & 2.5 & 1.20 & 5.1 \\
\hline Informal schooling (versus none) in Diourbel & & & & 1.0 & & \\
\hline Still in school & & & & 1.4 & 1.2 & 1.60 \\
\hline Not in school & & & & 1.0 & & \\
\hline Religious practice & $1.9^{\mathrm{c}}$ & 1.3 & 3.0 & 1.3 & 1.0 & 1.6 \\
\hline No religious practice & $1.0^{\mathrm{c}}$ & & & 1.0 & & \\
\hline $\begin{array}{l}\text { EL to BS OR among those with religious } \\
\text { practice }\end{array}$ & 0.4 & 0.2 & 0.6 & & & \\
\hline $\begin{array}{l}\text { EL to BS OR among those with no religious } \\
\text { practice }\end{array}$ & 1.0 & & & & & \\
\hline Religious practice versus none OR in Louga & 1.7 & 1.1 & 2.5 & & & \\
\hline Religious practice versus none OR in Diourbel & 1.0 & & 1.0 & & & \\
\hline Living with parents & 1.1 & 0.9 & 1.3 & 1.1 & 0.9 & 1.3 \\
\hline Not living with parents & 1.0 & & & 1.0 & & \\
\hline
\end{tabular}

*not significant under unadjusted model.

${ }^{a}$ In this model, OR is for males/females at baseline.

${ }^{b}$ In this model, OR is for schooling status in Diourbel.

${ }^{c}$ In this model, OR is for religious practice/no religious practice in Diourbel. 
Table A-4: Odds Ratios (OR) and confidence intervals of key explanatory variables (continued)

\begin{tabular}{|c|c|c|c|c|c|c|}
\hline \multirow{3}{*}{ Explanatory Variables } & \multicolumn{3}{|c|}{$\begin{array}{l}\text { Ever versus Never Had Sex } \\
\text { (among 13-19 years old) }\end{array}$} & \multicolumn{3}{|c|}{$\begin{array}{c}\text { Secondary Abstinence } \\
\text { (No versus Had Sex in Last } 6 \\
\text { months) }\end{array}$} \\
\hline & & \multicolumn{2}{|c|}{$95 \% \mathrm{Cl}$} & \multirow{2}{*}{ OR } & \multicolumn{2}{|c|}{$95 \% \mathrm{Cl}$} \\
\hline & OR & Lower & Upper & & Lower & Upper \\
\hline Endline(EL) & 2.4 & 1.0 & 5.8 & 0.8 & 0.3 & 2.0 \\
\hline Baseline(BS) & 1.0 & & & 1.0 & & \\
\hline EL to BS OR in St.-Louis & 2.0 & 0.7 & 5.8 & 1.0 & 0.3 & 3.8 \\
\hline EL to BS OR in Louga & 1.0 & 0.4 & 2.2 & 3.0 & 1.0 & 8.9 \\
\hline EL to BS OR in Diourbel & 1.0 & & & 1.0 & & \\
\hline Male & 10.9 & 6.7 & 17.6 & 0.9 & 0.5 & 1.7 \\
\hline Female & 1.0 & & & 1.0 & & \\
\hline Age $15-19$ & 5.2 & 3.0 & 8.8 & $1.0^{\mathrm{a}}$ & 0.6 & 1.9 \\
\hline Age 13-14 & 1.0 & & & $1.0^{\mathrm{a}}$ & & \\
\hline EL to BS OR among 15-19 & 0.3 & 0.2 & 0.6 & & & \\
\hline EL to BS OR among $13-14$ & 1.0 & & & & & 1.1 \\
\hline With formal schooling & 1.9 & 1.2 & 3.1 & 0.6 & 0.3 & 1.1 \\
\hline With informal/Koranic schooling & 1.0 & 0.5 & 2.0 & 0.6 & 0.3 & 1.3 \\
\hline No schooling & 1.0 & & & 1.0 & & \\
\hline Still in school & 0.8 & 0.5 & 1.2 & $2.0^{b}$ & 1.3 & 3.1 \\
\hline Out of school & 1.0 & & & $1.0^{\mathrm{b}}$ & & \\
\hline $\begin{array}{l}\text { EL to BS OR among those in school } \\
\text { EL to BS OR among those out of school }\end{array}$ & $\begin{array}{l}0.4 \\
1.0\end{array}$ & 0.2 & 0.7 & & & \\
\hline With religious practice & 0.6 & 0.4 & 0.8 & 1.6 & 1.0 & 2.5 \\
\hline No religious practice & 1.0 & & & 1.0 & & \\
\hline Living with parents & 0.8 & 0.5 & 1.3 & 1.0 & 0.5 & 1.9 \\
\hline Not living with parents & 1.0 & & & 1.0 & & \\
\hline
\end{tabular}

\footnotetext{
${ }^{\mathrm{a}}$ In this model, age groups across sites are included.

${ }^{b}$ In this model, schooling status across sites are included.
} 
Table A-4: Odds Ratios (OR) and confidence intervals of key explanatory variables (continued)

Talk to Parents about reproductive health

\begin{tabular}{|c|c|c|c|}
\hline \multirow{2}{*}{ Explanatory Variable } & \multirow[t]{2}{*}{ OR } & \multicolumn{2}{|c|}{$95 \% \mathrm{Cl}$} \\
\hline & & Lower & Upper \\
\hline Endline & 2.9 & 1.8 & 4.8 \\
\hline Baseline & 1.0 & & \\
\hline EL to BS OR in St.-Louis & 0.6 & 0.4 & 1.0 \\
\hline EL to BS OR in Louga & 0.6 & 0.4 & 1.0 \\
\hline EL to BS OR in Diourbel & 1.0 & & \\
\hline Male & 0.5 & 0.5 & 0.6 \\
\hline Female & 1.0 & & \\
\hline $15-19$ years & 1.2 & 1.0 & 1.5 \\
\hline $10-14$ & 1.0 & & \\
\hline $15-19$ at endline & 0.6 & 0.4 & 0.8 \\
\hline 10-14 at endline & 1.0 & & \\
\hline Married & 1.7 & 1.1 & 2.5 \\
\hline Unmarried & 1.0 & & \\
\hline $\begin{array}{l}\text { With formal schooling (versus no schooling at } \\
\text { BS) }\end{array}$ & 1.1 & 0.9 & 1.5 \\
\hline $\begin{array}{l}\text { With informal/Koranic schooling to no schooling } \\
\text { OR at BS }\end{array}$ & 0.8 & 0.5 & 1.2 \\
\hline With no schooling (at BS) & 1.0 & & \\
\hline $\begin{array}{l}\text { Informal/Koranic schooling (versus no } \\
\text { schooling) OR at EL }\end{array}$ & 1.7 & 1.1 & 2.1 \\
\hline Formal or with no schooling at EL & 1.0 & & \\
\hline Still in school at BS & 0.9 & 0.7 & 1.1 \\
\hline Out of school at BS & 1.0 & & \\
\hline Still in school at EL & 1.5 & 1.1 & 2.1 \\
\hline Out of school at EL & 1.0 & & \\
\hline Still in school (versus not in school) at St.-Louis & 0.8 & 0.6 & 0.9 \\
\hline $\begin{array}{l}\text { Still in school (versus not in school) in Diourbel } \\
\text { or Louga }\end{array}$ & 1.0 & & \\
\hline Religious practice at BS & 1.1 & 0.8 & 1.6 \\
\hline No religious practice at $B S$ & 1.0 & & \\
\hline Religious practice at EL & 0.6 & 0.4 & 1.0 \\
\hline No religious practice at EL & 1.0 & & \\
\hline $\begin{array}{l}\text { Religious practice (versus no practice) over } \\
\text { time in Saint-Louis }\end{array}$ & 2.9 & 1.8 & 4.5 \\
\hline $\begin{array}{l}\text { Religious practice (versus no practice) over } \\
\text { time in Louga }\end{array}$ & 3.2 & 2.1 & 4.9 \\
\hline $\begin{array}{l}\text { Religious practice (versus no practice) over } \\
\text { time in Diourbel }\end{array}$ & 1.0 & & \\
\hline Living with parents & 1.2 & 1.0 & 1.6 \\
\hline Not living with parents & 1.0 & & \\
\hline
\end{tabular}




\section{ANNEX B}

\section{Construction of Sampling and Analysis Weights}

At the baseline survey, the selection probabilities of age-eligible young adults may be written as:

$$
20 *\left(\mathrm{M}_{\mathrm{hi}} / \mathrm{M}_{\mathrm{h}}\right) *\left(25 / \mathrm{T}_{\mathrm{hi}}\right)
$$

where $M_{h i}$ is the projected measure of size (e.g., number of households for the $\mathrm{i}^{\text {th }} \mathrm{DR}$ ( $\mathrm{i}=1$ to 20 ) in the $h^{\text {th }}$ site $\left(h=1,2\right.$, or 3 to correspond to Louga, Saint-Louis, Diourbel, respectively). $T_{h i}$ is the number of listed households in the $i^{\text {th }} \mathrm{DR}$ in site $\mathrm{h}$.

If $\mathrm{M}_{\mathrm{hi}}$ and $\mathrm{T}_{\mathrm{hi}}$ are more or less equal, then within the same site the probability of selecting ageeligible young adults is about equal, and hence the weights may be fairly equal. This potentially equally weighted sample of clustered young adults within the same site may be adjusted for response rates if there are differences in response rates by key covariates, notably sex and age groups. Thus, the adjusted selection probabilities may be written as:

$$
20 *\left(\mathrm{M}_{\mathrm{hi}} / \mathrm{M}_{\mathrm{h}}\right) *\left(25 / \mathrm{T}_{\mathrm{hi}}\right)\left(\mathrm{R}_{\mathrm{k}}\right)
$$

where $R_{k}$ is the response rate for the $k^{\text {th }}$ subgroup.

At the endline survey, the sampling weights for study participants must be adjusted to take into account the stratification of households by inclusion at baseline. The probabilities of selection for households selected at both baseline and endline surveys may be written as:

$$
20 *\left(\mathrm{M}_{\mathrm{hi}} / \mathrm{M}_{\mathrm{h}}\right) *(15 / 25)
$$

The corresponding probabilities of selection for households not selected at baseline but at endline may be written as:

$$
20 *\left(\mathrm{M}_{\mathrm{hi}} / \mathrm{M}_{\mathrm{h}}\right) *\left(10 /\left(\mathrm{T}_{\mathrm{hi}}^{\prime}-25\right)\right)
$$

where $\mathrm{T}_{\mathrm{hi}}$ is the number of listed households at the endline survey. Adjustments for response rates may be considered as in the baseline survey, either for subgroups or for the full sample.

While weighting may not contribute significantly to increase in variance at baseline survey, potential differential in weighting induced by cohort selection at endline may lead to increase in variance.

Clustering of households within enumeration districts and of age-eligible young adults within households must be taken into account in variance estimation. With two-stage clustering and possible unequal weights across the pooled sample, the sample module in EPI-INFO may be used for descriptive analysis of the data. 


\section{Statistical Methods}

\section{Univariate Descriptive Statistics}

Univariate descriptive statistics include unweighted counts of study participants and weighted summary statistics including means for continuous variables, proportions for categorical variables, and measures of variability such as standard deviation or range. The calculation of weighted statistics and their measures of variability take into account that observations were made in sample of young adults and parents selected using complex sampling procedures.

\section{Stratified Analysis for Assessing Similarities in Background Characteristics and Assessing Effects of Interventions on Selected Outcomes}

The regression strategy for this analysis was to consider the measure of interaction of intervention groups by time of interviews to measure the effect of the intervention on outcomes (see below for the discussion of this measure of intervention effect). Summary statistics on outcome levels are presented in tables (and some in figures) by intervention and time of interviews.

In addition, we reported summary statistics separately by intervention groups and time of interviews for subgroups defined by sex and age groups. In particular, we tested the hypotheses that effects of interventions on outcomes differ by sex, age groups and possibly marital and schooling status, and other covariates.

Stratified chi-square tests of association of characteristics with intervention groups and time of interviews were conducted. Such chi-square tests of association took into account unequal weighting and clustering of sample young adults, where these apply.

\section{Unadjusted Measure of Intervention Effects}

\section{Unadjusted Assessment of Effect of Intervention Using Regression Analysis for Continuous Outcome (or for Weighted Statistics for Dichotomous Outcomes)}

We defined the effect of interventions in intervention group 1 by taking the difference of differences in outcome level at endline and baseline survey in the intervention group 1, and difference in outcome level at endline and baseline survey in the control group. Let the mean of key outcomes by experimental groups and time of interview be as specified in the following Table:

\begin{tabular}{|l|c|c|}
\hline & Baseline (0) & Endline (1) \\
\hline Intervention Group 1 & A & B \\
\hline Intervention Group 2 & C & D \\
\hline Control Group (0) & E & F \\
\hline
\end{tabular}

The overall test statistics for testing the effect of interventions using the above notation is as follows:

$\mathrm{H}_{01}:=(\mathrm{B}-\mathrm{A})-(\mathrm{F}-\mathrm{E})=0$ and

$\mathrm{H}_{02}:=(\mathrm{D}-\mathrm{C})-(\mathrm{F}-\mathrm{E})=0$. 


\section{Estimation Using Regression Approach:}

Pictorially, this is presented in Figure 1.

\section{Figure B-1: An Illustration of Measuring Intervention Effect}

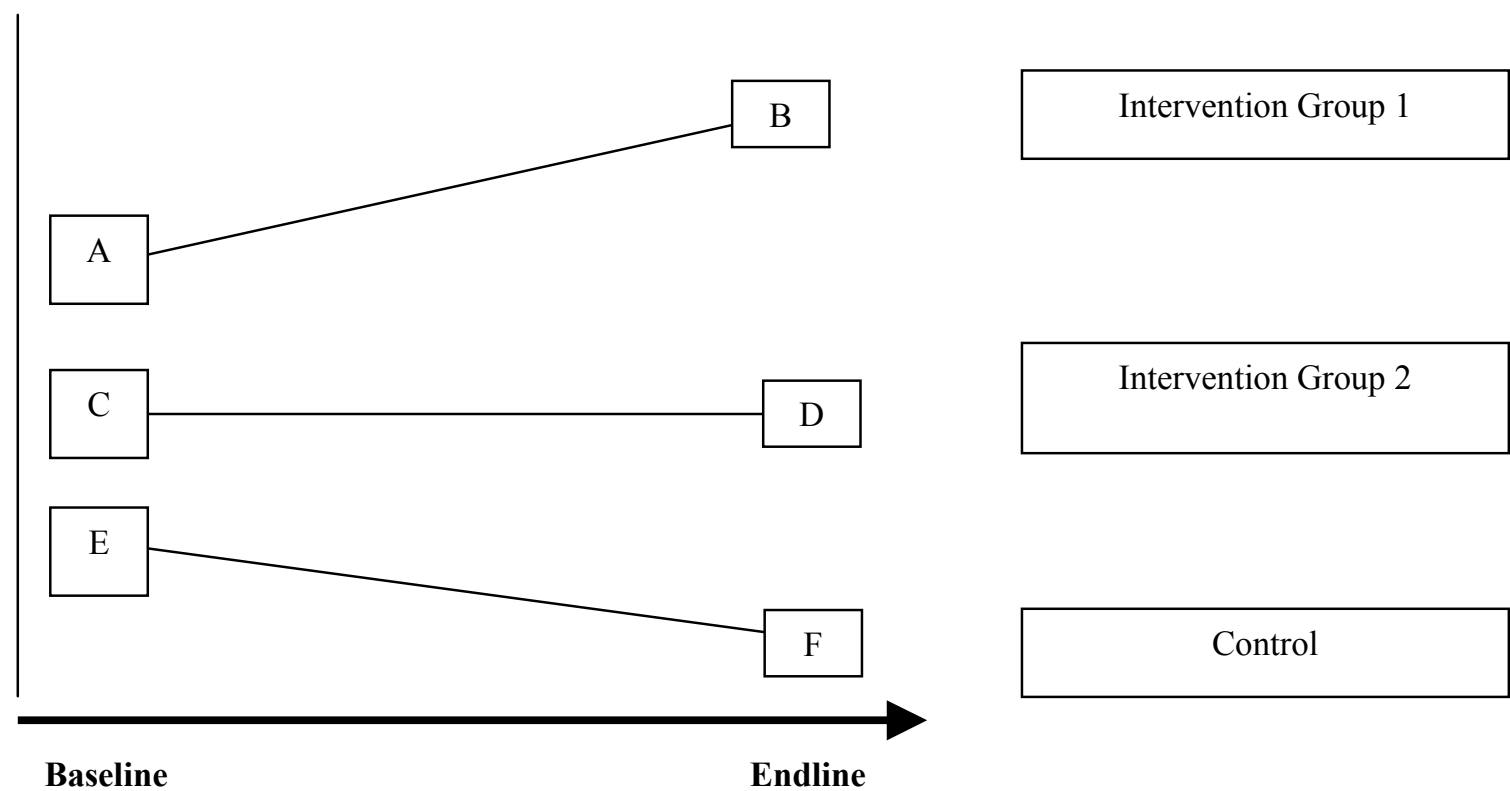

Let observations in intervention group 1 be coded as 1 , and those in control group be coded as zero; call this variable group1.

Let observations in intervention group 2 be coded as 1 , and those in control group be coded as zero; call this variable group2.

Let observations at endline survey be coded as 1 , and those at baseline be coded as zero; call this variable time.

Let two interaction variables be coded as follows:

group 1 tm $=$ group $1 *$ time

group $2 \mathrm{tm}=$ group $2 *$ time.

A linear regression model of outcomes for the above design can be fitted with the following line:

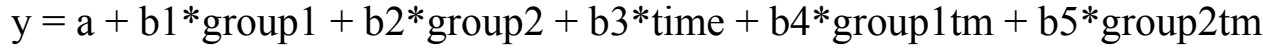

The mean of observations by experimental group and baseline/endline surveys can be expressed in terms of the coefficients of fitted line. Please see Table below.

\begin{tabular}{|l|c|c|}
\hline & Baseline (0) & Endline (1) \\
\hline Intervention Group 1 & $\mathrm{A}=\mathrm{a}+\mathrm{b} 1$ & $\mathrm{~B}=\mathrm{a}+\mathrm{b} 1+\mathrm{b} 3+\mathrm{b} 4$ \\
\hline Intervention Group 2 & $\mathrm{C}=\mathrm{a}+\mathrm{b} 2$ & $\mathrm{D}=\mathrm{a}+\mathrm{b} 2+\mathrm{b} 3+\mathrm{b} 5$ \\
\hline Control Group (0) & $\mathrm{E}=\mathrm{a}$ & $\mathrm{F}=\mathrm{a}+\mathrm{b} 3$ \\
\hline
\end{tabular}


Recalling the measure of effect of intervention cited above,

$\mathrm{H}_{01}:=(\mathrm{B}-\mathrm{A})-(\mathrm{F}-\mathrm{E})=0$ and

$\mathrm{H}_{02}:=(\mathrm{D}-\mathrm{C})-(\mathrm{F}-\mathrm{E})=0$

we find that an estimate of effect of intervention group 1 on a specific outcome can be calculated by taking the difference of B-A (essentially the slope of the line in Figure 1), and this is equal to $(\mathrm{b} 3+\mathrm{b} 4)$. Similarly, we take the difference (F-E), and this is equal to b3. Taking the difference of (B-A) - (F-E) is equal to b4. Following the same calculation, the effect of group 2 on outcome is estimated by the coefficient b5 of the regression line.

\section{Adjusted Measures of Effects of Interventions}

If characteristics of study participants associated with outcomes differ between intervention and control groups at baseline and endline surveys, then estimates of measures of effects of interventions have to be adjusted. To do such adjustment, we expanded the regression line for the unadjusted estimate (equation (1) above) by including in the model different characteristics of the sample young adults. Such characteristics include age, education, religion, ethnic grouping, household and parent characteristics, and characteristics of the study areas.

Thus, a model of effects of intervention adjusted for covariates takes the following form:

$$
\begin{aligned}
\mathrm{f}(\mathrm{y})= & \mathrm{a}{ }^{`}+\mathrm{b} 1{ }^{\prime} * \text { group } 1+\mathrm{b} 2{ }^{*} * \text { group } 2+\mathrm{b} 3{ }^{*} * \text { time }+\mathrm{b} 4{ }^{*} \text { group } 1 \mathrm{tm}+\mathrm{b} 5{ }^{`} \text { group } 1 \mathrm{tm}+\mathrm{b} 6 * \text { age }+ \\
& \mathrm{b} 7 * \text { working }+\mathrm{b} 8 * \text { educational attainment }+\ldots+\mathrm{bk}^{*} \mathrm{k}^{\text {th }} \text { covariate }
\end{aligned}
$$

Note that $\mathrm{f}(\mathrm{y})$ is a general indicator of outcome, and it may refer to means or logits as described above.

The estimates of effects of intervention remain the coefficients associated with the time by interaction terms b4 and b5 as discussed above. Should these interaction terms turn out to not be statistically significant, we refit the model without the interaction terms and consider as measures of intervention effects the coefficients associated with group1 and group2 variables.

\section{Selection of Covariates in Adjusted Models of Intervention Effects}

The covariates to be retained in the adjusted models of intervention effects consist of those variables that are not in the pathways of interventions and outcomes. For example, level of intervention outreach is not included in the model where intervention and control indicators are some of the key explanatory variables. Such inclusion is expected to dilute the measure of intervention effects.

However, we opt to consider models of reproductive health outcomes where the indicator of intervention consists of individual level report of exposure to the selected components of interventions. In such models, the intervention indicator variables are excluded. Adjusted models fitted separately by age groups and sex are pooled across these subgroups.

Any covariate added as explanatory variables in the adjusted models is assessed for the extent that the addition of such covariate changes the measure of intervention effects. An added covariate that leads to change in estimates of intervention effects by plus or minus 10 percent 
relative to model without the covariate is retained in the adjusted model regardless of the statistical significance of the coefficient of the added covariate (Rothman and Greenland 1998).

An addition of covariates in a linear model for continuous outcomes always increases the explanatory power of the model. However, when outcomes are dichotomous, additional covariates lead to problems in estimation, thus we are not be able to arbitrarily add covariates in logistic models. 


\section{REFERENCES}

Diop, Nafissatou J., Alimata Deme, and Edmonde Bagde. 2003. "Santé des Adolescents: les trois piliers d'une experience - Rapport sur la documentation du processus d'intervention [Adolescent Health: The three pillars of an experience - report on the intervention process]," FRONTIERS Report. Dakar: Population Council.

RamaRao, Saumya and Nafissatou J. Diop. 2003. "Serving the Reproductive Health Needs of Adolescents in Senegal: Analysis of Costs," FRONTIERS Report. Dakar: Population Council.

Rothman, K.J. and S. Greenland. 1998. Modern Epidemiology. Philadelphia: Lipincott-Raven Publishers. 